RATIONAL METHODS FOR PREDICTING QUALITY AND DIGESTIBLE ENERGY CONCENTRATION OF WARM-SEASON FORAGES FOR RUMINANTS

By

Edward J. Golding, III

A DISSERTATION PRESENTED TO THE GRADUATE COUNCIL OF THE UNIVERSITY OF FLORIDA

IN PARTIAL FULFILLMENT OF THE REOUIREMENTS FOR THE DEGREE OF DOCTOR OF PHILOSOPHY

UNIVERSITY OF FLORIDA

1976 
...to the future of my family, Astrid

Nicole

Christopher;

and to those who understood. 


\section{ACKNOWL EDGMENTS}

The author wishes to express his deep appreciation to Dr. John E. Moore, Chairman of the Supervisory Comittee, for his continued interest, helpful ideas and professional guidance during the investigations documented in, and during the writing of, this manuscript. Appreciation is also extended to the Members of the Supervisory Committee, Dr.s C. B. Ammerman, J. H. Conrad, D. E. Franke and G. O. Mott, for willingly sharing their knowledge and for reviewing this dissertation. The statistical aid provided by Dr. R. C. Littell and Dr. D. O. Dixon, and the mathematical assistance of Dr. K. N. Sigmon are greatly appreciated. Thanks are also extended to Miss Jan Ferguson and Mrs. Edwina Williams for aid in conducting chemical and in vitro analyses. Help provided the author by the staff and personnel of the Nutrition Laboratory in solving the every-day problems is gratefully acknowledged, as is the assistance and friendship of fellow graduate students.

Financial assistance provided by the Department of Animal Science, University of Florida, is gratefully acknowledged, as are the efforts of Dr. Moore and Dr. Conrad in obtaining these funds.

The author wishes to express his appreciation to Mrs. Susan Weller and Mrs. Pat Beville for typing this manuscript. 
TABLE OF CONTENTS

$\begin{array}{lr} & \text { Page } \\ \text { ACKNOWLEDGMENTS } & \text { ii } \\ \text { LIST OF TABLES } & \text { vii } \\ \text { LIST OF APPENDIX TABLES } & \text { viii } \\ \text { LIST OF FIGURES } & \text { ix } \\ \text { ABSTRACT } & \mathrm{x}\end{array}$

CHAPTER

I INIRODUCTION

II REVIEW OF LITERATURE 3

Expressions of Forage Quality 3

Digestible Energy Intake, Digestible Dry Matter Intake 3 and Digestible Organic Matter Intake

Nutritive Value Index 4

Retention Time of Organic Matter in the Rumen 7

Control of Forage Intake by Ruminants 8

The Distention Mechanism 8

$\begin{array}{ll}\text { Site and mechanism of distention control } & 10\end{array}$

Relative importance of "fill" and "retention time" 11

Factors Affecting Retention Time 12

Factors affecting rates of digestion and passage 14

$\begin{array}{ll}\text { Intake vs Rate of Digestion In Vitro } & 17\end{array}$

Prediction of Forage Nutritive Value 18

Applicability of Predictors of Nutrient Digestibility 19

$\begin{array}{ll}\text { Chemical analyses } & 19\end{array}$

$\begin{array}{ll}\text { In vitro organic matter digestion } & 19\end{array}$

$\begin{array}{ll}\text { Sumnative equations } & 20\end{array}$

Applicability of Predictors of DE Concentration in 20

$\begin{array}{ll}\text { Forage DM } & \\ \text { In vitro cellulose digestibility } & 20\end{array}$

$\begin{array}{ll}\text { Dry matter digestibility } & 21\end{array}$

$\begin{array}{ll}\text { Crude protein percentage of dry matter } & 22\end{array}$

$\begin{array}{ll}\text { Prediction of Forage Quality } & 22\end{array}$

Applicability of Various Techniques for Quality Pre- 23 
Chemical analyses and summative equations 23 In vitro techniques $\quad 23$ The nutritive value index $\quad 25$ Retention time of organic matter in the rumen 25

Mathematical Modeling of Dynamic Systems 25

III PREDICTION OF DIGESTIBLE ENERGY CONCENTRATION IN FORAGE FOR PURPOSES OF MARKETING SOUTHERN HAYS 28

$\begin{array}{ll}\text { Introduction } & 28\end{array}$

Experimental Procedure 29

Theory Related to Rational Prediction of DE/DM 29

$\begin{array}{ll}\text { Prediction of DOM } & 30\end{array}$

$\begin{array}{ll}\text { Prediction of DE/DM } & 32\end{array}$

Testing the Procedure 33

Forages and in vivo data 33

Laboratory analyses and prediction testing 34

Results and Discussion $\quad 35$

Chemical Analyses $\quad 35$

In Vivo and In Vitro Determinations 38

NDF digestibility 38

Digestible neutral-detergent fiber and neutral-
detergent solubles

OM digestibility $\quad 41$

Digestible organic matter $\quad 41$

Metabolic fecal organic matter by calculation 41

Estimation of metabolic fecal organic matter by
regression

Prediction of NDFD, DOM and DE/DM 43

Testing of DOM and DE/DM Predictions 47

Acceptability limits for judging the predictions 47

$\begin{array}{ll}\text { Acceptability of the predictions } & 48\end{array}$

General Discussion $\quad 54$

Non-Forage Factors Affecting DE/DM 54

Research Needs for Rapid and Accurate DOM Prediction 55

$\begin{array}{ll}\text { Summary } & 57\end{array}$

IV ELIMINATION OF ORGANIC SOLVENTS IN THE STUDY OF IN VITRO NEUTRAL-DETERGENT FIBER DIGESTION

$\begin{array}{ll}\text { Introduction } & 59\end{array}$

$\begin{array}{ll}\text { Experimental Procedure } & 59\end{array}$ 
TABLE OF CONTENTS-continued

Page

$\begin{array}{ll}\text { Results and Discussion } & 61\end{array}$

$\begin{array}{ll}\text { Summary } & 66\end{array}$

V A RATIONAL METHOD FOR PREDICTING QUALITY OF WARM-SEASON FORAGES FOR RUMINANTS

$\begin{array}{ll}\text { Introduction } & 67\end{array}$

Experimental Procedure 68

Development of Theory Related to Rational Method for $\begin{array}{ll}\text { Prediction of Forage Quality } & 68\end{array}$

$\begin{array}{ll}\text { Estimation of RTOM } & 70\end{array}$

Establishing the value of $g \quad 71$

$\begin{array}{ll}\text { Estimation of } k_{1} & 72\end{array}$

$\begin{array}{ll}\text { Estimation of } k & 73\end{array}$

Theory relative to ' $\mathrm{a}$ ', and its estimation 73

Prediction of organic matter digestibility $\quad 75$

$\begin{array}{ll}\text { Testing the Procedure } & 76\end{array}$

Forages and in vivo data $\quad 76$

Laboratory analysis of forages $\quad 77$

$\begin{array}{ll}\text { Regression analyses } & 78\end{array}$

Generation of the prediction equation $\quad 78$

$\begin{array}{ll}\text { Testing the acceptability of quality predictions } & 79\end{array}$

Results and Discussion $\quad 82$

Laboratory Characteristics of Forages Utilized 82

Actual and Predicted In Vivo Values of Forages Utilized 84

Testing of DOMI and OMI Predictions 90

Acceptability limits for quality and intake predictions 90

Acceptability of quality and intake predictions 92

Utility of Relationships Between Various Measurements
and Analyses

Prediction of organic matter digestibility 99

$\begin{array}{ll}\text { Prediction of intake from neutral-detergent fiber } & \\ \text { percentage } & 100\end{array}$

$\begin{array}{ll}\text { Prediction of } k_{2} & 101\end{array}$

$\begin{array}{ll}\text { Prediction of } k_{1}^{2} & 103\end{array}$

$\begin{array}{ll}\text { General Discussion } & 104\end{array}$

Non-Forage Factors Which Could Override or Modify RTOM 104

$\begin{array}{ll}\text { Theoretical Methods for Prediction of } k_{2} & 106\end{array}$

$\begin{array}{lr}\text { Summary } & 109\end{array}$

$\begin{array}{ll}\text { APPENDIX } & 112\end{array}$

$\begin{array}{lr}\text { LITERATURE CITED } & 131\end{array}$

$\begin{array}{lr}\text { BIOGRAPHICAL SKETCH } & 149\end{array}$ 


\section{LIST OF TABLES}

Table

Page

1. MEASURES OF CENTRAL TENDENCY AND DISPERSION OF THE CHARACTERISTICS OF 52 FLORIDA FORAGES

2. GROSS ENERGY, ENERGY DIGESTIBILITY AND ACTUAL AND PREDICTED DIGESTIBLE ENERGY CONCENTRATIONS IN 10 WARM-SEASON GRASSES

3. CONSERVATIVE AND LIBERAL ACCEPTABILITY LIMITS FOR TESTING PREDICTIONS OF DIGESTIBLE ORGANIC MATTER (DOM) AND DIGESTIBLE ENERGY (DE) CONCENTRATION

4. EFFECT OF ACETONE ON THE DETERMINATION OF ASH-FREE NEUTRAL-DETERGENT FIBER (NDFA) IN EIGHT HAYS

5. EFFECT OF HAY AND STOP-METHOD ON IN VITRO RESIDUAL ASH-FREE NEUTRAL-DETERGENT FIBER (NDFA)

6. EFFECT OF STOP-METHOD AND REPLICATE (REP) ON IN VITRO RESIDUAL ASH-FREE NEUTRAL-DETERGENT FIBER (NDFA)

7. MEASURES OF CENTRAL TENDENCY AND DISPERSION OF THE LABORATORY CHARACTERISTICS OF 31 WARM-SEASON GRASSES

8. MEASURES OF CENTRAL TENDENCY AND DISPERSION OF THE ACTUAL AND PREDICTED IN VIVO VALUES OF 31 WARMSEASON GRASSES

9. CONSERVATIVE AND LIBERAL ACCEPTABILITY LIMITS FOR TESTING PREDICTIONS OF DIGESTIBLE ORGANIC MATTER INTAKE (DOMI) AND ORGANIC MATTER INTAKE (OMI) 
LIST OF APPENDIX TABLES

Table

Page

10. LABORATORY CHARACTERISTICS OF 31 WARM-SEASON GRASSES

11. ACTUAL AND PREDICTED IN VIVO VALUES OF 31 WARM-SEASON GRASSES

12. LABORATORY CHARACTERISTICS AND ACTUAL AND PREDICTED IN VIVO VALUES OF 21 ADDITIONAL FORAGES USED TO TEST THEORETICAL EQUATION FOR PREDICTION OF DIGESTIBLE ORGANIC MATTER (DOM) AS PERCENT OF DRY MATTER

13. ALGEBRAIC MANIPULATIONS OF EQUATION 9 REQUIRED TO PROLUCE EQUATION 10 (CHAPTER V)

14. DYNAMO COMPUTER PROGRAM FOR PREDICTION OF FORAGE DOMI, DEI (WITH AND WITHOUT ENERGY SUPPLEMENT), REPLACEMENT RATE, OMI, OMD, DOM, DE/DM, DE/OM, NDFD, DNDF, A, B AND RTOM 


\section{LIST OF FIGURES}

Figure

Page

1. TEST OF THEORETICALLY RATIONAL METHOD FOR PREDICTION OF DIGESTIBLE ORGANIC MATTER AS A PERCENTAGE OF DRY

MATTER.

2. COMPARISON OF IN VIVO DIGESTIBLE ENERGY (DE) WITH THAT PREDICTED FROM ACTUAL IN VIVO DIGESTIBLE ORGANIC MATTER (DOM) AND CRUDE PROTEIN (CP) BY THE EQUATION:

$$
\mathrm{DE}=\frac{4.15 \mathrm{DOM}+1.299 \mathrm{CP}-4.59}{100} \text {. }
$$

3. COMPARISON OF IN VIVO DIGESTIBLE ENERGY (DE) WITH THAT PREDICTED FROM PREDICTED IN VIVO DIGESTIBLE ORGANIC MATTER (DOM $)_{P}$ ) AND CRUDE PROTEIN (CP) BY THE EQUATION:

$$
\mathrm{DE}=\frac{4.15 \mathrm{DOM}_{\mathrm{P}}+1.299 \mathrm{CP}-4.59}{100} \text {. }
$$

4. RELATIONSHIP BETWEEN NEUTRAL-DETERGENT FIBER DIGESTIBILITY IN VIVO AND IN VITRO FOR EACH OF THREE WARM-SEASON GRASSES (Data taken from Velasquez, 1974).

5. RELATIONSHIP BETWEEN DIGESTIBLE ORGANIC MATTER INTAKE AND RETENTION TIME OF ORGANIC MATTER IN THE RUMEN FOR THREE SPECIES OF WAKM-SEASON GRASSES.

6. RELATIONSHIP BETWEEN ORGANIC MATTER INTAKE AND ACIDDETERGENT FIBER PERCENTAGE FOR THREE SPECIES OF WARMSEASON GRASSES.

7. TEST OF RETENTION TIME OF ORGANIC MATTER IN THE RUMEN AS A RATIONAL PREDICTOR OF DIGESTIBLE ORGANIC MATTER INTAKE. 94

8. TEST OF THEORETICALLY RATIONAL METHOD FOR PREDICTION OF ORGANIC MATTER INTAKE.

9. TEST OF EMPIRICAL PREDICTION OF ORGANIC MATTER INTAKE FROM ACID-DETERGENT FIBER PERCENTAGE OF DRY MATTER. 


\section{Abstract of Dissertation Presented to the Graduate Council of the University of Florida in Partial Fulfillment of the Requirements for the Degree of Doctor of Philosophy \\ RATIONAL METHODS FOR PREDICTING QUALITY AND DIGESTIBLE ENERGY CONCENTRATION OF WARM-SEASON FORAGES FOR RUMINANTS}

\section{By}

Edward J. Golding, III

$$
\text { March, } 1976
$$

Chairman: Dr. John E. Moore

Major Department: Animal Science

Three separate studies were conducted to (a) devise and test theoretically rational and acceptably accurate methods for predicting digestible organic matter (DOM), digestible energy (DE) concentration and DOM intake (DOMI) of forages; and (b) investigate alternative laboratory methods which eliminate organic solvents in the determination of ash-free neutral-detergent fiber (NDFA) in hay samples and residues of in vitro fermentation. These studies included 43 hays from three species of warm-season grasses (Paspalum notatum Flugge, Cynodon dactylon (L) Pers., and Digitaria decumbens Stent) and nine hays of Medicago sativa L. Conservative and liberal acceptability limits, which corresponded to the weighted average of the 95 percent confidence interval for means, and plus and minus two weighted average population standard deviation estimates, respectively, were used to judge acceptability of DOM, DE and DOMI predictions.

Acceptable predictions of DE for 10 grasses were based on DOM and digestible crude protein concentrations in forage. Acceptable predictions of DOM were made for all 52 forages by summing neutral-detergent solubles (NDS) and in vivo digestible NDFA, and subtracting a constant 10.3 for metabolic fecal organic matter, all as percentages of dry matter 
(DM). The Van Soest Summative Equation did not accurately predict NDFA digestibility (NDFD) for warn-season grasses; and discrepancies apparent1y exist between alfalfa and grasses with respect to the in vivo NDFD in vitro NDFD relationship. The remaining challenge with respect to DOM and DE prediction, therefore, is development of a rapid procedure for accurate prediction of digestible NDFA over a wide range of forages. Acetone washes for determinations of NDFA in hays appeared necessary, but probably could be excluded when analyzing for in vitro residual NDFA. Terminating fermentation by setting tubes in an ice-water bath to the level of their contents for 1 hr was an acceptable alternative to use of toluene. These studies were based on eight hays having a wide range of NDFA and NDFD.

Ruminal retention time of organic matter (RTOM) was a theoretically rational independent variable for predicting DOMI. A published equation for plotting disappearance of cellulose from the rumen through time was applied to total organic matter (OM) and used to estimate RTOM values for 31 grasses. For each grass, the value for the rate constant $\left(k_{1}\right)$ for rate of digestion was estimated by in vitro procedures, while the rate constant $\left(k_{2}\right)$ for rate of passage was calculated from known lignin intake. Estimates of the potentially digestible fraction of ruminal OM ('a') were made using the formula for ' $a$ ' developed in this study, and the potentially indigestible fraction of ruminal OM was equal to one minus ' $a$ '. An equation for prediction of DOMI from RTOM was generated using 15 forages, and the 16 predictions produced by this equation were acceptable. Actual values of $k_{2}$, though relatively invariant, cannot be assumed constant among forages, nor can these values be predicted accurately at present from predicted values of 'a'. 
Rational prediction of OM intake (OMI) was accomplished by dividing predicted DOMI by predicted OM digestibility. This procedure was more acceptable than empirical prediction of OMI from acid-detergent fiber or NDFA percentage. 
CHAPTER I

\section{INTRODUCTION}

In 1972, forages provided some 73 percent of the feed requirements for beef cattle, 63 percent for dairy cattle and about 89 percent for sheep and goats in the United States (Wedin et al., 1975). These figures may be higher today, since grain feeding is less profitable in many areas and ruminant production is becoming increasingly dependent upon grassland farming. Thus, it is becoming imperative that producers possess accurate information relative to the quantity and quality of forage available to them. Relatively fast and accurate estimation of forage production offers little problem to the experienced practicioner, but rapid and accurate prediction of forage quality cannot be achieved across a wide range of forage species. Such predictions of forage quality are required by the objective producer even if limited grain is to be fed to ruminants. Thus, an important research area today concerns the rapid and accurate prediction of quality across a wide range of forages.

Accurate knowledge of forage quality by itself, however, may be of little value to the producer. This is because digestible nutrient intake may greatly diverge across a number of given situations from that indicated by laboratory predictions of forage quality. Dynamic computer modeling is a process which is becoming more widely employed in today's research in several biological disciplines. Such modeling may be capable of accurately predicting digestible nutrient intake for 
a given situation if the factors which affect this parameter, the methods by which such factors mediate their influence, and/or the magnitudes of the effects of these factors can be elucidated over a wide range of forages. Divulgence and use of such information, however, requires cooperation by teams of researchers who integrate their knowledge in order to achieve the rapid, efficient and accurate solution to a common problem. Such cooperation among researchers is fast becoming a requirement if the persistence or betterment of man's present standard of living is to be insured.

In this dissertation, three separate studies were conducted to (a) devise and test theoretically rational and acceptably accurate methods for predicting digestible energy concentration and digestible organic matter intake of forages; and (b) investigate alternative laboratory methods which eliminate organic solvents in the determination of ash-free neutral-detergent fiber in hay samples and residues of in vitro fermentation. 


\section{CHAPTER II}

\section{REVIEW OF LITERATURE}

\section{Expressions of Forage Quality}

Moore and Mott (1973) state that when forage availability is not a limiting factor, and when animal potential is invariant between treatments, then the best measure of forage quality is output per animal. Minson (1968) suggested that this output could be in terms of milk, meat or wool, and also agreed (1971a) that the grazing trial is the most reliable method of estimating the quality of different forages or the effect of a management treatment upon quality. Grazing trials to determine output per animal must be long-term endeavors and they become costly in terms of resources, time and capital. Thus, an expression of forage quality which is less expensive to determine, but which yields equally acceptable results, becomes a necessity if a large number of forages are to be evaluated.

Digestible Energy Intake, Digestible Dry Matter Intake and Digestible Organic Matter Intake

According to Heaney (1970), an expression of the feeding value of forages, or of forage quality, must have the following inherent characteristics: (1) it must be measurable vith a high degree of precision; (2) observations on a small number of aninals under controlled experimental conditions must be applicable to a more general production situation and animal population; and (3) it must be highly correlated with animal production when the evaluated feed is fed to animals. This author also stated that researchers now accept the combination of intake 
and digestibility into a single expression, such as digestible energy intake (DEI), for evaluating forage quality, and that this is the most effective method ever used. Jones (1972), Milford and Minson (1965a) and Crampton et al. (1960) agreed that intake and digestibility should be combined for determining quality, and Heaney (1970) and Ventura (1973) have reported evidence that neither intake nor digestibility by themselves can be considered a reliable expression of forage quality. Why, however, should intake and digestibility qualify as contributors to an expression of forage quality? In a practical sense, it is foolish to think of any indicator of forage quality which does not include some measure of the amount of a forage that animals will voluntarily eat, for animals will not produce without consuming the energy and nutrients needed for conversion to livestock products. Minson et al. (1964), Osbourn et al. (1966) and Milford (1967) reported deviations from a general constant relationship between voluntary intake and dry matter (DM) digestibility, both among and within forage species. Thus, a direct and separate estimate of voluntary intake of a forage must be made for inclusion in an expression of forage quality along with digestibility (Minson and Haydock, 1971). Some measure of nutritive value or net energy (NE) (Raymond, 1968; Moore and Mott, 1973) must also be included in the expression, since consumed nutrients and energy will not contribute to production unless they are digested and utilized. Since these functions are not solely under the influence of intake, the digestibilities of either DM or organic matter (OM) may be used as expressions of nutritive value (Moore and Mott, 1973) because NE for maintenance and fattening have been predicted satisfactorily from energy digestibility, which in turn is well correlated with the 
digestibility of either DM or OM (Armstrong et al., 1964). Thus, digestible dry matter intake (DDMI) or digestible organic matter intake (DOMI) can be included with DEI as quality expressions. Jones (1972), Ventura (1973) and Marsh (1974) concurred that DOMI is synonomous with forage quality.

If DEI,DDMI and DOMI are to be considered expressions of forage quality, they should be highly correlated with average daily gain of animals consuming the forage in question. Since an increase in digestible energy (DE) is associated closely with increases in metabolizable energy (ME) and NE, it should be expected that increases in DEI, as well as in other quality expressions, would be well correlated with increases in NE intake and output per animal. This has been found to be true. Elliott et a1. (1961) and Holmes et al. (1966), working with tropical pastures, found that liveweight gain of cattle was linearly related to DDMI. Heaney (1970) observed that forage DEI agreed exceptionally well with growth rates of lambs fed forages for seven to eight weeks, and Montgomery and Baumgardt (19.65a) found no significant differences between DEI's or between average daily gains when ruminants consumed high-quality rations. Thus, as stated by Pfander (1970), probably the most practical measure of forage quality would be DEI per kilogram of body weight raised to the .75 power. However, measurements of DDMI or DOMI are probably just as acceptable where energy deterninations cannot be or have not bren made.

No matter which expression is used to indicate forage quality, the relative contributions of intake and digestibility to the value of the expression are not the same. According to Heaney (1970), the range in recorded values of intake, going from low- to high-quality forages, is 
about 2.5 times that of recorded digestibilities. Thus, intake is more than twice as important as digestibility in determining the value of forage quality over a range of forages. Crampton (1957), Moore (1968), Osbourn et al. (1970) and Ventura et al. (1975) agreed that intake is the more important factor in deternining quality. Milford and Minson (1965a), working with tropical grasses, found that daily DDMI was more closely correlated with intake of DM than with its digestibility. Crampton et al. (1960) reported that variation in intake accounted for 70 percent of the variability in the Nutritive Value Index. Intake is more important than digestibility in determining quality among forages, and intake of a given forage is more variable between animals than is digestibility (Blaxter et al., 1961; Minson et a1., 1964; Heaney et ․‥, 1968; Capote, 1975). Therefore, intake should be investigated using six to ten animals per determination, while three or four will suffice for digestibility (Heaney, 1970). This variability in intake among animals on a given forage may be due to animal variation with respect to (1) weight (Heaney, 1970; Capote, 1975); (2) fatness (Bines et al., 1969; Foot, 1972; Capote, 1975); (3) physiological rumen volume (Purser and Moir, 1966); and/or (4) retention time of OM in the rumen (Campling et al., 1961; Phillips et al., 1960; Hungate, 1966). This discussion of intake variability is not to imply, however, that changes in digestibility are insignificant in their influence upon DEI or the other expressions of quality. Blaxter et al. (1961), under ad libitum feeding conditions, calculated that a change in digestibility of DM from 50 to 55 percent resulted in a 100 percent increase in weight gain. 
Nutritive Value Index

The Nutritive Value Index (NVI) was proposed by Crampton et al. (1960) as another expression of forage quality. For temperate forages, this index was highly correlated with both 12-hour in vitro cellulose digestibility (IVCD) (Donefer et al., 1960; Johnson et al., 1962b) and IVCD multiplied by the solubility of forage DM in $1.0 \mathrm{~N}$ sulfuric acid (Johnson and Dehority, 1968). Like the other proposed quality expressions, it also includes measures of (a) voluntary intake (actually "relative intake" compared to that of the standard forage proposed by Crampton et al. (1960)) and (b) digestibility (energy digestibility (ED)). Minson and Milford (1966) examined NVI in relation to DEI and found that, though NVI was highly correlated with DEI for the three forages studied, the regression coefficient for one of the forages was significantly different from the others. Interpretation of the results of Johnson et al. (1962a) reveals that for forages consumed in the fresh state, prediction of an NVI value from 12-hour IVCD would require different regression equations depending upon the DM percentage of the in vitro sample.' This was because of differences between the 12-hour IVCD values of undried versus artificially dried samples. Due to the absence of a constant caloric value for conversion of NVI to DEI, and due to the lack of tables of animal requirements for NVI, Minson and Milford (1966) concluded that the more direct method of expressing forage quality in terms of DEI per unit of metabolic size was superior to the NVI system.

Retention Time of Organic Matter in the Rumen

Blaxter (1962) reported that the qualities of different feeds were proportional to the rates at which they passed through the gut of 
ruminants. Thornton and Minson (1972, 1973) and Laredo and Minson (1975) concluded that the retention time of OM in the rumen (RTOM) was highly and inversely correlated with DOMI. Thus, if RTOM could be accurately predicted by means of laboratory analyses, it might prove a method which could greatly reduce the need for intake and digestion trials in forage evaluation research. Part of the research in this dissertation examines this hypothesis.

\section{Control of Forage Intake by Ruminants}

Capote (1975) and Golding (1973) have written literature reviews covering many of the proposed control mechanisms, as well as many of the factors which interact to control the voluntary intake of ruminants. Included in these reviews are the effects of the following factors upon intake: animal breed, weight, size, age, rate of production and fatness; ration caloric concentration; crude protein percentage of forage; blood and rumen metabolites; environmental conditions, such as ambient temperature, humidity and solar radiation; physiological condition, including lactation and pregnancy; hormones; frequency of feeding; water deprivation; amino acids; minerals; crude protein supplementation; and energy supplementation. Thus, these factors will not be dealt with, or will be touched upon only lightly, in the present review. This review will attempt to cover the physical or distention mechanism which has been proposed for control of forage intake by ruminants, as well as the factors which relate to the function of this mechanism.

The Distention Mechanism

The theoretical distention mechanism for controlling forage intake, formally proposed by Montgomery and Baumgardt (1965a) and Conrad (1966), 
appears to be an extension of the following concepts set forth by Crampton et al. (1960): (1) some specific degree of rumen load reduction probably is the primary determinant of recurring hunger in ruminants;

(2) the rates of forage cellulose and hemicellulose degradation are correlated with the rate at which the rumen load is reduced; and (3) the time period after which the rumen load reaches the degree of reduction at which hunger recurs is characteristic of the specific forage involved. Moore and Mott (1973) state that if nitrogen is not limiting, the mechanism related to the distention theory is that which most often controls intake of forage-fed animals. Work by Campling et al. (1962), Egan (1965), Weston (1967) and Minson and Milford (1968), however, indicated that the distention mechanism may also be involved in regulating intake, at least in part, when dietary crude protein (CP) is less than 7 percent of total DM. Baile (1968), Waldo (1970), Welch (1967) and Weston (1966) all agreed that physical distention of the rumino-reticulum was an important feedback mechanism for the regulation of forage intake by ruminants.

The distention control mechanism is generally dominant with long forages until the digestibility of DM reaches some upper point in the range of about 65-70 percent. The form in which forage is fed (Blaxter et a1., 1961; Montgomery and Baumgardt, 1965a) and the physiological condition of the animal consuming it (Waldo, 1970) have been shown to change this point. This theory suggests that forage intake and digestibility should be highly correlated. This may be true when forage quality differences are due to maturity differences, but may not be so when quality differences are due to forage species (Milford, 1967; 
Weston and Hogan, 1967; Minson et al., 1964; Van Soest, 1964) or cultivars within a species (Osbourn et al., 1966). This possibly is because chemical and structural differences may exist which cause differing rates of digestibility, though final digestibilities are similar, across a given set of forages (Van Soest, 1965a; Demarquilly et a1., 1965; Milford and Minson, 1965a). Thus, the relationship between intake and digestibility may be sufficiently accurate for predictive purposes only when limited to maturity differences within individual species and/or cultivars.

Site and mechanism of distention control

Earlier work by Blaxter et 로. $(1956,1961)$ and Conrad et al. (1964) stressed the importance of distention of the entire gastrointestinal tract of ruminants in controlling forage intake. Thus, the rate of passage of digesta through the entire tract was thought important in limiting consumption. However, fecal DM output varies across the various forms in which forages are fed (chopped, wafered, ground, pelleted, etc.) (Waldo, 1970), and positive relationships have been reported between intake and amounts of material in sections of the tract posterior to the ruminoreticulum (Ingalls et al., 1966). Such observations led many workers (Ingalls et al., 1966; Ulyatt et al., 1967; Waldo, 1970; Ulyatt, 1973) to discount the importance of sections of the tract posterior to the rumino-reticulum (hereafter referred to as the rumen) in limiting forage consumption. Thus, most researchers now agree with the contention of Campling et a1. (1961) and Waldo (1970) that the rumen is that portion of the gastro-intestinal tract in which distention control over forage intake is exercised. Further, they agreed that distention control is governed by two main factors: (a) fill, or 
the amount of digesta in the rumen (Campling and Balch, 1961; Weston, 1966) and (b) retention time, or the extent of delay of digesta in the rumen (Campling, 1965, 1970; Thornton and Minson, 1972). Importance of the rumen to this mechanism is indicated by receptors sensitive to ruminal stretch or tension (Be11, 1961; Comline and Titchen, 1961; Kay, 1963; Leek, 1969), though the nature and location of the sensory nerve endings have not yet been reported (Campling, 1970). Still, some evidence indicates that intake of finely ground and pelleted forage diets may be partly controlled, either directly or indirectly, by distention of the abomasum and intestines (Campling et al., 1963; Campling and Freer, 1966). Relative importance of "fill" and "retention time"

Retention time is probably more important than fill in limiting forage intake because rumen DM fill per kilogram of metabolic weight $\left(\mathrm{W}_{\mathrm{kg}}{ }^{75}\right)$ has been shown relatively constant across a range of forage quality (Blaxter et al., 1961; Ulyatt et al., 1967; Thornton and Minson, 1972). Campling et al. (1961) and Egan (1970), feeding diets of cereal straws and hays, reported that fill on such diets was low relative to that produced by higher-quality forages. The straw and hay diets contained less than 1 percent nitrogen. Thus, nitrogen deficiency may have led to the low fill observed with these diets. In such cases, amount of rumen fill may be more important in controlling forage intake than when forages of higher quality are considered. The actual amount of DM fill in the rumen has been reported to vary from 1.7 percent (Thomas et a1., 1961) to 2.2 percent (Waldo et al., 1965) or 2.44 percent (Ingalls et al., 1966) of body weight. This 
variation may be due to differences in DM intake across the diets used in these experiments (Ingalls et al., 1966; Egan, 1970; Thomas et al. , 1961).

That intake depends to a great extent upon average retention time of material in the rumen has been shown by many researchers (Ulyatt, Ir '); 01tjen et a1., 1971; E11iott and Topps, 1960; Laredo and Minson, 1975; Thornton and Minson, 1972, 1973). Calculations made in the present study from data presented by Laredo and Minson (1975) and Thornton and Minson $(1972,1973)$ showed that retention time of OM in the rumen (RTOM) was highly correlated with digestible OM intake per $W_{k g} .75$. If RTOM could be predicted accurately from parameters related to forage composition and/or structure, accurate predictions of forage quality might be obtainable from RTOM. This could decrease the necessity of running intake and digestibility trials with ruminants. Theory and relationships between various parameters reported by Waldo et al. (1972) may prove useful in attaining this goal.

\section{Factors Affecting Retention Time}

For a given forage, RTOM depends upon rate of digestion in the rumen (Campling, 1965; Jones and Bailey, 1974) and upon the rate at which undigested residues leave this organ (Campling, 1964, 1965; Waldo et al., 1972). This suggests that there are two important rates to consider, and that there are two types of material in the rumen: (a) one which leaves the rumen due to digestion (i. e., by absorption and eructation), and (b) one which must exit via passage to the lower gut (Waldo et al., 1965, 1972). McLeod and Minson (1974a) and de 1a Torre (1974) suggest that this latter material contains all the lignified fractions of the plant cell wall, and hence all the lignin in the diet. 
However, part of the potentially digestible material must also evacuate the rumen via passage, since not all of this material is digested in the rumen. This important fact is included in the model derived by Waldo et al. (1972) to describe the manner in which cellulose disappears from the rumen. Also included in this model are the concepts that both the rate of digestion of digestible material (Gill et al., 1969; Smith et al., 1971, 1972) and the rate of passage of indigestible residues (Meyer et al., 1967; Alexander et al., 1969; Brandt and Thacker, 1958) follow the laws set forth for first-order dynamic processes. That is, these rates proceed in proportion to the amounts of material undergoing digestion and passage. Gill et al. (1969) reported that the relative rate of digestible cellulose digestion (K) in vitro was highly correlated with the digestible DM intake of cows consuming high-DM legume-grass silage. Such was not the case when Lechtenberg et al. (1974) fed corn stover silage from two different corn genotypes to sheep. These authors postulated that rate of digestion of total cell walls was more important than $\mathrm{K}$ in determining intake. They also reported that rate of digestion of total cell walls was affected by lignification, but that $K$ was not.

A negative relationship between intake and retention time has been noted by many workers (Thornton and Minson, 1972; Ingalls et al., 1966; Waldo et al., 1965). The decrease in RTOM with increased level of feeding may be responsible for observed decreases in DM digestibility (Laredo and Minson, 1975). However, Minson (1966) reported that retention time of DM in the rumen was only slightly influenced by the level of DM intake of the same diet, since reducing intake by 51 percent yielded only an 18 percent increase in retention time. Thus, Thornton 
and Minson (1972) reasoned that among forage diets which exhibited DM intakes of from 659 to $1355 \mathrm{~g} /$ day, intake level could have accounted for no more than 20 percent of the difference in ruminal retention time, which varied from 13.3 to 27.1 hours. These investigators concluded that retention time in the rumen was controlled largely by chemical composition of forage, particularly neutral-detergent fiber (NDF) and lignin. Lignin was highly correlated with intake in their study, however, and such is not always the case (Golding, 1973).

Non-forage factors which may exert important influences upon RTOM have been reported. Graham and Williams (1962) observed that retention time of residues in the gut increased as pregnancy advanced in sheep given a constant amount of feed. Studies by Warren et al. (1974) and Wayman et al. (1962) indicated that RTOM may increase at high ambient temperatures. In this latter study, animals were forced-fed at high ambient temperatures to offset any effect of decreased intake on RTOM. Factors affecting rates of digestion and passage

of the many factors which interact to determine rates at which forage OM digests in and passes from the rumen, probably chemical composition and organizational structure of cell walls of ingested forage are the most important (Akin et al., 1974a; Van Soest, 1965a; Thornton and Minson, 1972; Laredo and Minson, 1973). That chemical composition is important in this respect was shown by Campling et al. (1962), Egan (1965) and Weston (1967). These workers increased rate of digestion and the intake of diets low in $\mathrm{CP}$ percentage by supplementing with urea. Such increases would not have occurred unless CP was the first limiting factor. The fact that lignin can limit rate of digestion 
was brought out by Lechtenberg et al. (1974) and Crampton (1957). Thornton and Minson (1972) reported a high correlation between lignin content of forage and retention time of DM in the rumen. This, at least in part, was undoubtedly a reflection of the effect of lignin on rate of digestion of forage cell walls. When forages are supplementeu with energy, rates of DM or cellulose digestibility decline, perhaps due to mineral imbalances (Burroughs et al., 1948) or nitrogen competition (el-Shazley et al., 1961). Minimum requirements of some rumen bacteria for phosphorus, magnesium, calcium, sodium and potassium have been established, and iron, cobalt, copper, manganese and zinc have been shown to be beneficial to others (Hungate, 1966). Therefore, deficiencies of these minerals, as well as imbalances concerning their relative concentrations in the rumen, could cause decreases in rate of digestion of forage cell walls.

Rate of passage of indigestible OM from the rumen is limited by the rate at which large particles in this organ are reduced to a size small enough to pass to the omasum. Rate of breakdown, while certainly under the influence of composition of feed and animal factors such as efficiency of chewing and strength and/or frequency of ruminal contractions, is regulated to a great extent by organizational structure of the forage cell wall fraction (Akin et al., 1974a; Ulyatt, 1973). Further histochemical studies of the nature of those by de la Torre (1974), Akin et a1. (1974a) and Monson et al. (1972) are needed to elucidate the relationships between cell wall structure and rates of OM breakdown in, and passage from, the rumen. Perhaps grinding energy, as proposed by Chenost (1966), deserves more experimental work as a method for predicting rate of breakdown in the rumen. 
Other factors which aid in determining rates of digestion and passage are those related to animal breed, the form in which forages are fed and supplementation of forages with energy. Phillips (1961) and Hungate et a1. (1960) observed that Zebu cattle demonstrated higher rates of digestion and passage of forage diets than did steers of European breeds. In the latter of these studies, the higher rates correlated well with lower retention times exhibited by Zebu animals, and it was postulated that the advantage of Zebus relative to European breeds with respect to rates of digestion and passage would be increased under conditions of stress and submaintenance feeding. Forages fed in pelleted form have shown faster rates of digestion and passage and decreased retention times of digesta in the rumen relative to the same forages fed in the long or chopped forms (Johnson et al., 1964; 01tjen et a1., 1971; Laredo and Minson, 1975). The advantage demonstrated by pellets in this respect seems to be greatest when low-quality forages are fed (Minson and Milford, 1968). Intake is not always increased by pelleting, however, if nitrogen is a limiting factor (Minson, 1967; Minson and Milford, 1968). Supplementation of forage with energy causes the forage portion of the diet to be retained longer in the rumen than when forage is fed alone (Montgomery and Baumgardt, 1965b; Campling, 1966; Eng et a1., 1964). This appears to be caused by decreased activity of the cellulolytic microflora in the rumen when forage is supplemented with starchy energy feeds (Campling, 1970; el-Shazley et al., 1961). A lower intake of forage may also contribute to lengthening its retention time under these conditions. 
Intake vs Rate of Digestion In Vitro

Since rate of digestion in the rumen has been shown to be instrumental in determining retention time (Campling, 1965; Jones and Bailey, 1974) and, therefore, intake, it follows that in vitro rate of digestion should also be highly correlated with these parameters. Minson and Milford (1967a) found that 12-hour in vitro DM digestion predicted the voluntary intake of Rhodes grass (Chloris gayana), and Crampton et al. (1960) suggested that rate of in vitro cellulose digestion was related to voluntary intake. Donefer et al. (1960) and Johnson et al. (1962b) reported that 12-hour IVCD was highly correlated with NVI, and Jones (1972) found that intake of four temperate grasses was highly correlated with rate of in vitro DM digestion.

Minson (1971a) described less promising results when correlating in vitro digestion rate with intake of different varieties of Panicum. Karn et al. (1967), using temperate grasses and alfalfa, obtained low correlation coefficients ( $r$ values) between intake and in vitro rates of cellulose or DM digestion at various times between five and 11 hours of fermentation. Laredo and Minson (1973) observed no difference between mean in vitro rates of digestion of leaf and stem fractions of five different warm-season grasses, though mean voluntary intake of leaf was 46 percent higher than that of stem. These authors stated that this discrepancy was probably due to the fact that all in vitro samples had been ground to pass a one millimeter (mr) screen, thus destroying the structural differences across samples which had produced the large difference in in vivo intake. This work suggests that high correlations reported by other workers between intake and rate of in vitro digestion may have been caused by factors other than differences in fiber structure across forages. 
Examination of the grasses used by Crampton et al. (1960) and Minson and Milford (1967a) showed a positive correlation between intake and nitrogen content of those forages (Laredo and Minson, 1973). These results suggest that when forage samples are ground to pass a $1 \mathrm{~mm}$ screen prior to determining in vitro rates of digestion, such determina.tions will be highly correlated with intake only when intake is related to chemical composition. High correlations should not be the case when cell wall structure plays the dominant role in determining intake, since differences in in vivo rates of digestion probably will be masked in vitro.

Another discrepancy between in vivo and in vitro rates of digestion, which could cause low correlations between intake and in vitro rate of digestion, could occur with forages of low CP percentage. Glover et al. (1960) showed that when forages which contained less than 5 percent $C P$ on a DM basis were fed over prolonged periods of time, a sharp decrease in in vivo digestibility was likely to occur. This decrease probably would not appear in vitro due to the relatively short fermentation times, and also because rumen fluid for sample inoculation is normally drawn from donor animals whose diets are adequate in CP. Thus, low in vivo rate of digestion and decreased intake of low CP forages which had been fed for some time might not be reflected by in vitro rate of digestion of that forage.

\section{Prediction of Forage Nutritive Value}

Moore and Mott (1973) stated that most forage researchers generally use ED or apparent digestibility of DM (DMD) or OM (OMD) as expressions of forage nutritive value. They also concluded, based upon work by 
Armstrong (1964), Armstrong et al. (1964) and Graham (1967) that digestible energy (DE) per $g$ DM (DE/DM) was a very meaningful and useful criterion of forage nutritive value for both tropical and temperate forages.

Applicability of Predictors of Nutrient Digestibility Chemcial analyses

No chemical determination, whether based upon the Weende proximate analysis system, the Van Soest method of fiber fractionation or one of several solubility techniques, will predict OMD or DMD with a high degree of consistent accuracy across a wide range of forage species (Johnson and Dehority, 1968; Butterworth and Diaz, 1970; Moore and Mott, 1973; Golding, 1973). Nor will an empirical multiple regression equation based upon several such chemical determinations allow accurate prediction of nutritive value over such a range of forages (Butterworth and Diaz, 1970; Moore and Mott, 1973; Golding, 1973). Some chemical determinations will exhibit a high degree of correlation with $O M D$ or $D M D$ over a narrow range of forages if maturity is the primary determinant of quality. However, when the resultant regression equation is applied to a different set of forages than that which produced the equation, digestibility predictions are generally lacking in accuracy.

In vitro organic matter digestion

The in vitro OM digestion procedure for estimation of in vivo $\mathrm{OMD}$, while more rational and accurate for this purpose than chemical analyses, is akin to these analyses in that discrepancies exist in the in vivo in vitro relationship across forage species (Moore and Mott, 1973; 
McLeod and Minson, 1974b). Thus, across species, different regression equations must be utilized in the prediction of OMD. Weller (1973) found that the particle-size distribution over 12 warm-season grasses from three different species did not contribute to this discrepancy. However, among forages which exhibit true differences in the structur. make-up of fibrous $O M$, fine grinding of forages before subjecting them to fermentation may still influence the degree of an observed discrepancy (Laredo and Minson, 1973).

\section{Summative equations}

Sumative equations presented by Van Soest (1965b) and Minson (1971b) (for prediction of DMD and OMD, respectively) are also not good predictors of DMD or OMD when applied to a wide range of forage species. These equations are theoretically rational in that they sum the various apparently digestible fractions of DM or OM. However, they include hypothesized cause and effect relationships which are invalid across forages for estimating digestibilities of various fibrous fractions. If the summative principle could be combined with the Nutritive Entity concept of Lucas and Smart (1959), and with some consistent cause and effect relationship for predicting digestibility of fibrous OM, the OMD could be more accurately predicted across forages. This has been shown by Velasquez (1974), who used in vitro NDF digestion to predict in vivo digestibility of NDF. This procedure, however, is too time consuming to be employed in routine forage evaluation. Applicability of Predictors of DE Concentration in Forage DM In vitro cellulose digestibility

Hershberger et al. (1959) found a high correlation $(r=.92)$ between kilocalories (kcal) DE/DM and IVCD after 24 hr of fermentation 
over four temperate grasses and two legumes. Johnson et al. (1962b) reported a high $r$ value (.99) for the relationship between ED of temperate grasses and IVCD at $24 \mathrm{hr}$, but when legumes were included in the analysis, $\mathrm{r}$ dropped to .88 after $24 \mathrm{hr}$, as opposed to .99 after just $12 \mathrm{hr}$ of fermentation. Thus, it appeared to these workers that 12-hr IVCD compared most favorably with ED across forage species. Johnson and Dehority (1968), working with temperate species, found $\mathrm{r}$ values of only $.79, .54$ and .64 within groups of 22 grasses, 25 legumes and 30 mixed forages, respectively, for the relationship between ED and 12-hr IVCD. Across all 77 forages, the $r$ value for this relationship was only .64, suggesting that IVCD, after either 12 or $24 \mathrm{hr}$ of fermentation, would not be an accurate predictor of DE/DM. Also, none of the Van Soest fiber fractions or solubility techniques studied by Johnson and Dehority (1968) would effectively fill this role. Across all forages, cellulose solubility in cupriethylenediamine multiplied by DM solubility in $1.0 \mathrm{~N}$ sulfuric acid exhibited the highest correlation with ED, but $r$ was only .82 .

\section{Dry matter digestibility}

Moir (1961) reported a highly significant relationship between $D E / D M$ and DM digestibility $(D M D)(r=.98)$, and proposed that a general equation could be used to predict DE/DM from DMD. Butterworth (1964), however, found an $r$ value of only .86 between these two parameters for 24 tropical forages. Minson and Milford (1966) stated that when they used the equation suggested by Moir (1961) to predict $\mathrm{DE} / \mathrm{DM}$, estimates from pastures of low digestibility were in agreement with actual $\mathrm{DE} / \mathrm{DM}$ values. With pastures of high digestibility, actual 
$\mathrm{DE} / \mathrm{DM}$ values were 7 percent lower than estimated. Therefore, use of a general equation to predict DE/DM from DMD could lead to inaccurate results.

Crude protein percentage of dry matter

Glover et al. (1960) showed that over a wide range of $\mathrm{CP}$, as a percentage of $\mathrm{DM}, \mathrm{CP}$ was well correlated with DE concentration in forages. Minson and Milford (1966) also observed a positive correlation $(r=.84)$ between the caloric value of $O M$ and $C P$ percentage. Therefore, wide variation in CP may explain part of the discrepancy found in the relationship between DE/DM and DMD. This would occur because digestible CP (DCP), which is highly correlated with CP (Holter and Reid, 1959; Milford and Minson, 1965b), exhibits a higher caloric value than does digestible carbohydrate (Maynard and Loosli, 1969). It is doubtful, however, that CP will be always highly correlated with DE/DM over a wide range of forages, since CP does not generally exhibit a strong cause and effect relationship with DMD. Still, some combination of rational factors related to $D M D$ and $C P$ may produce more accurate predictions of $\mathrm{DE} / \mathrm{DM}$ over a wide range of forages than would either of these factors alone.

\section{Prediction of Forage Quality}

The best measure of forage quality is output per animal under certain conditions (Moore and Mott, 1973). Heaney (1970) and Ventura (1973) found that neither intake nor digestibility alone could be considered a reliable expression of forage quality. Thus, most researchers now accept some combination of intake and nutritive value, such as DEI, DOMI or DDMI, as meaningful expressions of forage quality. 


\section{Applicability of Various Techniques for Quality Prediction}

Chemical analyses and summative equations

Moore and Mott (1973) and Golding (1973) have presented literature reviews of research to define methods for accurate prediction of forage quality. Conclusions of these authors will be briefly summarized in this section, and in those which follow. Quality over a wide range of forage species defied prediction by single laboratory chemical analyses, or by empirical multiple regression equations based upon several such determinations. Digestibility probably could be accurately predicted by summative equations if these were based upon the Nutritive Entity concept of Lucas and Smart (1959) and included an accurate predictor of cell wall digestibility. Accurate summative equations for digestibility prediction would not insure accurate prediction of forage quality, however, since digestibility and intake are not highly correlated over a wide range of forage species. In vitro techniques

In vitro OM digestion (IVOMD) by rumen microorganisms is the best available predictor of OMD. Across forages, however, discrepancies have been observed in the in vivo - in vitro relationship, i. e., IVOMD many times will be different at a given level of in vivo OMD (Moore and Mott, 1973). Even if in vivo OMD could be accurately predicted from IVOMD with a high degree of consistency, IVOMD would not be a generally accurate predictor of forage quality due to the frequent lack of relationship between intake and digestibility. It is possible that microanatomical studies (Monson et al., 1972; Akin and Burdick, 1973; de la Torre, 1974) of differences in composition, organization 
and rates of digestion of structural components of OM may help in removing discrepancies in the relationships between in vivo OMD and IVOMD, and between intake and digestibility.

In vitro rates of DM or cellulose digestion have been studied (Crampton et al., 1960; Minson and Milford, 1967a; Karn et a1., 1967; Minson, 1971a; Laredo and Minson, 1973) as possible predictors of forage quality. Such determinations may be inadequate for this purpose when structure of fibrous OM fractions is important for control of forage intake. This is because forage samples are generally ground to pass a $1 \mathrm{~mm}$ screen before being studied by in vitro procedures, thus greatly removing variation in structure of fibrous oM fractions among forages. It is possible that studies of in vitro rates of $O M$ digestion which employ more intact forage samples could produce rates of digestion which would correlate highly with forage quality. Such samples might also be examined microscopically before being fermented, and some attribute(s) might correlate highly with rate of OM digestion. In this case, microscopic examination of a small forage sample would lead to rapid prediction of forage quality. It is quite probable, however, that both chemical composition and the structural nature of fibrous $O M$ must be considered in an attempt to produce a method for prediction of quality over a wide range of forage species.

The rate constant for rate of cellulose digestion in vitro (K) was reported by Gill et al. (1969) to be highly correlated with digestible DM intake of high-DM legume-grass silage by cows. This concept was refuted by Lechtenberg et a1. (1974), who fed corn stover silage to sheep. Thus, it is doubtful that $\mathrm{K}$ is highly correlated with forage quality in a general sense. 
The nutritive value index

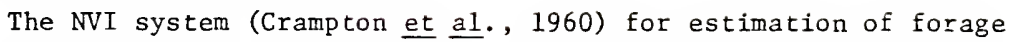
quality has received wide-spread attention from researchers, as well as much use in a practical sense. Discrepancies revealed by Minson and Milford (1966) and Johnson et al. (1962a) between actual forage quality and NVI values may, however, decrease the utility of this system as a quality estimator over a wide range of forages. Also, the fact that rapid NVI determination is based upon 12-hr IVCD might cause errors in quality estimation when structure of fibrous $O M$ is an important determinant of intake.

Retention time of organic matter in the rumen

Thornton and Minson $(1972,1973)$ showed that RTOM determined in vivo was highly and negatively correlated with forage quality. Therefore, RTOM may ultimately prove to be an accurate predictor of quality across forages, since it seemingly should be related to both chemical composition and structural microanatomy of forage OM. Across forages, values of RTOM may reflect rate and extent of OM digestion in the rumen which, in turn, should be determined by the microbial and physical degradability of forage OM.

\section{Mathematical Modeling of Dynamic Systems}

Forrester (1968), Joandet and Cartwright (1975) and Blincoe (1975) presented material which outlined the steps to be followed, types of information required and benefits to be reaped when mathematical computer models are employed to simulate the action of a given dynamic system. Forrester (1968) developed a method for modeling such systems, and Pugh (1973) presented the computer language, called Dynamo, which makes 
use of this modeling procedure possible. This procedure has been employed successfully in such fields as ecology, sociology, plant sciences, physical sciences and engineering. In the areas of animal science and agronomy, models utilizing this procedure, as well as others, have been applied to simulate forage production (Bravo, 1973; Smith and Williams, 1973; Patten, 1972); forage production under grazing (Christian et al., 1972; Paltridge, 1972; Vickery, 1972); rumen fermentation (Baldwin et al., 1970); animal energetics (Baldwin and Smith, 1971a); intermediate metabolites (Baldwin and Smith, 1971b); energy metabolism of the steer under feedlot conditions (Paine et al., 1972); sheep production (Wright, 1970); the efficiency of nutrient utilization by different cattle genotypes (Joandet, 1967); and the utility of different production alternatives from the economic point of view (Shumway et al., 1974; Anderson, 1972; Trebeck, 1972). The relationship between OMI by cattle on pasture and forage production has been included in the simulation of forage production and pasture utilization by the animal (Vickery and Hedges, 1974; Donnelly et al., 1970; Jones, 1969; Morley and Spedding, 1968). This relationship has been based upon a relatively simple set of assumptions not consistent with most practical situations (Joandet and Cartwright, 1975). Thus, proper description of the forage production - OMI relationship is one problem which must be overcome to achieve accurate simulation of pasture production and forage utilization by the ruminant animal.

The utility of mathematical models lies in the fact that they require accurate definition of the structure and function of the system or process which is being modeled (Forrester, 1968). They a1so indicate 
areas where research is needed by means of the degree of sensitivity which they display to changes in inputs; and they make possible the study of situations which cannot be achieved experimentally, or which are too risky or expensive to attempt otherwise (BIincoe, 1975). Perhaps the greatest attribute of mathematical computer models, however, is that their construction and use, as well as the interpretation of results which they generate, generally require the effort of a team of researchers who integrate their knowledge in trying to solve a common problem. 
CHAPTER III

PREDICTION OF DIGESTIBLE ENERGY CONCENTRATION IN FORAGE

FOR PURPOSES OF MARKETING SOUTHERN HAYS

\section{Introduction}

Forages probably would be marketed most fairly on the basis of their potential to support animal production, i. e., forage quality. Estimation of quality for marketing purposes requires a fast, simple and accurate method which presently is not available over a wide range of forage species. Thus, marketing of forages must be based on some other forage attribute. Intake will not serve as this attribute since lack of a sufficiently accurate method for prediction of intake (Minson, 1971a) is the main cause of problems encountered in attempting to predict forage quality. At present, therefore, forages must be marketed on the basis of their nutritive value. This nutritive value cannot be that which is realized in a given situation, but must be that which is a basic attribute of a given forage. Digestibility of dry matter (DM) or organic matter (OM) as estimated from in vitro digestions would satisfy this requirement over narrow ranges of forages. A rancher probably has little appreciation of such a parameter, however, and animals' energy requirements are tabulated on the basis of total digestible nutrients (TDN) or digestible energy (DE) concentration, not digestibility. Forages should be marketed, therefore, based on their values of $\mathrm{kcal} \mathrm{DE} / \mathrm{g} D M(D E / D M)$. This value is closely related to TDN, since the caloric value of TDN is approximately 
$4.4 \mathrm{kcal} \mathrm{DE} / \mathrm{g}$ TDN (Maynard and Loosli, 1969). If TDN of a forage is known, DE/DM can be calculated and a bomb calorimeter need not be employed.

If a prediction method for DE/DM is to be adopted widely for hay classification and marketing, it should be equally applicable to grasses, legumes and mixed hays, and must be inexpensive and rapid. No laboratory chemical analysis, whether used alone or in combination with other such analyses, will serve for accurate prediction of $\mathrm{DE} / \mathrm{DM}$ over a wide range of forages (Johnson and Dehority, 1968; Butterworth and Diaz, 1970; Moore and Mott, 1973), nor will in vitro digestion of OM or DM (Minson and Milford, 1966; Moore and Mott, 1973). Summative equations (Van Soest, 1965b; Minson, 1971b) may be adequate for DE/DM prediction if they encompass cause and effect relationships which hold true across forages (Moore and Mott, 1973), and if they include the Nutritive Entity concept of Lucas and Smart (1959).

The objective of this study was to define and test a theoretically rationa1 method, based upon use of summative equations, for the acceptably accurate prediction of DE/DM over a wide range of Southern haycrop forages.

\section{Experimental Procedure}

Theory Related to Rational Prediction of DE/DM

Forage digestible OM (DOM), as a percentage of DM, generally contains very little digestible ether extract (DEE) (Glover and Douga11, 1960). Thus, DOM is comprised mainly of digestible crude protein (DCP) and digestible carbohydrate, both as percentages of DM. The digestible carbohydrate fraction, in terms of the Weende proximate analysis, is 
composed of digestible crude fiber (DCF) and digestible nitrogen-free extract (DNFE). If forage DOM could be predicted and the caloric value of its digestible carbohydrate fraction added to that of DCP in DOM, then an accurate estimation of DE/DM should result.

With most hays, the numerical values of TDN and DOM are nearly identical. This can be illustrated as follows (values as percentage of DM):

$$
\mathrm{TDN}=\mathrm{DCP}+\mathrm{DCF}+\mathrm{DNFE}+2.25(\mathrm{DEE}),
$$

and

$$
\mathrm{DOM}=\mathrm{DCP}+\mathrm{DCF}+\mathrm{DNEE}+\mathrm{DEE} \text {. }
$$

Therefore,

$$
\mathrm{TDN}=\mathrm{DOM}+1.25(\mathrm{DEE}) .
$$

Since DEE is negligible in most hays, values of TDN and DOM are numerically equal for all practical purposes. This fact, in itself, probably will not lead to rapid and accurate prediction of DOM across a wide range of forages since TDN is not predictable with a high degree of accuracy over such a range (Butterworth and Diaz, 1970). The inability to predict TDN accurately among forages may be due to two facts: (a) crude fiber (CF) and nitrogen-free extract (NFE) are not Nutritive Entities (Moore and Mott, 1973); and (b) CF and NFE generally do not conform to their definitions in terms of composition (Harris et al., 1972).

\section{Prediction of DOM}

The first step in the rational prediction of DE/DM in the laboratory is the prediction of DOM, as a percentage of DM. Rational laboratory 
prediction of DOM is probably best approached using the Nutritive Entity concept of Lucas and Smart (1959) as expressed in terms of a summative equation (Raymond, 1969; Barnes, 1973; Moore and Mott, 1973). Perhaps the most rational summative equation for DOM prediction would include the fractions which constitute this parameter (values as percentages of DM):

$$
\mathrm{DOM}=\mathrm{DNDS}+\mathrm{DNDF}-\mathrm{MFOM} \text {, }
$$

where DNDS = digestible ash-free neutral-detergent solubles;

$$
\text { DNDF = digestible ash-free neutral-detergent fiber; }
$$

and MFOM = metabolic fecal OM excretion.

The DNDS include readily soluble or digestible carbohydrates, DCP and whatever digestible lipids may be present. Total ash-free neutral-detergent solubles (NDS) are, in theory, readily and almost completely degraded in the rumen, either by direct solution or by rapid microbial digestion. True digestibility of NDS may be approximately 100 percent (Van Soest, 1967), and NDS may be considered a Nutritive Entity which varies as a percentage of DM among forages, but not in digestibility. Thus, it is possible that replacing DNDS in equation (4) with NDS would not lead to unacceptable errors in pradiction of DOM. This would produce the following rational summative equation for prediction of DOM (values as percentages of DM):

$$
\text { DOM }=\text { NDS }+ \text { DNDF }- \text { MFOM. }
$$

Ash-free neutral-detergent fiber (NDF) varies as a percentage of DM, and in digestibility, among forages. With forages high in $\mathrm{NDF}$, such as warm-season grasses, there is not a close relationship between percentage and digestibility of NDF or its constituents 
(Velasquez, 1974; Minson, 1971b). Since NDF is not a Nutritive Entity, both NDF and NDF digestibility (NDFD) must be known to estimate DNDF.

Both NDS and DNDF must be determined for each forage for which DOM is to be predicted, unless one of them is invariant within a narrow and wel1-defined group of forages. Since MFOM in concept is a constant proportion of DM (Van Soest, 1967), there may be little error associated with use of one MFOM value for all forages when predicting DOM. If two of the three right-hand members of equation (5) are not highly variable across a given group of forages, then values for the third member should be highly correlated with DOM. Such a situation may occur within legumes (Tilley et a1., 1969; Johnson and Dehority, 1968). In such a case, an empirical prediction equation based only on the third component could predict in vivo DOM values which were nearly identical with those of forages used to generate the equation. This same equation might not predict DOM accurately within a large group of forages in which a different component of the equation was more highly correlated with DOM, or in which two of the three components were highly variable. Therefore, if a summative equation for prediction of DOM is to have wide applicability, independent estimates of NDS and DNDF will probably be required for each forage.

Prediction of DE/DM

The DE value of DOM (DE/DOM) varies among forages due to variation in DCP as a percentage of DM (Minson and Milford, 1966; Golding, 1973). Such variation in $D E / D O M$ is due to different average caloric values of proteins and carbohydrates ( 5.65 vs $4.15 \mathrm{kcal} / \mathrm{g}$; Maynard and Loosli, 1969). A correction can be made for this difference, and perhaps should 
be made since DCP may vary widely among forages. A theoretical correction is indicated by the following equation, under the assumption that DEE as a percentage of $\mathrm{DM}=0$ ( $\mathrm{DE}$ values as $\mathrm{kcal} / \mathrm{g} \mathrm{DM}$; others as percentages of DM):

$$
D E=\frac{4.15(D C F+D N F E)+5.65(D C P)}{100}
$$

Since equation (2), for most forages, can be written

$$
\mathrm{DOM}=\mathrm{DCP}+\mathrm{DCF}+\mathrm{DNFE},
$$

then

$$
\mathrm{DE}=\frac{4.15(\mathrm{DOM})+1.50(\mathrm{DCP})}{100}
$$

Values of DCP can be predicted from CP for most forages (except those that are heat damaged) by the following equation (N.R.C., 1971) (values as percentages of $\mathrm{DM})$ :

$$
\mathrm{DCP}=.866(\mathrm{CP})-3.06 \text {. }
$$

The combined theoretical equation for predicting DE/DM from predicted DOM and determined $C P$ is (DE as $\mathrm{kcal} / \mathrm{g} \mathrm{DM}$; others as percentages of DM)

$$
\begin{gathered}
\mathrm{DE}=\frac{4.15(\mathrm{DOM})+1.50(.866 \mathrm{CP}-3.06)}{100}, \\
\mathrm{DE}=\frac{4.15(\mathrm{DOM})+(1.50 \cdot .866)(\mathrm{CP})-(1.50 \cdot 3.06)}{100}, \\
\mathrm{DE}=\frac{4.15(\mathrm{DOM})+1.299(\mathrm{CP})-4.59}{100} .
\end{gathered}
$$

\section{Testing the Procedure}

Forages and in vivo data

Fifty-two forages, including 43 warm-season grasses and nine cuts of 'Florida 66' alfalfa (Medicago sativa L.) were used in this 
study. The 43 grasses were comprised of 31 which will be described in Chapter $\mathrm{V}$, and eight additional cuts of Pensacola bahiagrass (Paspalum notatum Flugge); one of Suwannee bermudagrass (Cynodon dactylon (L) Pers.); and three of Pangola digitgrass (Digitaria decumbens Stent). The latter 12 grasses were fed at less than ad libitum levels (restricted-fed) to sheep when studied in vivo, while alfalfas were fed ad libitum. All other details of in vivo trials involving alfalfas or restricted-fed grasses were as will be described for 31 grasses in Chapter $V$.

Laboratory analyses and prediction testing

Procedures relative to (a) laboratory analyses; (b) determinations of correlation coefficients ( $r$ values) and residual standard deviations ( $s_{y \cdot x}$ values) between laboratory analyses and/or in vivo values; (c) prediction of in vivo parameters; (d) setting of conservative and liberal acceptability limits $( \pm t(s / \sqrt{n})$ and $\pm 2 s$, respectively); and (e) testing of predictions, were the same as will be described in Chapter $V$. In addition, in vivo digestible energies ( $\mathrm{kcal} / \mathrm{g} \mathrm{DM}$ ) were determined for 10 grasses. Values of DE/DM $(\mathrm{kcal} / \mathrm{g})$ were predicted for these 10 grasses using equation (12). Predicted values of DOM, as a percentage of DM, were obtained for all 52 forages from equation (5). Values of NDS inserted into equation (5) were calculated as OM minus ash-free NDF (both as percentages of DM), while DNDF values were those determined in vivo. Values of MFOM for each hay were calculated as (NDS + DNDF) minus in vivo DOM, all as percentages of DM. 


\section{Results and Discussion}

Chemical Analyses

Ranges, means and coefficients of variation (CV) resulting from various laboratory chemical analyses conducted on the nine alfalfas and 43 grasses are presented in table 1 . Values of these parameters for individual forages can be found in Appendix tables 10 and 12 .

Values of $\mathrm{CP}$ ranged from 16.8 to 30.6 for alfalfa, with a mean of 22.5 (table 1), and from 3.8 to 19.5 for grasses, with a mean of 9.3. Though mean alfalfa maturity was less than that of grasses $(4.7$ vs $7.3 \mathrm{wk}$, respectively), these data reflect the generally higher CP percentages of legumes. For all forages, mean CP was 11.6 percent.

Values of ash-free NDS ranged from 39.9 to 50.3 for alfalfa, and the mean was 46.0 percent. The NDS content of grasses ranged from 16.1 to 30.5 percent with a mean of 20.7 percent. Mean NDS for all forages was 25.0 percent. Though differences in average maturity between alfalfa and grasses may have somewhat influenced these results, NDS was much higher in legumes than in grasses (Van Soest, 1965a; Smith et al., 1972). There was much less ash-free NDF present in legumes than in grasses. Alfalfa contained an average of only 44.0 percent of $\mathrm{NDF}$, while this figure for grasses was 75.1 percent. Again, differences in average maturity between alfalfa and grasses may have influenced these results, but grasses are generally considered to contain more NDF than legumes. For all forages, NDF ranged from 33.2 to 81.3 percent, and averaged 69.7 percent. 
TABLE 1. MEASURES OF CENTRAL TENDENCY AND DISPERSION OF THE CHARACTERISTICS OF 52 FLORIDA FORAGES

Item

Alfalfa

Number of forages

Number of species

1

Crude protein $(\mathrm{CP})^{\mathrm{a}}$

Mean $(\mathrm{CV})^{\mathrm{C}}$
Range

$22.5(19.9)$

$16.8-30.6$

Organic matter $(\mathrm{OM})^{\mathrm{a}}$

Mean (CV)

$89.9 \quad(3.2)$

Range

83.5-92.1

Neutral-detergent solubles

$($ ash-free) (NDS)

Mean (CV)

$46.0 \quad(7.7)$

Range

39.9-50.3

Neutral-detergent fiber

$\left(\right.$ ash-free) $(\mathrm{NDF})^{\mathrm{a}}$

Mean (CV)

$44.0(13.5)$

Range

$33.2-52.1$

NDF digestibility (ash-free)

Mean (CV)

$54.9(11.2)$

(NDFD) ${ }^{b}$

Range

$47.4-64.4$

Predicted NDFD (ash-free) ${ }^{\mathrm{b}}$

Mean (CV)

Range

In vitro $\mathrm{NDF}$ digestion (ash-free)

Mean (CV)

$43.5(13.5)$

(IVNDFD) $72 \mathrm{hr}^{\mathrm{b}}$

Range

$38.5-55.2$

Digestible NDF (ash-free) (DNDF) ${ }^{a}$

Mean (CV)

$23.9 \quad(8.8)$

Range

20.8-26. 9

OM digestibility (OMD) ${ }^{\mathrm{b}}$

Mean (CV)

$67.1(5.6)$

Range

$62.5-72.2$

Digestible OM (DOM) ${ }^{a}$

Mean (CV)

$60.3(3.5)$

Range

$57.6-64.2$

Predicted $\mathrm{DOM}^{\mathrm{a}}$

Mean (CV)

$59.5(4.6)$

Range

$56.5-64.6$

Metabolic fecal ON $(M F O M)^{a}$

Mean (CV)

$9.5(11.2)$

Range

7.5-10.9

${ }^{a}$ As $\%$ of dry matter. ${ }^{b}$ In $\%$. ${ }^{c}$ Coefficient of variation, in $\%$.

$\mathrm{d}_{\text {Restricted-fed. }}{ }^{\mathrm{Ad}}$ libitum-fed. 
Table 1 - extended.

\begin{tabular}{|c|c|c|c|}
\hline Grasses $^{\mathrm{d}}$ & Grasses $^{e}$ & Grasses & A11 \\
\hline 12 & 31 & 43 & 52 \\
\hline 3 & 3 & 3 & 4 \\
\hline $\begin{array}{l}9.3(18.8) \\
5.5-11.9\end{array}$ & $\begin{array}{l}9.3(47.1) \\
3.8-19.5\end{array}$ & $\begin{array}{l}9.3(40.9) \\
3.8-19.5\end{array}$ & $\begin{array}{c}11.6(54.8) \\
3.8-30.6\end{array}$ \\
\hline $\begin{array}{l}95.1 \quad(.8) \\
94.2-96.4\end{array}$ & $\begin{array}{l}96.0 \quad(1.3) \\
93.3-97.5\end{array}$ & $\begin{array}{l}95.7 \quad(1.2) \\
93.3-97.5\end{array}$ & $\begin{array}{l}94.7 \quad(2.9) \\
83.5-97.5\end{array}$ \\
\hline $\begin{array}{l}19.5 \quad(6.9) \\
17.6-21.5\end{array}$ & $\begin{array}{l}21.1(21.9) \\
16.1-30.5\end{array}$ & $\begin{array}{l}20.7(19.5) \\
16.1-30.5\end{array}$ & $\begin{array}{l}25.0(41.7) \\
16.1-50.3\end{array}$ \\
\hline $\begin{array}{l}75.6 \quad(2.2) \\
73.4-78.1\end{array}$ & $\begin{array}{l}74.9 \quad(7.4) \\
63.6-81.3\end{array}$ & $\begin{array}{l}75.1 \quad(6.4) \\
63.6-81.3\end{array}$ & $\begin{array}{l}69.7(18.5) \\
33.2-81.3\end{array}$ \\
\hline $\begin{array}{l}60.4(12.7) \\
45.8-68.9\end{array}$ & $\begin{array}{l}55.3(17.5) \\
42.0-76.1\end{array}$ & $\begin{array}{l}56.7(16.5) \\
42.0-76.1\end{array}$ & $\begin{array}{l}56.4(15.7) \\
42.0-76.1\end{array}$ \\
\hline $\begin{array}{l}57.6(16.2) \\
38.4-68.6\end{array}$ & $\begin{array}{l}53.3(18.2) \\
39.4-71.8\end{array}$ & $\begin{array}{l}54.5 \quad(17.8) \\
38.4-71.8\end{array}$ & - \\
\hline $\begin{array}{l}54.3(13.4) \\
41.3-63.4\end{array}$ & $\begin{array}{l}52.2(23.9) \\
33.9-74.8\end{array}$ & $\begin{array}{l}52.8(21.2) \\
33.9-74.8\end{array}$ & $\begin{array}{l}51.2(21.5) \\
33.9-74.8\end{array}$ \\
\hline $\begin{array}{l}45.7(12.9) \\
35.3-52.8\end{array}$ & $\begin{array}{l}40.9(11.4) \\
33.1-50.0\end{array}$ & $\begin{array}{l}42.3(12.8) \\
33.1-52.8\end{array}$ & $\begin{array}{l}39.1 \quad(22.1) \\
20.8-52.8\end{array}$ \\
\hline $\begin{array}{l}11.8(12.2) \\
10.3-14.2\end{array}$ & $\begin{array}{l}9.9(21.1) \\
6.9-14.1\end{array}$ & $\begin{array}{c}10.5(20.1) \\
6.9-14.2\end{array}$ & $\begin{array}{c}10.3(19.3) \\
6.9-14.2\end{array}$ \\
\hline $\begin{array}{l}56.1(10.9) \\
44.9-63.3\end{array}$ & $\begin{array}{l}54.3(14.6) \\
42.8-69.7\end{array}$ & $\begin{array}{l}54.8 \quad(13.6) \\
42.8-69.7\end{array}$ & $\begin{array}{l}57.0(14.7) \\
42.8-72.2\end{array}$ \\
\hline $\begin{array}{l}53.3(10.5) \\
43.3-60.0\end{array}$ & $\begin{array}{l}52.1 \quad(13.7) \\
41.7-65.0\end{array}$ & $\begin{array}{l}52.4(12.8) \\
41.7-65.0\end{array}$ & $\begin{array}{l}53.8(12.7) \\
41.7-65.0\end{array}$ \\
\hline $\begin{array}{l}54.9 \quad(9.7) \\
44.4-60.8\end{array}$ & $\begin{array}{l}51.7(15.7) \\
40.2-67.8\end{array}$ & $\begin{array}{l}52.6(14.3) \\
40.2-67.8\end{array}$ & $\begin{array}{l}53.8(13.8) \\
40.2-67.8\end{array}$ \\
\hline
\end{tabular}




\section{In Vivo and In Vitro Determinations}

Ranges, means and CV's from in vivo and in vitro determinations conducted using all 52 forages are also presented in table 1 . Values of these parameters for individual forages can be found in Appendix tables 11 and 12 .

\section{NDF digestibility}

Mean in vivo NDFD percents were similar for alfalfa and grasses, though grasses exhibited a wider range in NDFD. The fact that NDFD percents were similar, though alfalfa was less mature than grasses and contained considerably less NDF, suggests that NDFD probably is not controlled by NDF concentrations. The similar NDFD percents may have been due to higher lignin concentrations in alfalfa NDF (Smith et al., 1972). The wider NDFD range exhibited by grasses was due probably to a wider range in grass maturity relative to alfalfa maturity (Appendix tables 11 and 12). Within grasses, NDFD was higher in those which were restricted-fed (table 1). This effect may have been due to increases in retention time when forages were restricted-fed (Blaxter et al., 1956), but Minson (1966) reported that intake level had a relatively small effect upon rumen retention time of a given forage. In the present study, grasses which had been restricted-fed were perhaps naturally higher in NDFD than grasses which were fed ad libitum. Support for this hypothesis is drawn from the fact that IVNDFD after 72 hr of fermentation was higher for restricted-fed grasses than for other grasses.

Mean values of IVNDFD after $72 \mathrm{hr}$ were also lower for alfalfa than for grasses ( 43.5 and 52.8 percent, respectively). Since Smith 
et a1. (1972) reported that lignin concentration was higher in legume NDF than in that of grasses, the lower IVNDFD exhibited by alfalfa after $72 \mathrm{hr}$ may have been due to the fact that mechanical breakdown of NDF is not simulated by the in vitro system. Since mechanical breakdown does take place in vivo, lack of this process in vitro could exf. in the discrepancy shown here between alfalfa and grasses in the in vivo in vitro relationship. Whatever the cause of this discrepancy among forages, different equations would have to be employed for alfalfa and grasses in predicting in vivo NDFD from IVNDFD after $72 \mathrm{hr}$ of fermentation. Also, the relationship between in vivo NDFD and IVNDFD after $72 \mathrm{hr}$ may not be quite as strong for alfalfa as for grasses. For 31 grasses, this relationship was characterized by an $\mathrm{r}$ value of .96 $\left(r^{2}=.92\right)$ and an $s_{y \cdot x}$ of 2.71 , while for the nine alfalfas these values were $.91(.83)$ and 2.73 , respectively. Digestible neutral-detergent fiber and neutral-detergent solubles Mean ash-free DNDF was lower for alfalfa than for grasses (23.9 and 42.3 percent, respectively; table 1), since alfalfa contained a lower percent of ash-free NDF than did grasses. Within alfalfa, the facts that MFOM is theoretically constant (Van Soest, 1967) and that DNDF was smaller and less variable in an absolute sense than NDS raise the possibility that NDS alone would be a good predictor of alfalfa DOM. Simple linear regression revealed that while the relationship between DOM and DNDF for alfalfa was represented by an $r$ value of $-.10\left(r^{2}=.01\right)$ and an $s_{y \cdot x}$ of 2.30 , the relationship between DOM and NDS exhibited such values of .77 (.60) and 1.46 , respectively. The 
relationship between DOM and (NDS + DNDF) for alfalfa was represented by an $r$ value of $.93\left(r^{2}=.87\right)$ and an $s_{y \cdot x}$ of .85 . Thus, (NDS + DNDF) may be a better predictor of alfalfa DOM than NDS would be alone. This hypothesis should be investigated in terms of acceptability of alfalfa DOM predictions. Within grasses, though DNDF was higher and more variable in absolute terms than was NDS, it also appears that (NDS + DNDF) would be a better predictor of DOM than DNDF would be alone. Restricted-fed grasses exhibited higher DNDF than did grasses fed ad Iibitum (table 1), since restricted-fed grasses showed higher NDFD percents. As pointed out earlier, these higher NDFD percents may not have been strictly the direct result of lower intake.

It is possible that one reason for failure of the Van Soest Summative Equation (Van Soest, 1965b) to accurately predict digestibility of warm-season grasses (Velasquez, 1974) may be that in such grasses ash-free DNDF is larger and more variable than digestible ash-free NDS (DNDS), or (ash-free NDS - MFOM). The Van Soest Summative Equation was developed on temperate forages, and in these forages DNDF appears less variable than DNDS' (Tilley et al., 1969). In the present study, ash-free DNDF for 31 grasses averaged 40.9 percent (table 1 ), and the variance $\left(s^{2}\right)$ associated with this mean was 21.7 units. Ash-free DNDS averaged 11.1 percent and $s^{2}$ was 15.2 units. Therefore, the high amount and variability of DNDF in warm-season grasses may limit the utility of the Van Soest Sumative Equation, per se, for predicting digestibility of such grasses. 


\section{OM digestibility}

Mean OMD was higher for alfalfa than for grasses (67.1 and 54.8 percent, respectively; table 1). This was due to NDS being higher in alfalfa, and to NDFD being similar between alfalfa and grasses. The CV for OMD was less for alfalfa (5.6 percent) than for grasses (13.6 percent). This was caused by the higher mean $O M D$ for alfalfa, and probably also by the lower maturity range among alfalfas than among grasses. Within grasses, mean OMD was higher for those which had been restricted-fed. This, however, may not have been directly related to lower intake of these grasses.

\section{Digestible organic matter}

Mean DOM, as a percentage of DM, was also higher for alfalfa than for grasses ( 60.3 and 52.4 percent, respectively). This was due to the much higher NDS in alfalfa more than compensating for higher DNDF in grasses. Values of CV for DOM were lower for alfalfa than for grasses, probably due to the same factors which caused this same response with respect to OMD. Values of DOM for restricted-fed grasses were similar to those for grasses fed ad libitum because NDS in restricted-fed grasses was slightly lower than in ad libitum-fed grasses and MFOM was slightly higher.

\section{Metabolic fecal organic matter by calculation}

Mean values of MFOM, as a percentage of DM, were 9.5 for alfalfa, 10.5 for grasses and 10.3 for all forages. Thus, a constant value of 10.3 was inserted for MFOM into equation (5) when making DOM predictions. Within grasses, MFOM means were (as percentages of DM) bahiagrass, 12.2; 
bermudagrass, 8.3; and Pangola digitgrass, 11.4. The reason that MFOM for the 12 restricted-fed grasses was higher than the average for all forages was that eight restricted-fed grasses were bahiagrasses and three were Pangola digitgrasses. Mean values of MFOM in this study compare favorably with the 9.5 percent reported by Minson (1971b) for Panicum species, and the 9.8 and 12.9 percent metabolic fecal DM for temperate forages found by Colburn et al. (1968) and Van Soest (1967), respectively. Capote (1975) reported that 10 percent could be used for bermudagrass pellet MFOM. Still, accurate prediction of MFOM for a given forage, rather than use of a constant value for this parameter among forages, might produce more accurate DOM predictions when using equation (5). Estimation of metabolic fecal organic matter by regression Velasquez (1974) reported that MFOM for warm-season grasses was 5.4 percent. Actual mean MFOM, as a percentage of DM, for the 40 forages utilized by this worker, however, was 10.4. This discrepancy possibly arose because the value of 5.4 for MFOM was the ordinate intercept which resulted when a test for nutritional uniformity (Lucas and Smart, 1959) was applied to NDS, as a percentage of DM, over a sma11 range of NDS, i. e., 15.9 to 30.5 percent. It is true that in a test for nutritional uniformity of NDS, the ordinate intercept should approximate MFOM if the slope of the resultant regression line is close to 1.0 , as it should have been in the work by Velasquez (1974) (Van Soest, 1967; Minson, 1971b). However, the slope of the regression line was only .75 . This low slope probably resulted because Velasquez (1974) worked with a narrow range of NDS values which, in effect, reduced the 
sample size from the true population of NDS values for all existing forages. This small sample size probably did not allow the true slope of the regression line for all existing forages to express itself, and resulted in an inaccurate estimation of this slope, which should have been close to 1.0 . Thus, incorrect estimation of the slope for the true relationship between DNDS and NDS probably caused the ordinate intercept of 5.4 to inaccurately estimate the true average MFOM value of 10.4 percent. This hypothesis was tested in the present study. Using 31 grasses which ranged in NDS from 16.1 to 30.5 percent, the regression of DNDS on NDS produced a line with a slope of .75 , and an MFOM estimate of 4.7 percent. Actual mean MFOM for these 31 grasses was 9.9 percent. Repeating this analysis using all 52 forages resulted in an NDS range of from 16.1 to 50.3 percent, or a range which was 238 percent of that used previously. In this case, regression of DNDS on NDS produced a line with a slope of 1.00 , and an MFOM estimate of 10.4 percent. Actual mean MFOM for these 52 forages was 10.3 percent (table 1). Thus, if a test of nutritional uniformity is used to estimate the actual mean value of MFOM, a range of NDS large enough to allow expression of the true slope of the relationship between DNDS and NDS must be used.

Prediction of NDFD, DOM and DE/DM

Ranges, means and $\mathrm{CV}^{\prime} \mathrm{s}$ for predicted values of NDFD and DOM are presented in table 1. Predicted values of these parameters for individual forages appear in Appendix tables 11 and 12 . Individual values for actual and predicted DE/DM for 10 grasses are presented in table 2 . 


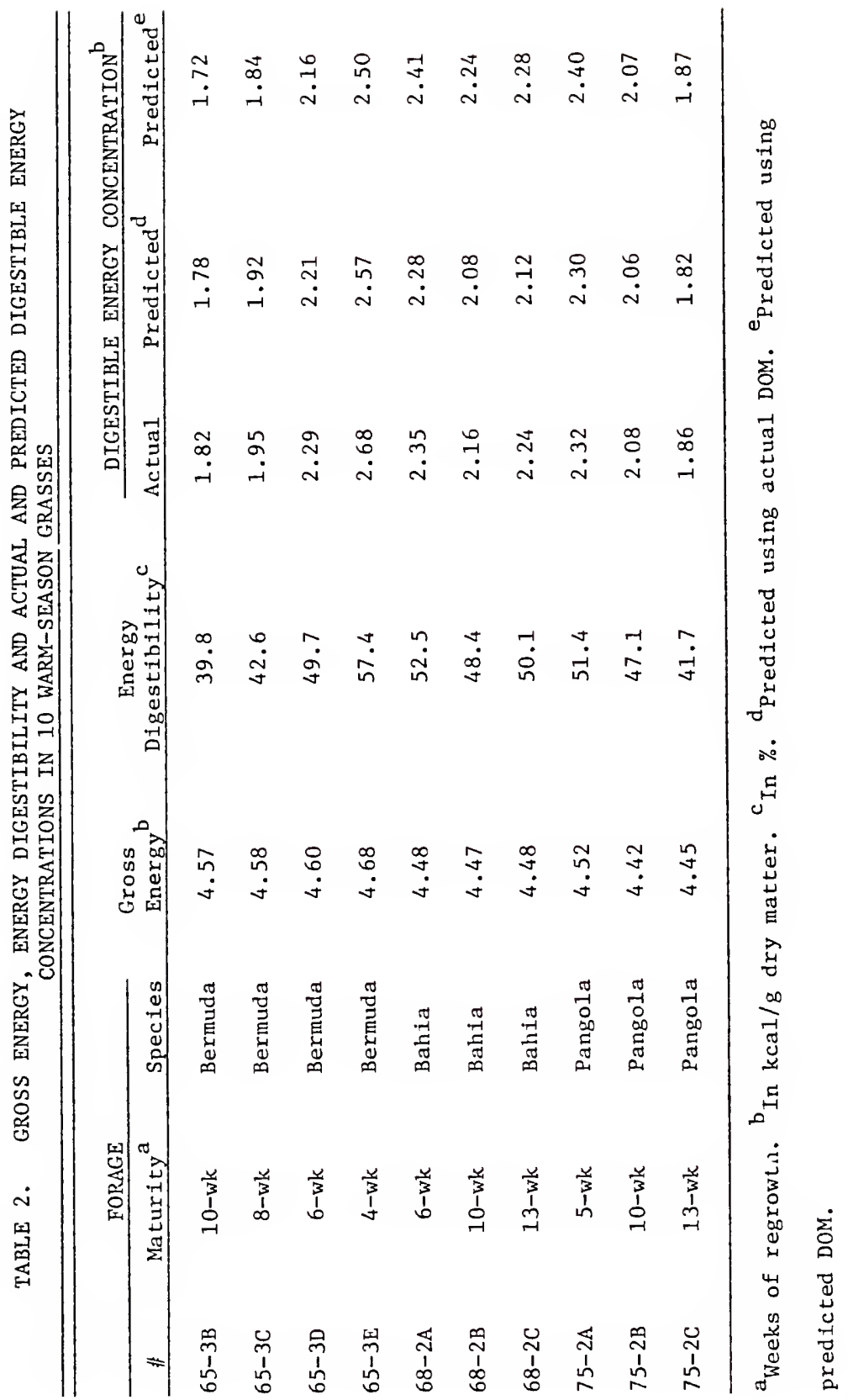


For grasses, predicted values of ash-free NDFD ranged from 38.4 to 71.8 , and the mean was 54.5 percent (table 1). Predictions of NDFD were not made for alfalfas since no previously generated prediction equation was available, and the nine alfalfas used in this study were not enough to effectively generate and test such an equation. For al1 43 grasses, simple linear regression of actual NDFD on predicted NDFD produced an $r$ value of $.98\left(r^{2}=.96\right)$ and an $s_{y \cdot x}$ of 2.0 percentage units. These values were high even within grasses which had been restricted-fed, i. e., $r=.98\left(r^{2}=.96\right)$ and $s_{y . x}=1.5$ percentage units. Thus, even when warm-season grasses are restricted-fed, IVNDFD after $72 \mathrm{hr}$ of fermentation appears to be an excellent independent variable from which to accurately predict NDFD. Determination of this IVNDFD parameter in the laboratory, however, requires considerable time and effort, and development of a more rapid procedure for predicting in vivo NDFD would accelerate and facilitate forage evaluation. Micro-anatomical studies of forages (Akin et a1., 1974a; Monson et a1., 1972; de 1a Torre, 1974) may aid in developing such a procedure.

Another possible reason why the Van Soest Summative Equation (Van Soest, 1965b) does not apply to warm-season grasses (Velasquez, 1974) may be that the equation used to predict NDFD is not truly applicable to such forages. The equation presented by Van Soest (1965b) for NÂFD prediction is

$$
\hat{\mathrm{NDFD}}=147.8-78.9 \mathrm{~L},
$$

where $L$ represents the common log of lignin percentage in acid-detergent fiber. For the 43 warm-season grasses utilized in the present study, 
simple linear regression of actual NDFD on NDFD predicted using equation (13) produced an $r$ value of only $.73\left(\mathrm{r}^{2}=.54\right)$ and an $\mathrm{s}_{\mathrm{y} \cdot \mathrm{x}}$ of 6.4 percentage units. Thus, it appears that equation (13), which was developed on temperate forages, does not possess a high degree of utility for accurate prediction of NDFD in warm-season grasses.

For alfalfa, predictions of DOM, as a percentage of DM, generated by equation (5) ranged from 56.5 to 64.6 (table 1), with a mean of 59.5; and for grasses, predictions ranged from 40.2 to 67.8 , with a mean of 52.6. For all forages, DOM predictions ranged from 40.2 to 67.8 , and the mean was 53.8 percent. Using all 52 forages, regression of actual in vivo DOM on predicted DOM produced an $r$ value of $.96\left(r^{2}=.93\right)$ and an $s_{y . x}$ of 1.8 percentage units. Within either grasses or alfalfa this relationship was just as strong, with $r$ and $s_{y . x}$ values being $.96\left(r^{2}=.93\right)$ and 1.8 for grasses, and $.94\left(r^{2}=.88\right)$ and .8 for alfalfa, respectively. These results suggest that equation (5) can be used for accurate prediction of DOM in alfalfa and warm-season grasses, and that MFOM can be considered constant at 10.3 percent for these forages. Before either of these hypotheses can be considered true, however, DOM predictions must be acceptable when judged by statistically defined acceptability 1imits.

Predictions of DE/DM ( $\mathrm{kcal} / \mathrm{g})$ were generated for 10 warm-season grasses using equation (12). Two predictions of DE/DM were produced for each grass: (a) by inserting actual in vivo DOM into equation (12); and (b) by using predicted values of DOM in this equation. Actual values of $\mathrm{DE} / \mathrm{DM}$ ranged from 1.82 to 2.68 , with a mean of $2.18 \mathrm{kcal} / \mathrm{g}$ (table 2). Predictions generated by method (a) ranged from 1.78 to 
2.57 , with a mean of 2.11 ; and for method (b), from 1.72 to 2.50 , with a mean of 2.15. Regression of actual DE/DM on that predicted by method (a) produced an $r$ value of $.99\left(r^{2}=.99\right)$ and an $s_{y . x}$ of $.03 \mathrm{kcal} / \mathrm{g}$. This procedure with respect to method (b) resulted in an $r$ value of .93 $\left(\mathrm{r}^{2}=.87\right)$ and an $\mathrm{s}_{\mathrm{y} \cdot \mathrm{x}}$ of $.10 \mathrm{kcal} / \mathrm{g}$. These results suggest that equation (12) is rational for prediction of DE/DM, and that equation (5) can be employed in conjunction with equation (12) for accurately predicting this parameter. As was the case relative to such conjecture concerning DOM prediction, predictions of DE/DM by both method (a) and method (b) must be acceptable when judged by statistically defined limits before the above hypotheses can be considered true. Testing of DOM and DE/DM Predictions Acceptability limits for judging the predictions

Theory underlying the definition of acceptability limits used in this study is presented in Chapter V. Differences between actual and predicted values of DOM or DE/DM were deemed acceptable in a conservative sense if the absolute values of these differences were less than or equal to the weighted average of $t(s / \sqrt{n})$ when this expression was evaluated at the .95 confidence level for all 52 or 10 forages, respectively. Such differences were termed acceptable in a liberal sense when their absolute values were less than or equal to the weighted average of $2 \mathrm{~s}$ for the 52 or 10 forages. Though in this study acceptability limits were calculated for each forage species, only limits applicable to all forages were used to test predictions. This policy negates the necessity of referring to such limits for each forage species when qualifying predictions of 
DOM or DE/DM. Conservative and liberal acceptability limits determined by applying their respective expressions to the 52 or 10 forages, as well as to alfalfa, bahiagrass, bermudagrass or Pangola digitgrass alone, are shown in table 3 .

Acceptability of the predictions

Figure 1 shows the test of acceptability of DOM predictions. The points plotted in this figure are coordinates of actual DOM and predicted DOM values, and the continuous middle line represents the set of points where actual DOM equals predicted DOM. The vertical deviation of any plotted point from the continuous middle line represents the error in predicting that value of DOM. The inner set of broken lines represent conservative acceptability limits, and the outer set of broken, dotted lines mark the liberal acceptability limits. In this study, a11 52 DOM predictions were acceptable when judged by liberal limits, and 38 predictions were acceptable by conservative standards. These results confirm the hypotheses that equation (5) can be used to produce acceptable predictions of DOM for alfalfa and warm-season grasses, and that MFOM can be considered constant at 10.3 percent among these forages. Forages for which DOM predictions were not acceptable when judged by conservative limits included one alfalfa, six bahiagrasses, six bermudagrasses and one Pangola digitgrass. Margins by which DOM predictions for these forages were unacceptable according to conservative limits ranged from .1 to 1.3 percentage units, and only five such margins were greater than .5 percentage units. Since in vivo DNDF values were inserted into equation (5) to produce DOM predictions, the absolute value of a given difference between actual and predicted DOM was equal 
TABLE 3. CONSERVATIVE AND LIBERAL ACCEPTABILITY LIMITS FOR TESTING PREDICTIONS OF DIGESTIBLE ORGANIC MATTER (DOM) AND DIGESTIBLE ENERGY (DE) CONCENTRATION

FORAGE SPECIES

\begin{tabular}{lccccc} 
Item & Alfalfa & Bahia & Bermuda & Pangola & All \\
DOM, \% of dry matter & & & & & \\
Conservative $[ \pm t(\mathrm{~s} / \sqrt{\mathrm{n}})]$ & \pm 2.6 & \pm 2.2 & \pm 2.5 & \pm 3.1 & \pm 2.6 \\
$\quad$ Liberal $( \pm 2 \mathrm{~s})$ & \pm 3.3 & \pm 4.3 & \pm 5.2 & \pm 5.0 & \pm 4.7 \\
DE, kcal/g dry matter & - & \pm .12 & \pm .10 & \pm .17 & \pm .13 \\
Conservative & - & \pm .24 & \pm .20 & \pm .32 & \pm .25 \\
Liberal & & & & & \\
\hline
\end{tabular}




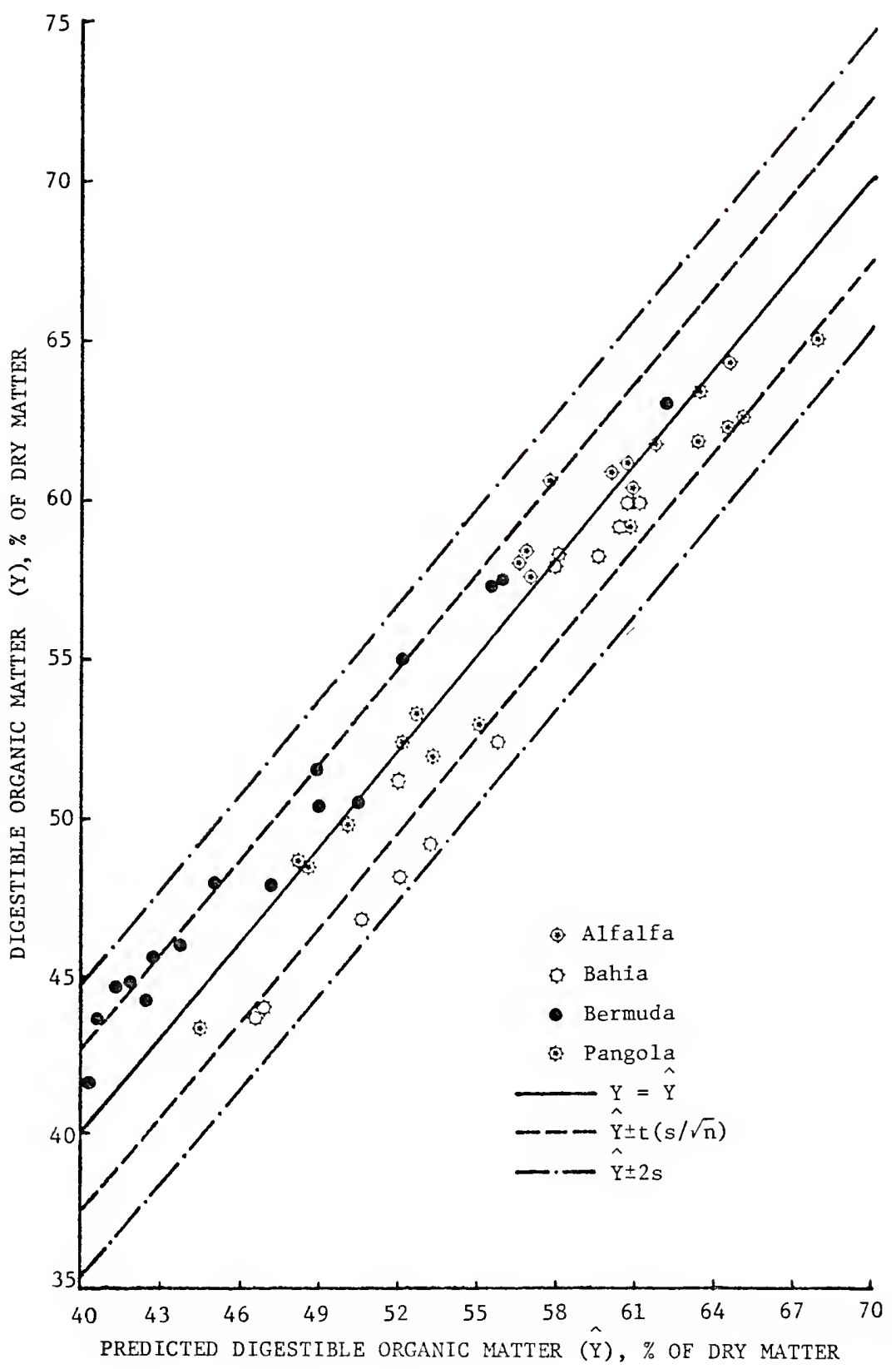

Figure 1. Test of theoretically rational method for prediction of digestible organic matter as a percentage of dry matter. 
to the absolute value of the difference between MFOM for a given forage and the assumed constant MFOM value of 10.3 percent. Absolute differences between this constant MFOM value and actual mean MFOM for bahiagrass and bermudagrass were 1.9 and 2.0 percentage units, respectively. More accurate estimation of actual mean MFOM for bahiagrass and bermudagrass would result in a greater number of conservatively acceptable DOM predictions for these grasses when using equation (5). For all forages in this study, however, use of a constant MFOM value of 10.3 percent produced acceptable predictions of DOM.

Figure 2 shows that prediction of DE/DM (kcal/g) by method (a) slightly underestimated actual DE/DM for all 10 grasses. This may have been due to assuming DEE, as a percentage of DM, to be nonexistent in these forages. However, al1 $10 \mathrm{DE} / \mathrm{DM}$ predictions were acceptable when judged by conservative limits. This result confirms the hypothesis that equation (12) is rational for prediction of $D E / D M$ for warm-season grasses. Figure 3 shows that prediction of DE/DM by method (b) produced predictions which both overestimated and underestimated actual DE/DM. Inspection of Appendix tables 11 and 12 and table 2 shows that actual DE/DM was over-predicted when actual DOM was over-predicted by equation (5), and vice-versa. The one exception to this generality may have been due to the possibility that 10-wk Pangola digitgrass (table 2) contained a small but significant amount of DEE. Still, figure 3 indicates that alI DE/DM predictions resulting from method (b) were acceptable when judged by liberal limits, and that 


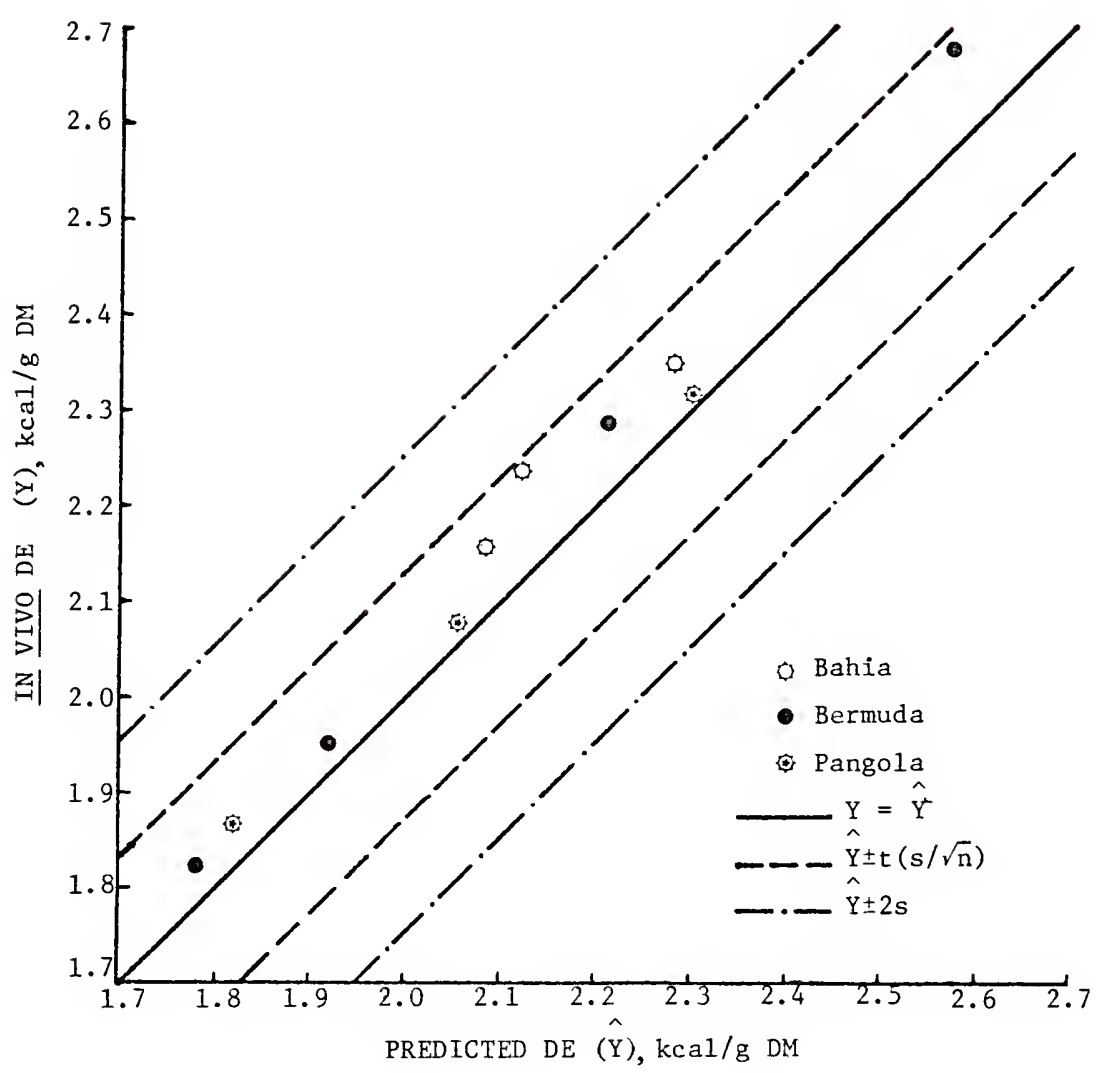

Figure 2. Comparison of in vivo digestible energy (DE) with that predicted from actual in vivo digestible organic matter (DOM) and crude protein (CP) by the equation:

$$
\mathrm{DE}=\frac{4.15 \mathrm{DOM}+1.299 \mathrm{CP}-4.59}{100} \text {. }
$$




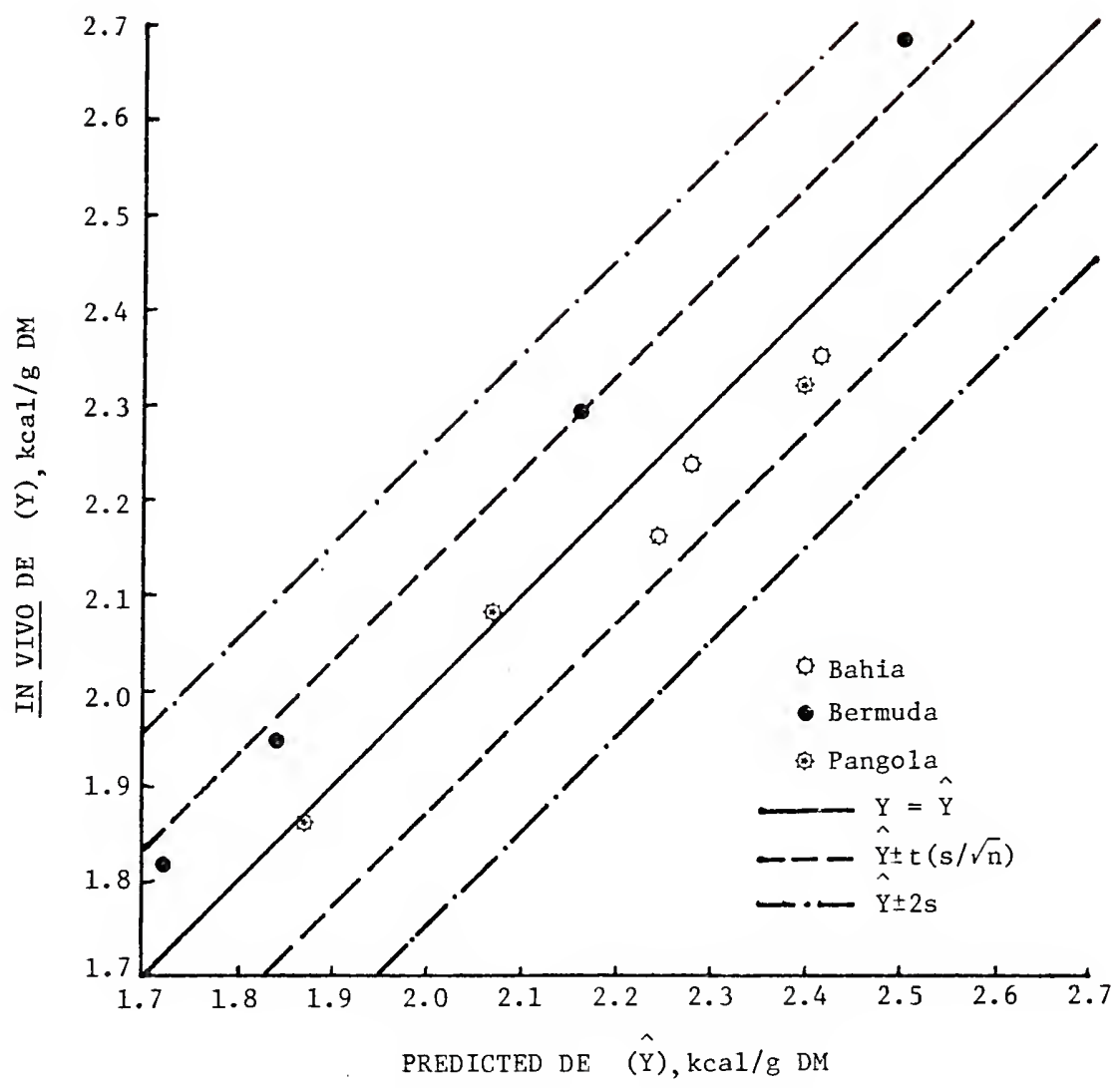

Figure 3. Comparison of in vivo digestible energy (DE) with that predicted from predicted in vivo digestible organic matter ( $\mathrm{DOM}_{\mathrm{p}}$ ) and crude protein (CP) by the equation:

$$
\mathrm{DE}=\frac{4.15 \mathrm{DOM}_{\mathrm{P}}+1.299 \mathrm{CP}-4.59}{100}
$$


nine predictions were acceptable by conservative limits. That predicted DE/DM for 4-wk bermudagrass was too low to be acceptable by conservative limits, though its actual DOM value was underpredicted to a lesser extent than that of 8-wk bermudagrass (table 2), may have been due to a higher amount of DEE in 4-wk bermudagrass. The results shown in figure 3 confirm the supposition that equation (5) can be employed effectively together with equation (12) to produce acceptable predictions of DE/DM.

\section{General Discussion}

Non-Forage Factors Affecting DE/DM

When predicted DOM, as a percentage of DM, from equation (5) is inserted into equation (12), acceptably accurate predictions of DE/DM (kcal/g) can be obtained for warm-season grasses. This procedure, however, predicts $D E / D M$ as an attribute of a given forage, and not as that which might be realized in a given production situation. This is because there are many factors influencing forage nutrient digestibility in a given situation which are not taken into account in existing laboratory procedures used to estimate digestibility. Such factors generally are related to the animals which consume a given forage, to environmental conditions or to the management policy under which forages are fed to ruminants. These factors are termed nonforage factors, since they are not related directly to chemical composition or structural organization of forages, per se. Non-forage factors which have been documented in the 1iterature, and which may affect $D E / D M$ in a given situation, include

(1) type of ruminant to which forages are fed, i. e., cattle or sheep (Cipolloni et a1., 1951; Alexander et al., 1962; Blaxter et al., 1966); 
(2) breed of ruminant within type (Ashton, 1962; Ledger et al., 1970; Riewe and Lippke, 1970; Essig et al., 1975);

(3) the form in which forages are fed, i. e., long, chopped, ground or ground and pelleted (Rodrigue and Allen, 1956; Minson, 1967; Church, 1969; Terry et al., 1972);

(4) energy supplementation of forages (Burroughs et al., 1949; el-Shazly et al., 1961; Clanton and Rittenhouse, 1970; Golding, $1 \overline{973})$;

(5) CP supplementation of low-CP forages (Smith, 1962; Campling et al., 1962; Chapman and Kretschmer, 1964; Ventura, 1973);

(6) level of feeding (Blaxter et al., 1956; Moe et al., 1965; Brown, 1966; Terry et al., $19 \overline{72})$;

(7) animal level of internal parasites (Spedding, 1954; cited by Raymond, 1969);

(8) ambient temperature (Blaxter and Wainman, 1961; Bailey, 1964); and

(9) water deprivation (French, 1956; Phillips, 1961).

These non-forage factors, if present at functional levels in a given production situation, could cause discrepancies between actual and predicted DE/DM. If effects of these factors upon DE/DM could be quantified over a wide range of forage quality, then dynamic computer modeling might allow accurate prediction of DE/DM for given production situations.

Research Needs for Rapid and Accurate DOM Prediction

Results of this study showed that acceptable predictions of DOM were obtained when a constant MFOM value of 10.3 percent of DM was inserted into equation (5) along with actual in vivo DNDF. Thus, further work on MFOM appears unnecessary in achieving the rapid and acceptable prediction of DOM for alfalfa and warm-season grasses.

Attention now must be turned toward the rapid, acceptable prediction of DNDF percentage. Percentage of NDF can be determined 
rapidly in the laboratory (Van Soest and Wine, 1967), but in predicting DNDF it is not sufficient to measure only NDF, since this fiber fraction is not a Nutritive Entity (Moore and Mott, 1973). Digestibility of NDF is predicted best by IVNDFD after a 72-hr fermentation. Thus, NDFD prediction is laborious and time consuming, and it is possible that discrepancies exist among forages in this in vivo-in vitro relationship. In this study, the only chemical component which correlated highly with NDFD or DNDF in 31 grasses was lignin ( $r=-.89$ and -.81 , respectively), but these correlations may not be this high over a wider range of forages (Moore and Mott, 1973). Correlation coefficients between (NDS + DNDF) and lignin or NDF were -.91 or -.90 , respectively, for the 31 grasses, but again these $r$ values probably will decline over a wider range of forages. Moir (1972) suggested that DNDF be considered constant among temperate and tropical grasses at 40 percent of $\mathrm{OM}$, and among legumes at 19.8 percent. In the present study, DNDF ranged from 33.1 to 52.8 percent of DM for 43 grasses (table 1), and from 20.8 to 26.9 percent for nine alfalfas. Thus, the suggestion of Moir (1972) appears inaccurate. Research now must be directed toward development of a rapid, acceptable procedure for predicting DNDF percentage, or NDFD percent, as a forage attribute over a wide range. Results of recent microscopic studies of NDF degradation by rumen microorganisms suggest that NDF in some forage tissues is indigestible, whereas NDF in other tissues is digestible (Moore and Mott, 1973; Barnes, 1973; de la Torre et al., 1974). Therefore, the NDF fraction may contain two Nutritive Entities, one 
being potentially digestible NDF with a digestibility near 100 percent, and the other being potentially indigestible NDF with a digestibility near 0 percent. This concept has been suggested as the basis for a model of cellulose digestion (Waldo et al., 1972), and could be valid for NDF digestion as well. Thus, microscopic studies to examine patterns of NDF organization and degradation over a wide range of forages may aid in development of a procedure for rapid, acceptable prediction of DNDF among forages.

\section{Summary}

Summative equation and Nutritive Entity concepts should serve as the basis for rational prediction of the digestible energy (DE)/DM (kcal/g) values of forages. Acceptably accurate predictions of $\mathrm{DE} / \mathrm{DM}$ can be obtained by summing the caloric values of the major portions of forage digestible OM (DOM), i. e., digestible carbohydrate and digestible CP. Acceptable predictions of DOM can be obtained by summing digestible neutral-detergent solubles (DNDS) and digestible neutral-detergent fiber (DNDF), and subtracting metabolic fecal OM (MFOM), all as percentages of DM. Use of a constant 10.3 percent for MFOM and determination of neutral-detergent solubles (NDS) to estimate DNDS both lend themselves to a rapid and inexpensive procedure for prediction of DOM. If MFOM is to be predicted for a given group of forages using a test for nutritional uniformity, care must be taken to include forages which exhibit a wide range of NDS in the analysis. Though DNDF is smaller and less variable than NDS within alfalfa, this latter parameter by itself may not produce acceptable predictions 
of alfalfa DOM. Values for neutral-detergent fiber digestibility (NDFD) can be predicted accurately for grasses from in vitro NDFD after $72 \mathrm{hr}$ of fermentation. This in vitro procedure is time consuming and laborious, and discrepancies apparently exist in the in vivo NDFD - in vitro NDFD relationship among alfalfas and grasses. Thus, the remaining challer with reference to DOM, and ultimately DE/DM, prediction is development of a rapid procedure for acceptable prediction of DNDF over a wide range of forages.

The reasons that Van Soest's Summative Equation, which was developed on temperate forages, does not predict digestibility of warm-season grasses accurately may be that (a) in warm-season grasses, DNDF appears larger and more variable than DNDS; and (b) the equation used to predict NDFD does not predict this parameter accurately for warm-season grasses. 
CHAPTER IV

ELIMINATION OF ORGANIC SOLVENTS IN THE STUDY OF IN VITRO NEUTRAL-DETERGENT FIBER DIGESTION

Introduction

In vitro studies of forage neutral-detergent fiber (NDF) digestion will be increasingly important in the future (Chapter III). Two organic solvents which may be hazardous to laboratory technicians have been used in determination of in vitro NDF digestion, e. g., toluene (Goering and Van Soest, 1970) when contents of fermentation tubes were held for later analysis; and acetone in the NDF determinations (Van Soest and Wine, 1967). The effectiveness of toluene may be questionable, since Meites et al. (1951) reported that cellulolytic activity of rumen microorganisms continued for up to $48 \mathrm{hr}$ after addition of toluene.

The objectives of this experiment were (a) to establish whether acetone washes were required for accurate determination of ash-free NDF (NDFA) in either hay samples or in residues after in vitro fermentation; and (b) to develop a procedure for terminating in vitro fermentation which did not require use of toluene.

\section{Experimental Procedure}

Artificially dried hays of different quality made from two cuts of 'Florida 66' alfalfa (Medicago sativa L.) (hays 73-B and 73-D, Appendix table 12), two cuts of Pensacola bahiagrass (Paspalum notatum Flugge) (47-2A and 47-4C, Appendix tables 10 and 11), two cuts of Suwannee bermudagrass (Cynodon dactylon (L) Pers.) (65-1A and 65-1F, Appendix 
tables 10 and 11), and two cuts of Pangola digitgrass (Digitaria decumbens Stent) (55-2A, Appendix tables 10 and 11; 75-2C, Appendix table 12) were used to examine the necessity of acetone washes in determinations of NDFA, as a percentage of DM, in hay samples. Treatments used were (a) the control, in which residues were washed with both boiling water and acetone (Van Soest and Wine, 1967); and (b) the modification, in which residues were washed with boiling water alone. Dried residue was ashed and the difference in weight between dry and ashed residues represented weight of NDFA. Three separate runs, each including all eight hays, were made for a total of three NDFA observations per treatment. The experimental design and analysis of variance were those for complete randomized blocks (Snedecor and Cochran, 1967), with hays representing blocks.

The same eight hays were used to investigate the necessity of washing in vitro residual NDF with acetone when determining in vitro NDFA digestion, and to determine an alternate stop-method to toluene for terminating fermentation. In vitro fermentations followed the procedure of Moore and Mott (1974) except that fermentation lasted $28 \mathrm{hr}$ and residual NDFA was determined. Toluene was not used in any stop-method. The four stop-methods were (a) immediate analysis for residual NDFA (Goering and Van Soest, 1970); (b) addition to tubes of $25 \mathrm{ml}$ neutraldetergent (ND) reagent, followed by $40 \mathrm{hr}$ of refrigeration; (c) immersion of tubes to the level of their contents in an ice-water bath for I hr, followed by $40 \mathrm{hr}$ of refrigeration; and (d) addition to tubes of $6 \mathrm{ml}$ of 20 percent (v/v) hydrochloric acid (HC1) in $1,1,2$ and $2 \mathrm{ml}$ increments, 
followed by $40 \mathrm{hr}$ of refrigeration. Acetone treatments were as described earlier for determination of NDFA in hay samples. Treatments were analyzed in duplicate within run, and two separate runs were made, for a total of four observations per treatment. The experimental design consisted of complete randomized blocks, with blocking by hays. Analysis of variance was done using least-squares procedures described by Harvey (1960), and interaction means were compared using Duncan's Multiple Range Test (Duncan, 1955). Due to high precision of in vitro and chemical determinations, statistical testing was done at the .01 level to reduce the possibility of claiming differences significant when such differences were not large in a biological sense.

\section{Results and Discussion}

Table 4 shows results of determinations of hay NDFA for the eight individual hays when the two acetone treatments (+ or - ) were applied. Treatment means for + or - acetone were 68.4 and 69.2 percent, respectively. There was no difference $(.01<\mathrm{P}<.05)$ between these means. However, the rankings of 4-wk bahiagrass and 13-wk Pangola digitgrass were reversed between treatments. The largest difference between treatments for an individual hay (2.2 percentage units with 2-wk Pangola digitgrass) was a positive 3.3 percent of the + acetone value, or greater than the 3 percent generally accepted for laboratory error. Thus, though there was no difference $(.01<P<.05)$ between acetone treatments, results of this experiment suggest that unacceptable errors in determination of hay NDFA could result if an acetone wash is not employed.

In the in vitro experiment, acetone was not involved in any twoway interactions (P>.05). Since the main effect of acetone was not 
TABLE 4. EFFECT OF ACETONE ON THE DETERMINATION OF ASH-FREE NEUTRALDETERGENT FIBER (NDFA) IN EIGHT HAYS

\begin{tabular}{lcc}
\hline & \multicolumn{2}{c}{ TREATMENT } \\
\cline { 2 - 3 } Hay $^{\mathrm{a}}$ & +Acetone & -Acetone \\
\hline $73-\mathrm{B}$ (3-wk alfalfa) & $41.3^{\mathrm{b}}$ & 41.5 \\
$73-\mathrm{D}$ (4.5-wk alfalfa) & 47.2 & 47.3 \\
55-2A (2-wk Pangola digitgrass) & 67.6 & 69.8 \\
$65-1 \mathrm{~A}$ (2-wk bermudagrass) & 73.0 & 74.8 \\
47-2A (4-wk bahiagrass) & 77.3 & 78.7 \\
$75-2 \mathrm{C}$ (13-wk Pangola digitgrass) & 78.2 & 78.5 \\
$47-4 \mathrm{C}$ (mature bahiagrass) & 78.8 & 83.5 \\
$65-1 \mathrm{~F}$ (12-wk bermudagrass) & 83.6 & 69.2 \\
\hline Mean & 68.4 & \\
\hline
\end{tabular}

${ }^{a}$ Number, weeks of maturity and species. ${ }^{b}$ NDFA, \% of dry matter. 
significant $(P>.05)$, results of this experiment suggest that washing in vitro residues with only boiling water should not produce errors in determinations of $\underline{\text { in }}$ vitro residual NDFA or in vitro NDFA digestion.

Results differed $(\mathrm{P}<.01)$ among in vitro stop-methods. However, there were interactions $(\mathrm{P}<.01)$ between stop-method and hays, and between stop-method and replications (reps). Table 5 shows the statistical comparison of stop-method $\mathrm{x}$ hays means, and table 6 presents these comparisons for stop-method $\mathrm{x}$ reps means. For all hays, terminating fermentation with either $25 \mathrm{ml}$ of $\mathrm{ND}$ reagent or an ice-water bath, both followed by $40 \mathrm{hr}$ of refrigeration, produced values for in vitro residual NDFA which were not different $(P>.01)$ from those produced by control. Terminating fermentation with $6 \mathrm{ml}$ of $\mathrm{HCl}$, followed by refrigeration, yielded values for in vitro residual NDFA which were higher $(\mathrm{P}<.01)$ than control values for all hays. These results suggest that stopping fermentation with either ND reagent or an ice-water bath could replace toluene in this respect. Table 6 reveals that only the ice-water stop-method produced results equal $(P>.01)$ to those of the control for all reps. The ND reagent yielded lower $(P<.01)$ in vitro residual NDFA than the control in rep 3, and the $6 \mathrm{ml} \mathrm{HCl}$ produced results higher $(P<.01)$ than the control for all reps. Thus, results of this experiment suggest that only the ice-water method could stop fermentation effectively in tubes which were to be held for subsequent in vitro residual NDFA determinations. The ice-water method is also the easiest of the four methods when large numbers of tubes are involved. Tubes could be stored in a refrigerator for at least $40 \mathrm{hr}$ between icebath treatment and analysis. 
TABLE 5. EFFECT OF HAY AND STOP-METHOD ON IN VITRO RESIDUAL ASH-FREE NEUTRAL-DETERGENT FIBER (NDEA)

\begin{tabular}{|c|c|c|c|c|c|}
\hline \multirow[b]{2}{*}{ Hay $^{\mathrm{a}}$} & \multicolumn{5}{|c|}{ STOP-METHOD } \\
\hline & Control ${ }^{b}$ & $\mathrm{ND}$ & $\begin{array}{l}25 \mathrm{ml} \\
\text { Reagent }\end{array}$ & Ice-water & $\begin{array}{l}6 \mathrm{~m} 1 \\
\mathrm{HCl}\end{array}$ \\
\hline 73-B (3-wk alfalfa) & $26.3^{d, e}$ & & $25.1^{e}$ & $26.3^{e}$ & $28.6^{\mathrm{f}}$ \\
\hline 73-D (4.5-wk alfalfa) & $34.3^{e}$ & & $34.0^{e}$ & $35.1^{e}$ & $36.7^{\mathrm{f}}$ \\
\hline 55-2A (2-wk Pangola digitgrass) & $36.3^{\mathrm{e}}$ & & $35.1^{\mathrm{e}}$ & $37.1^{\mathrm{e}}$ & $40.1^{f}$ \\
\hline 65-1A (2-wk bermudagrass) & $46.0^{\mathrm{e}}$ & & $44.3^{e}$ & $44.9^{e}$ & $49.1^{\mathrm{f}}$ \\
\hline 47-2A (4-wk baniagrass) & $57.8^{e}$ & & $56.8^{e}$ & $56.8^{e}$ & $63.6^{\mathrm{f}}$ \\
\hline 75-2C (13-wk Pangola digitgrass) & $59.1^{e}$ & & $58.5^{e}$ & $58.7^{e}$ & $61.4^{\mathrm{f}}$ \\
\hline $65-1 \mathrm{~F}$ (12-wk bermudagrass) & $63.8^{e}$ & & $62.8^{\mathrm{e}}$ & $63.1^{e}$ & $67.0^{\mathrm{f}}$ \\
\hline 47-4C (mature bahiagrass) & $64.6^{\mathrm{e}}$ & & $63.8^{\mathrm{e}}$ & $65.0^{e}$ & $70.6^{f}$ \\
\hline Mean & 48.5 & & 47.6 & 48.4 & 52.2 \\
\hline
\end{tabular}

${ }^{a}$ Number, weeks of maturity and species. ${ }^{b}$ In vitro residual NDFA run immediately. ${ }^{C}$ Neutral-detergent reagent (Goering and Van Soest, 1970). $\mathrm{d}_{\text {In vitro }}$ residual NDFA, \% of dry mattex. ${ }^{e, f}$ Means in same row bearing same superscript are not different $(P>.01)$. 
TABLE 6. EFFECT OF STOP-METHOD AND REPLICATE (REP) ON IN VITRO RESIDUAL ASH-FREE NEUTRAL-DETERGENT FIBER (NDFA)

\begin{tabular}{|c|c|c|c|c|}
\hline \multirow[b]{2}{*}{ Rep 非 } & \multicolumn{4}{|c|}{ STOP-METHOD } \\
\hline & Contro $1^{a}$ & $\begin{array}{l}25 \mathrm{ml} \\
\text { ND Reagent }\end{array}$ & Ice-water & $\begin{array}{l}6 \mathrm{ml} \\
\mathrm{HCl} \\
\end{array}$ \\
\hline 1 & $48.8^{c, d}$ & $48.5^{d}$ & $48.8^{\mathrm{d}}$ & $53.5^{\mathrm{f}}$ \\
\hline 2 & $49.0^{d}$ & $48.1^{d}$ & $50.3^{d}$ & $54.1^{\mathrm{f}}$ \\
\hline 3 & $48.1^{\mathrm{d}}$ & $46.3^{e}$ & $47.1^{d}$ & $50.6^{\mathrm{f}}$ \\
\hline 4 & $48.2^{\mathrm{d}}$ & $47.3^{d}$ & $47.2^{d}$ & $50.3^{\mathrm{f}}$ \\
\hline Mean & 48.5 & 47.6 & 48.4 & 52.1 \\
\hline
\end{tabular}

${ }^{a}$ In vitro residual NDFA run immediately. ${ }^{b}$ Neutral-detergent reagent (Goering and Van Soest, 1970). In $_{\text {vitro }}$ residual NDFA, \% of dry matter. $d, e, f_{\text {Means }}$ in same row bearing same superscript are not different $(\mathrm{P}>.01)$. 


\section{Summary}

An experiment which included two hays from each of 'Florida 66 ' alfalfa, Pensacola bahiagrass, Suwannee bermudagrass and Pangola digitgrass was conducted to investigate the necessity of acetone washes for determinations of ash-free neutral-detergent fiber (NDFA) in hays or in vitro residues; and to establish an alternate method to toluene for terminating in vitro fermentation. Acetone washes for determinations of NDFA in hays appeared necessary, but probably could be excluded when analyzing for in vitro residual NDFA. Fermentation could be terminated by setting tubes in an ice-water bath for $1 \mathrm{hr}$, and tubes can then be stored under refrigeration. 
CHAPTER V

A RATIONAL METHOD FOR PREDICTING QUALITY OF WARM-SEASON FORAGES FOR RUMINANTS

\section{Introduction}

Forage quality must be known if intensive high-forage systems of ruminant production are to be based soundly upon principles of nutrition and economics. Since determining quality of a large number of forages by means of grazing trials is an almost impossible task, forage researchers now generally accept the intake of digestible energy (DE), digestible dry matter (DDM) or digestible organic matter (DOM) by ruminants fed ad libitum in confinement as expressions of forage quality (Heaney, 1970; Holmes et al., 1966; Jones, 1972). For prediction of any of these measures of digestible nutrient intake, digestibility generally can be predicted with acceptable accuracy by one of several methods, the best of which is probably the two-stage in vitro fermentation system (Moore and Mott, 1973). Intake is not always highly correlated with digestibility, especially among forage species (Minson et a1., 1964; Van Soest, 1964; Milford, 1967). At present, there appears to be no method which accurately predicts intake among forages. Therefore, a fast, simple, accurate procedure for prediction of intake and/or quality is of utmost necessity for forage evaluation and efficient ruminant production.

The objective of the present investigation was to devise and test a theoretically rational and acceptably accurate method based upon laboratory forage analyses for prediction of forage quality over a wide range of forage species. 


\section{Experimental Procedure}

Development of Theory Related to Rational Method for Prediction of Forage Quality

Forage intake by ruminants is regulated by distention or fill of some part of their gastro-intestinal tract (Crampton et al., 1960; Montgomery and Baumgardt, 1965a; Conrad, 1966; Hungate, 1966). The level of fill at which distention limits intake apparently fluctuates with such factors as nitrogen status of the animal (Egan, 1970) and the animal's physiological state (Campling, 1970). Any theory derived to predict forage quality must center around distention or fill as the limiting mechanism when forage dry matter (DM) digestibility is less than approximately 65 to 70 percent. Pelleting of forage may lower this digestibility figure (Montgomery and Baumgardt, 1965a). Campling (1965, 1970) concluded that voluntary intake was limited by capacity of the rumen (including reticulum) and by extent of delay of food in this organ. Extent of delay of digesta is equivalent to retention time of digesta in the rumen, so that this latter parameter can be used with equal success in theoretical considerations.

Thornton and Minson (1972) presented an equation for predicting voluntary DM intake from retention time. Converting this equation to the organic matter (OM) basis gives

$$
\text { OMI }=24(\mathrm{Q} / \mathrm{RTOM}) \text {, }
$$

$$
\begin{aligned}
\text { where } \mathrm{OMI} & =\text { voluntary } \mathrm{OM} \text { intake, g/day; } \\
\mathrm{Q} & =\text { quantity of } \mathrm{OM} \text { in the rumen, } \mathrm{g} ; \\
\text { and } \mathrm{RTOM} & =\text { retention time of } \mathrm{OM} \text { in the rumen, hr. }
\end{aligned}
$$

Since ( $Q / R T O M)$ is the rate at which OM leaves the rumen, in $g / h r$, equation (I) is consistent with the theory developed by Hungate (1966) 
that rates at which material flows into and out of the rumen must be equal when the distention mechanism is limiting intake.

If both sides of equation (1) are divided by animal metabolic weight $\left(\mathrm{W}_{\mathrm{kg}}{ }^{.75}\right)$, the form of the equation is unchanged, but OMI has units of $\mathrm{g} / \mathrm{W}_{\mathrm{kg}} \cdot 75 / \mathrm{day}$ while $\mathrm{Q}$ is in $\mathrm{g} / \mathrm{W}_{\mathrm{kg}}{ }^{75}$. Since $\mathrm{Q}$ is constant among forages (Blaxter et al., 1961; Ulyatt et al., 1967; Thornton and Minson, 1972), OMI ( $\mathrm{g} / \mathrm{W}_{\mathrm{kg}} .75 /$ day) can be considered a function of RTOM (hr), such that:

$$
O M I=f(R T O M) \text {. }
$$

Multiplying both sides of equation (2) by apparent digestibility of OM (OMD) gives the following equation:

$$
\mathrm{DOMI}=\mathrm{f}(\mathrm{RTOM} \cdot \mathrm{OMD}) \text {, }
$$

where DOMI represents digestible OM intake, or forage quality, in $\mathrm{g} / \mathrm{w}_{\mathrm{kg}} \cdot 75 /$ day.

The right-hand members of equation (3), i. e., RTOM and OMD, are highly correlated among forages (Thornton and Minson, 1973). Therefore, (RTOM.OMD) should correlate highly with RTOM, and should be obtained accurately by knowing RTOM and the relationship between RTOM and OMD. Based upon this theoretical consideration, the following equation can be written:

$$
\text { DOMI }=\mathrm{f}(\mathrm{RTOM})
$$

This equation is theoretically rational and reflects a high degree of functional integrity since RTOM should be indicative of both chemical and structural composition of forage OM. Thus, a procedure for estimating RTOM, or a value highly correlated with it, from laboratory analyses was developed and tested for predicting forage quality. 
Estimation of RTOM

An equation developed by Waldo et al. (1972) for plotting disappearance of cellulose from the rumen through time was used for estimating RTOM, in hr. This equation is

$$
g=a e^{-\left(k_{1}+k_{2}\right) t}+b e^{-k_{2} t}
$$

$$
\begin{aligned}
\text { where } g= & \text { decimal fraction representing remaining labeled } \\
& \text { cellulose in the rumen as a function of time per } \\
& \text { unit of labeled cellulose intake; } \\
\mathrm{a}= & \text { decimal fraction of total ruminal cellulose which } \\
& \text { is potentially digestible; } \\
\mathrm{b}= & \text { one minus 'a', or decimal fraction of total ruminal } \\
& \text { cellulose which is potentially indigestible; } \\
\mathrm{k}_{1}= & \begin{array}{l}
\text { grams of cellulose digested per hour per gram of } \\
\text { digestible cellulose present in the rumen; }
\end{array} \\
\mathrm{k}_{2}= & \text { grams of indigestible cellulose passing from the } \\
& \text { rumen per hour per gram of indigestible cellulose } \\
& \text { present in this organ; } \\
\text { and } t= & \text { time, in hr. }
\end{aligned}
$$

This equation was applied to the total OM present in the rumen. Assuming that ' $a$ ', $b, k_{1}$ and $k_{2}$ are known, if some rational value for $g$ can be developed for the time when $t$ is equal to RTOM, then $t$, and therefore RTOM, can be found by sequential approximation using Newton's method for approximating roots of equations (Thomas, 1972). This iterative procedure must be used in estimating $t$ since equation (5) cannot be solved in a general way for $t$.

The equation used to approximate $t$, or RTOM, in equation (5) by Newton's sequential method was

$$
t_{n+1}=t_{n}-\frac{a e^{-\left(k_{1}+k_{2}\right) t_{n}+b e^{-k_{2} t_{n}}-g}}{-\left(k_{1}+k_{2}\right) a e^{-\left(k_{1}+k_{2}\right) t_{n}-k_{2} b e^{-k_{2} t_{n}}}},
$$




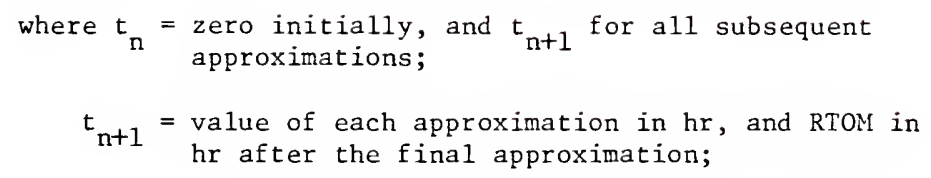

and ' $a$ ', $b, k_{1}$ and $k_{2}$ are as defined for equation (5). Starting with $t_{n}$ equal to zero, four approximations should be sufficient to estimate the final value of $t_{n+1}$, or RTON, to within .1 hr of its actual value. Establishing the value of $g$

Hungate (1966) assumed that rumen digesta was homogenous, and that rumen evacuation proceeded according to a first-order exponential decay function. Calculations made in the present study from data presented by Thornton and Minson (1972, 1973), who worked under the same assumptions, showed a high correlation (-.94 and -.92 in 1972 and 1973, respectively) between DOMI and RTOM. Per unit of digesta undergoing partial and continuous removal from the rumen via a firstorder exponential decay function, the fraction still in the rumen at time $t$ is equal to $e^{-x t}$. In this expression, the rate constant ' $x$ ' equals the constant rate at which a unit of digesta is removed from the rumen.

Equation (5) assumes that there are two types of digesta undergoing removal from the rumen, $i$. e., one which is potentially totally digestible, and which leaves the rumen by digestion and passage; and one which evacuates the rumen only by passage, since it is totally indigestible (Waldo et al., 1972). Therefore, equation (5) does not fit exactly the general form of the first-order exponential decay function. However, the semilog plot of equation (5), which would be linear if digesta disappeared from the rumen via a true first-order function, appears only slightly curvilinear (Waldo et al., 1972). 
This fact, plus the success of Thornton and Minson (1972, 1973) in correlating DOMI with RTOM under the first-order assumption, suggests that taking this assumption as true might not lead to errors of appreciable importance in determining an acceptable value of RTOM from equation (5).

If the suggestion that rumen evacuation adheres to a firstorder process is acceptable, then .37 can be inserted into equation (6) for g (Hungate, 1966). Mathematically, this is because, with reference to a "container" which empties itself via first-order dynamics, RTOM is equal to $1 / x$ (Waldo et al., 1965; Hungate, 1966). If $t$, at the time it equals RTOM, is set equal to $1 / x$ in the expression $\mathrm{e}^{-\mathrm{xt}}$, then the value of this expression is $\mathrm{e}^{-1}$, or .37 . Thus, if assuming that rumen evacuation adheres to first-order dynamics does not produce major errors, inserting a constant value for $g$ of .37 into equation (6) means that $t$ will equal RTOM when the equation is solved by sequential approximation with 'a', b, $k_{1}$ and $k_{2}$ known. Estimation of $k_{1}$

Values of $k_{1}(\mathrm{~g} / \mathrm{hr} / \mathrm{g})$ for forages in this study were determined according to the procedure described by Gill et al. (1969) and Lechtenberg et al. (1974). The mathematical basis for estimating $k_{1}$ by this procedure can be appreciated by studying the initial pages of Chapter 10 in Fruton and Simmonds (1958). In vitro OM digestiun (IVOND) was measured after $3,6,15,30,48,60$ and $72 \mathrm{hr}$ of fermentation, and was calculated for each forage at each time as the mean of three separate determinations. The percent of OM digested after $72 \mathrm{hr}$ of in vitro fermentation was assumed to represent complete digestion of a given forage (Akin et al., 1973, 1974b). 
Estimation of $k_{2}$

Since no procedure could be found for estimation of $k_{2}$ from laboratory analyses, this parameter was calculated from known lignin intakes of the 31 forages by the following equation presented by Waldo et al. (1972):

$$
\mathrm{k}_{2}=\frac{\text { amount of lignin } \mathrm{fed} / \mathrm{hr}}{\text { average amount of rumen lignin }} .
$$

The numerator of this equation was calculated by dividing known lignin intake $\left(\mathrm{g} / \mathrm{w}_{\mathrm{kg}} 1.0 / \mathrm{day}\right)$ by 24 . The denominator was estimated using a simple linear regression equation generated from data reported by Ingalls et al. (1966):

$$
\begin{gathered}
\text { Rumen 1ignin }\left(\mathrm{g} / \mathrm{W}_{\mathrm{kg}} 1.0\right)= \\
.35+1.54 \text { 1ignin intake }\left(\mathrm{g} / \mathrm{W}_{\mathrm{kg}} 1.0 / \text { day }\right) .
\end{gathered}
$$

As described by equation ( 7$)$, dividing lignin intake $\left(\mathrm{g} / \mathrm{W}_{\mathrm{kg}} 1.0 / \mathrm{hr}\right)$ by rumen lignin $\left(\mathrm{g} / \mathrm{W}_{\mathrm{kg}}{ }^{1.0}\right)$ yielded an estimate of $\mathrm{k}_{2}(\mathrm{~g} / \mathrm{hr} / \mathrm{g})$. In generating the regression equation from data provided by Ingalls et al. (1966), values for rumen lignin at $6 \mathrm{hr}$ postprandial were used, this being the theoretically closest approximation to rumen lignin under steady-state conditions available from these data.

Theory relative to ' $a$ ', and its estimation

Waldo et al. (1972) reported that for cellulose, ' $a$ ' was equal to $\frac{A}{A+B}$, where $A$ was amount of potentially digestible cellulose present initially in the rumen, and $B$ was amount of indigestible cellulose initially present in this organ. This concept was extended to cover total ruminal OM instead of just cellulose when estimating 
' $a$ ' for grasses utilized in the present investigation. Amount of ruminal OM depends upon intake (Thomas et al., 1961; Egan, 1970), and would be difficult to predict when intake was not known. This, of course, would be the case in most instances where forage quality predictions were required. Thus, it was necessary to develop an equation for estimation of ' $a$ ' in which intake was not included.

The rationale behind development of such an equation was based upon the manner in which amounts of OM designated $A$ and $B$ would occur in the rumen under steady-state conditions. Given such conditions, and knowledge that digestible material evacuates the rumen via firstorder kinetics (Waldo et al., 1972), A $\left(\mathrm{g} / \mathrm{W}_{\mathrm{kg}}{ }^{.75}\right.$ ) would equal DOMI $\left(\mathrm{g} / \mathrm{W}_{\mathrm{kg}} .75 /\right.$ day $)$ multiplied by the average number of days which DOMI would be delayed in the rumen, or retention time of this intake. This retention time would equal $\frac{1}{24\left(k_{1}+k_{2}\right)}$, since digestible oM leaves the rumen via both digestion and passage. The value of $B$ $\left(\mathrm{g} / \mathrm{W}_{\mathrm{kg}} .75\right.$ ) would equal amount of indigestible OM intake $\left(\mathrm{g} / \mathrm{W}_{\mathrm{kg}} .75 / \mathrm{day}\right)$ multiplied by days of retention time of this indigestible material. In this case, retention time would be $\frac{1}{24 \mathrm{k}_{2}}$, since indigestible OM evacuates the rumen via only passage, which is also a first-order process. Thus, if forage quality were to be predicted, 'a' would be equal to $\frac{A}{A+B}$, or:

$$
\frac{\frac{1}{24\left(k_{1}+k_{2}\right)}\left(O_{p}\right)(O M I)}{\frac{1}{24\left(k_{1}+k_{2}\right)}\left(O M D_{p}\right)(O M I)+\frac{1}{24 k_{2}}\left(100-O D_{p}\right)(O M I)},
$$

where OMI is in $\mathrm{g} / \mathrm{W}_{\mathrm{kg}} .75 /$ day. By algebraic manipulation (Appendix 
table 13), equation (9) can be reduced to the following equation:

$$
' a^{\prime}=\frac{\left(k_{2}\right)\left(O M D_{p}\right)}{\left[\left(k_{2}\right)\left(\mathrm{OMD}_{\mathrm{p}}\right)\right]+\left[\left(\mathrm{k}_{1}+\mathrm{k}_{2}\right)\left(100-\mathrm{OMD}_{\mathrm{p}}\right)\right]},
$$

where ' $a$ ' = decimal fraction of total ruminal OM which is potentially digestible;

$$
\begin{aligned}
& \mathrm{k}_{1}=\text { rate of digestion rate constant, } \mathrm{g} / \mathrm{hr} / \mathrm{g} ; \\
& \mathrm{k}_{2}=\text { rate of passage rate constant, } \mathrm{g} / \mathrm{hr} / \mathrm{g} ;
\end{aligned}
$$

and $O \mathrm{MD}_{\mathrm{P}}=$ predicted in vivo $\mathrm{OMD}$, in percent.

Since $k_{2}$ was calculated from previously known in vivo data in this investigation, estimation of ' $a$ ' provided no subsequent problems. Values of $b$ were calculated as one minus ' $a$ '.

\section{Prediction of organic matter digestibility}

In equation (10), predicted $\mathrm{OMD}\left(\mathrm{OMD}_{\mathrm{p}}\right)$, in percent, was determined using the following formula:

$$
\mathrm{OMD}_{\mathrm{p}}=\frac{\mathrm{NDS}-10.3+(\mathrm{NDF} \cdot \mathrm{NDFD})}{\mathrm{OM}}
$$

$$
\begin{aligned}
\text { where } \mathrm{NDS}= & \text { ash-free neutral-detergent solubles (OM } \\
& \text { minus } \mathrm{NDF}), \text { as percent of } \mathrm{DM} ; \\
\mathrm{NDF}= & \begin{array}{l}
\text { ash-free neutral-detergent fiber, as per- } \\
\text { cent of } \mathrm{DM} ;
\end{array} \\
\mathrm{NDFD}= & \text { decimal fraction representing } \mathrm{NDF} \\
& \text { digestibility; } \\
\mathrm{OM}= & \text { organic matter, as decimal fraction o. } \mathrm{DM} ; \\
\text { and } 10.3= & \text { average value of metabolic fecal OM, as } \\
& \text { percent of } \mathrm{DM} \text { (Chapter III). }
\end{aligned}
$$

Predictions of digestible OM (DOM), as a percentage of DM, were made using the numerator of equation (11). 
Values for NDFD in equation (11) were estimated as suggested by Velasquez (1974), and simple linear regression equations for this purpose were generated from data reported by this author. These equations were,

$$
\text { for Pensacola bahiagrass, NDFD }=\frac{12.69+.88 \mathrm{z}}{100} \text {; }
$$

for Coastal or Suwannee bermudagrass, NDFD $=\frac{15.27+.71 \mathrm{z}}{100}$;

$$
\text { and for Pangola digitgrass, } \mathrm{NDFD}=\frac{-2.69+1.0 \mathrm{z} ;}{100}
$$

where $z=$ in vitro NDF digestion (IVNDFD) after $72 \mathrm{hr}$ of fermentation, in percent. In the present investigation, values of $z$ inserted into equations (12), (13) and (14) were means of three individual observations done in separate runs.

\section{Testing the Procedure}

Forages and in vivo data

Thirty-one warm-season grasses of known in vivo OMD and OMI by sheep were utilized for testing the theoretically rational procedure for prediction of DOMI, or forage quality, from RTOM. These 31 forages included five cuts of Pensacola bahiagrass (Paspalum notatum Flugge), 15 cuts of Coastal or Suwannee bermudagrass (Cynodon dactylon (L) Pers.) and 11 cuts of Pangola digitgrass (Digitaria decumbens Stent). These forages had been studied previously in seven different in vivo trials comprising 187 individual animal observations of both intake and digestibility. In these trials, all grasses were fed 
ad libitum as chopped, artificially dried hays to yearling or tnature wethers in individual metabolism crates with slatted wooden floors. Water, salt and defluorinated phosphate were provided ad libitum. Each experimental period consisted of a 14-day preliminary period to allow sheep to attain voluntary intake, followed by a seven-day totalcollection period for determination of voluntary intake and apparent nutrient digestibility. Voluntary OMI was calculated on the basis of grams per kilogram of body weight raised to the .75 power per day $\left(\mathrm{g} / \mathrm{W}_{\mathrm{kg}} \cdot{ }^{75}\right)$, and nutrient digestibility was calculated in percent. Forage quality, or DOMI in $\mathrm{g} / \mathrm{W}_{\mathrm{kg}} \cdot 75 /$ day, was determined for each of the 31 forages by multiplying OMI in $\mathrm{g} / \mathrm{W}_{\mathrm{kg}} .75 /$ day by apparent OMD. Laboratory analysis of forages

Analyses previously determined on all 31 forages were DM, GI and crude protein (CP), the latter two being as percentage of DM (A.O.A.C., 1970); acid-detergent fiber (ADF) and acid-insoluble lignin, both on the DM basis (Van Soest, 1963); and NDF as a percentage of DM (Van Soest and Wine, 1967). For this latter determination, dry residue was ashed and the difference between dry and ashed weights was calculated as weight of ash-free NDF.

In the present study, ash-free NDS as a percentage of DM was calculated by subtracting ash-free $\mathrm{NDF}$ from $\mathrm{OM}$. Determination of IVOMD after various periods of fermentation was done according to the two-stage procedure out1ined by Moore and Mott (1974).

Velasquez (1974) determined IVNDFD by employing the procedure of Moore and Mott (1974) during $72 \mathrm{hr}$ of fermentation. One ml of toluene per tube followed by refrigeration was used to stop fermentation and hold residual NDF for subsequent determination (Goering and Van Soest, 
1970). Residual ash-free NDF was determined by the method of Van Soest et al. (1966). This procedure was modified slightly for determining IVNDFD in the present investigation. The modification consisted of using an ice-water bath for $1 \mathrm{hr}$ instead of $1 \mathrm{ml}$ of toluene to stop fermentation after $72 \mathrm{hr}$ of incubation. Tubes and their contents were refrigerated for $40 \mathrm{hr}$ before ash-free residual NDF was determined (Chapter IV).

Regression analyses

Correlations among laboratory analyses and/or in vivo parameters were determined using the UFSPL020 linear regression and correlation program on the University of Florida's IBM 370 digital computer. Generation of the prediction equation

With both forage quality, in terms of DOMI, and estimated RTOM known for each of the 31 grasses, 15 grasses were selected as representative of the entire group in order to generate a simple linear regression equation for prediction of forage quality from estimated RTOM, i. e., (DOMI) $=b_{0}+b_{1}$ (RTOM). The 15 forages selected covered the entire maturity range of the 31 grasses (2 to $14 \mathrm{wk}$ ) and met the restriction of containing at least 6 percent CP on a DM basis. This restriction was imposed so that the relationship between DOMI and RTOM exhibited by the prediction equation would not be confounded with other possible effects of low CP upon measurements of forage quality. For generation of the prediction equation, DOMI values for the 15 selected forages were regressed upon these forages' estimated RTOM values using a simple linear regression program. Values of DOMI for the remaining 16 forages were predicted using this equation. 
Prediction of DOMI for a given forage can be obtained with the Dynamo computer program shown in Appendix table 14 when values of constants (C statements) are known.

Testing the acceptability of quality predictions

In testing the utility of the resultant prediction equation, the question now arises: How much can predicted DOMI deviate from actual DOMI and still be considered an acceptable prediction? The answer to this question cannot be supplied by $r$ values or residual standard deviation $\left(s_{y, x}\right)$ values unless some criterion of acceptability relative to the absolute value of prediction error is attached to them. Perhaps the answer varies depending upon the context in which one is working. Researchers must work within a policy of error acceptance which is based upon sound statistical considerations. One such policy would accept predictions from a given equation if the equation could predict means within their 95 percent confidence interval 95 percent of the time. Under this policy, the width of the confidence interval encompssing a given mean would be $\pm t(s / \sqrt{n})$, where $t$ is the tabulated approximation to the normal when the population variance is unknown; $\mathrm{s}$ is the estimate of the population standard deviation; and $\mathrm{n}$ is the number of observations upon which the mean is based. If the value of $t$ at the 95 percent level of confidence is used in calculating the value of the above expression, then a prediction which falls within the resultant range must be acceptable. This is because if the experiment were repeated it could be stated with 95 percent confidence that the mean would fall within the calculated range. Thus, if a prediction falls within this range, it must be acceptable since it is of the same worth as repeating the experiment. This policy, it seems, would be the ultimate in judging prediction acceptabiiity. 
This method of judging prediction acceptability may be too conservative for present use. There exists a paucity of literature relative to (1) manners in which all factors which affect forage quality mediate their effects; and (2) quantification of effects of these factors and their interactions upon forage quality over a wide range of forages. Thus, it is practically impossible to generate a prediction equation which will yield acceptable predictions of forage quality in any given situation for any given forage. This means that either we will do without acceptable prediction equations, or that we must relax the standards by which we judge such equations. The standards still must be based, however, upon sound statistical considerations. Such a set of standards probably would be produced by considering mean predictions acceptable if they fall within plus and minus two population standard deviation estimates $( \pm 2 \mathrm{~s})$ from the actual mean. The rationale for postulating this acceptability range is that the range is still limited by the population standard deviation, and that according to the statistical Empirical Rule (Mendenhall, 1971), approximately 95 percent of the individual observations taken from a normal population will fall into this range. A prediction in this range may differ at the 95 percent confidence level from the actual mean, but it should approximate closely at least some of the individual observations which constitute the mean. Therefore, acceptability limits at \pm 2 s from the mean would allow use of a "good" prediction equation, though the equation was not "perfect" according to limits at $\pm t(s / \sqrt{n})$ from the mean. The acceptability range afforded by $\pm 2 \mathrm{~s}$ would be wider than that provided by $\pm t(s / \sqrt{n})$ 
but the multiple would not be necessarily great since the number of observations per treatment in animal experiments is usually small. Also, if the experiments were conducted well, s may be small and the difference between the two limits may be minor in absolute terms. In comparing two or more prediction equations which appear "good" when judged by the wider acceptability limits, the number of predictions from each which fall into the range defined by $\pm t(s / \sqrt{n})$ from the mean when $t$ is taken at the 95 percent confidence level might be taken into account in choosing the equation for predicting means.

In this study, DOMI predictions were judged with reference to statistically defined acceptability limits around the actual mean DOMI values being predicted. All predictions which fell within the range defined by acceptability limits were judged acceptable. Since quality values being predicted were in terms of mean DOMI, a conservative set of acceptability limits was defined by a weighted average of the expression $\pm t(s / \sqrt{n})$ for all 31 forages. This weighted average was calculated by determining the weighted average of $s$ for the 31 forages. The weighted average for $s$ was calculated as the square root of the value of the expression $\sum\left(n_{i}-1\right) s_{i}{ }^{2}$. In this $\frac{1}{\sum\left(n_{i}-1\right)}$

expression, $i$ defines each individual among the 31 forages. The value of $\mathrm{n}$ in the expression for the weighted 95 percent confidence interval was taken as the arithmetic mean of the $n_{i}$ for all 31 forages. This average value of $\mathrm{n}$ also was used to determine the tabulated $t$ at the 95 percent confidence level. A liberal set of acceptability limits also was determined, these being defined by the expression $\pm 2 \mathrm{~s}$. 


\section{$\underline{\text { Results and Discussion }}$}

\section{Laboratory Characteristics of Forages Utilized}

Ranges, means and coefficients of variation (CV) for laboratory characteristics of the 31 warm-season grasses used in this investigation are reported in table 7. Individual values are shown in Appendix table 10. As percentages of DM, mean CP for all forages was 9.3, while mean ash-free NDF and NDS were 74.9 and 21.1 , respectively. The CV for NDS was about three times that for NDF because the estimated standard deviations (s) for NDS and NDF were similar (4.6 and 5.5 percentage units, respectively). Mean IVOMD increased from 14.6 to 50.9 percent as fermentation time increased from 3 to $72 \mathrm{hr}$. As fermentation time became longer, the CV for IVOMD decreased because the mean increased faster than did $s$. Thus, it appears that IVOMD is less variable in a relative sense, though more variable in absolute terms, after longer periods of fermentation. This may explain results reported by Velasquez (1974), who found that IVOMD after $72 \mathrm{hr}$ of fermentation correlated slightly higher with in vivo OMD than did IVOMD after $48 \mathrm{hr}$. Thịs slightly higher correlation probably would not offset problems encountered in substituting fermentation times of $72 \mathrm{hr}$ for those of $48 \mathrm{hr}$ now used as standard procedure in routine, large-scale programs of forage analysis.

Values of ' $a$ ' averaged .2518 for all forages (table 7), and the mean for $b$ was .7482 . These results indicate that among forages, only about 25 percent of total ruminal OM would be potentially digestible at a given point in time.

Estimated $k_{1}$ averaged $.0557 \mathrm{~g} / \mathrm{hr} / \mathrm{g}$ (table 7), or about 2.5 times average calculated $k_{2}$, which was $.0227 \mathrm{~g} / \mathrm{hr} / \mathrm{g}$. The $\mathrm{CV}$ for $\mathrm{k}_{2}$ for 


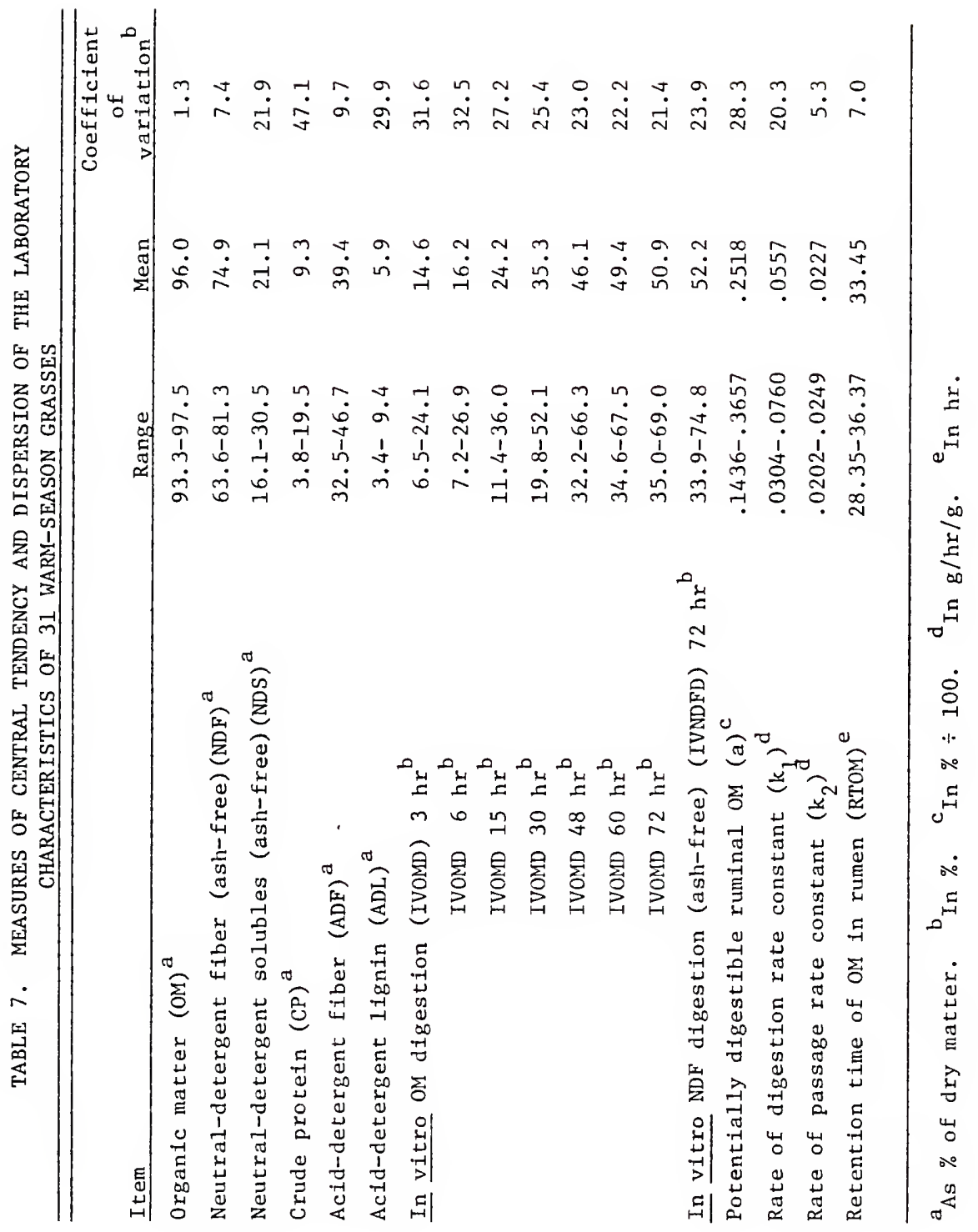


31 forages was only 5.3 percent, and the range for these values was only .0047 units. Since at present no laboratory procedure exists for estimation of $k_{2}$, these results suggest that assuming $k_{2}$ to be constant among forages at $.0227 \mathrm{~g} / \mathrm{hr} / \mathrm{g}$ might not lead to errors of appreciable importance in estimation of RTOM. Estimated RTOM ranged from 28.35 to $36.37 \mathrm{hr}$ in this study, with a mean of $33.45 \mathrm{hr}$ and a CV of only 7 percent for all forages. Actual and Predicted In Vivo Values of Forages Utilized

Ranges, means and $\mathrm{CV}^{\prime} \mathrm{s}$ for actual and predicted mean values of in vivo parameters are presented in table 8 . Means for individual grasses are reported in Appendix table 11. Calculated MFOM (ashfree NDS minus ash-free DNDS) averaged 9.9 percent of DM. This is analogous to the 9.5 percent of DM reported by Minson (1971b), who worked with three cultivars of each of two Panicum species, but higher than the 5.4 percent found by Velasquez (1974) for warm-season grasses. For temperate forages, metabolic fecal DM has been reported at 12.9 percent (Van Soest, 1967) and 9.8 percent (Colburn et al., 1968; Deinum and Van Soest, 1969).

Actual in vivo NDFD ranged from 42.0 to 76.1 percent, with a mean of 55.3 and a CV of 17.5 percent (table 8). Predictions of this parameter ranged from 39.4 to 71.8 percent, with a mean of 53.3 and a $\mathrm{CV}$ of 18.2 percent. The separate regression equations used to predict NDFD are shown in figure 4. Simple linear regression of in vivo NDFD on predicted NDFD for all 31 grasses produced an $r$ value of $.98\left(x^{2}=.96\right)$ and an $s_{y . x}$ of 1.90 percentage units. Thus, 


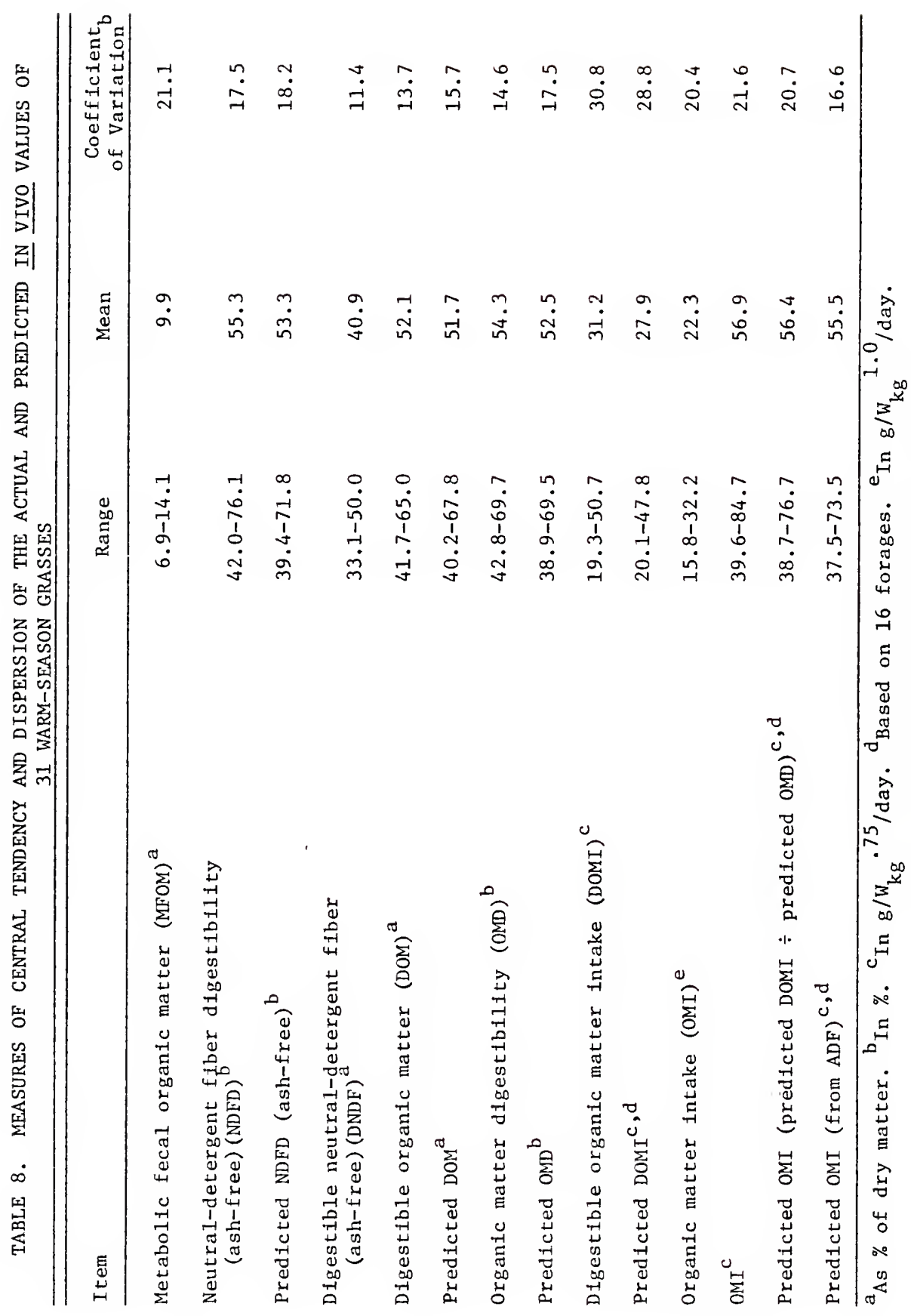


음

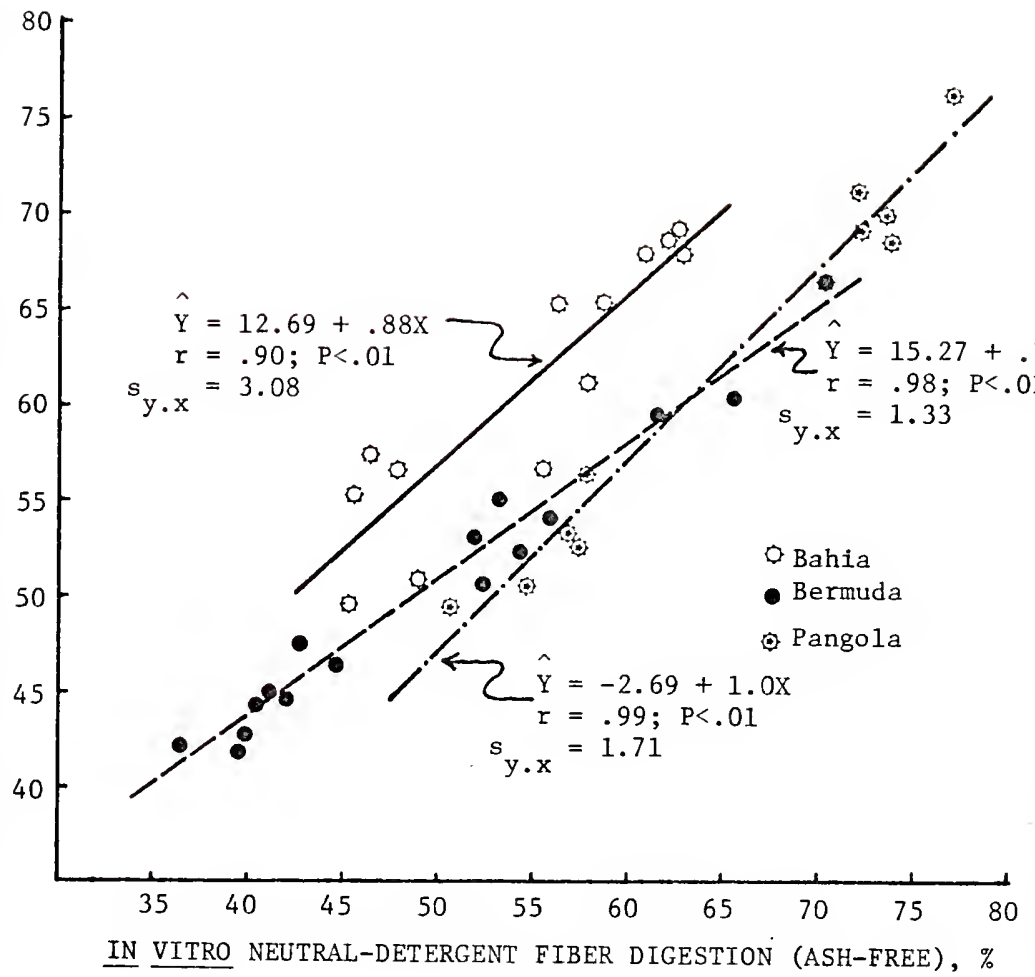
AT $72 \mathrm{hr}$

Figure 4. Relationship between neutral-detergent fiber digestibility in vivo and in vitro for each of three warm-season grasses. (Data taken from Velasquez, 1974). 
ash-free in vitro NDFD after $72 \mathrm{hr}$ of fermentation appears an excellent predictor of in vivo NDFD. Determinations of in vitro NDFD, however, require seven working days, which is too slow for rapid estimation of forage quality. Actual in vivo DNDF ranged from 33.1 to 50.0 percent of DM, with a mean of 40.9 and a CV of 11.4 percent (table 8). This mean is in accord with the 40 percent of OM found by Moir (1972) for both temperate and tropical forages, but seems too variable to be considered constant or to depend upon physiology of ruminant digestion rather than forage quality, as suggested by that author.

Actual in vivo DOM and predictions of this parameter were quite similar in range, mean and $\mathrm{CV}$ (table 8 ). Simple linear regression of in vivo DOM on predicted DOM yielded an $r$ value of $.97\left(r^{2}=.94\right)$ and an $s_{y . x}$ of 1.7 percentage units. Actual in vivo OMD and predicted OMD were also quite similar, and regression analysis produced an $r$ value of $.95\left(x^{2}=.90\right)$ and an $s_{y . x}$ of 2.6 percentage units. Since DOM prediction is based upon estimation of NDFD, which in turn depends upon in vitro NDFD after $72 \mathrm{hr}$ of fermentation, IVOMD after $48 \mathrm{hr}$ would not have to be determined in order to obtain accurate predictions of in vivo OND for warm-season grasses. The future challenge is to develop an accurate predictor of in vivo NDFD which is determined more quickly and easily in the laboratory than is in vitro NDFD after 72 hr of fermentation.

That RTOM might be utilized to obtain accurate predictions of forage qualfty over a wide range of forage species has been suggested by Thornton and Minson (1972, 1973) and Laredo and Minson (1975). In 
their studies, RTOM was determined by means of hourly ad libitum feeding of sheep and complete removal of digesta from the rumen via a fistula (Minson, 1966). Measuring RTOM by this method does little to expedite forage quality determinations, since DOMI itself can be measured in vivo during the same amount of time, and probably at lower cost. In the present study, actual DOMI ranged from 19.3 to $50.7 \mathrm{~g} / \mathrm{w}_{\mathrm{kg}} .75 /$ day for the 31 grasses, with a mean of 31.2 and a $\mathrm{CV}$ of 30.8 percent (table 8 ). Fifteen of these grasses were used to generate an equation for prediction of DOMI from estimated RTOM. The equation, shown in figure 5, was

$$
\hat{\mathrm{Y}}=169.8-4.14 \text { (RTOM), }
$$

where $\hat{\mathrm{Y}}$ represents predicted DOMI $\left(\mathrm{g} / \mathrm{W}_{\mathrm{kg}} .75 /\right.$ day). Use of this equation to predict quality for the remaining 16 grasses resulted in DOMI predictions which ranged from 20.1 to $47.8 \mathrm{~g} / \mathrm{W}_{\mathrm{kg}} .75 / \mathrm{day}$, with a mean of 27.9 and a CV of 28.8 percent. Simple linear regression of actual in Vivo DOMI for these 16 grasses on their respective predicted DOMI values produced an $r$ value of $.95\left(r^{2}=.90\right)$ and an $s_{y \cdot x}$ of 2.4 units. Thus, this rational method for predicting forage quality appeared promising, but the acceptability of predictions generated by equation (15) remained to be tested by use of appropriate acceptability limits. Actual OMI by sheep ranged from 39.6 to $84.7 \mathrm{~g} / \mathrm{W}_{\mathrm{kg}} .75 /$ day for all 31 grasses, with a mean of 56.9 and a CV of 21.6 percent ('able 8). Predictions of this parameter generated for 16 grasses (predicted DOMI $\div$ predicted OMD) ranged from 38.7 to $76.7 \mathrm{~g} / \mathrm{W}_{\mathrm{kg}} .75 /$ day, with a mean of 56.4 and a CV of 20.7 percent. Simple linear regression of 


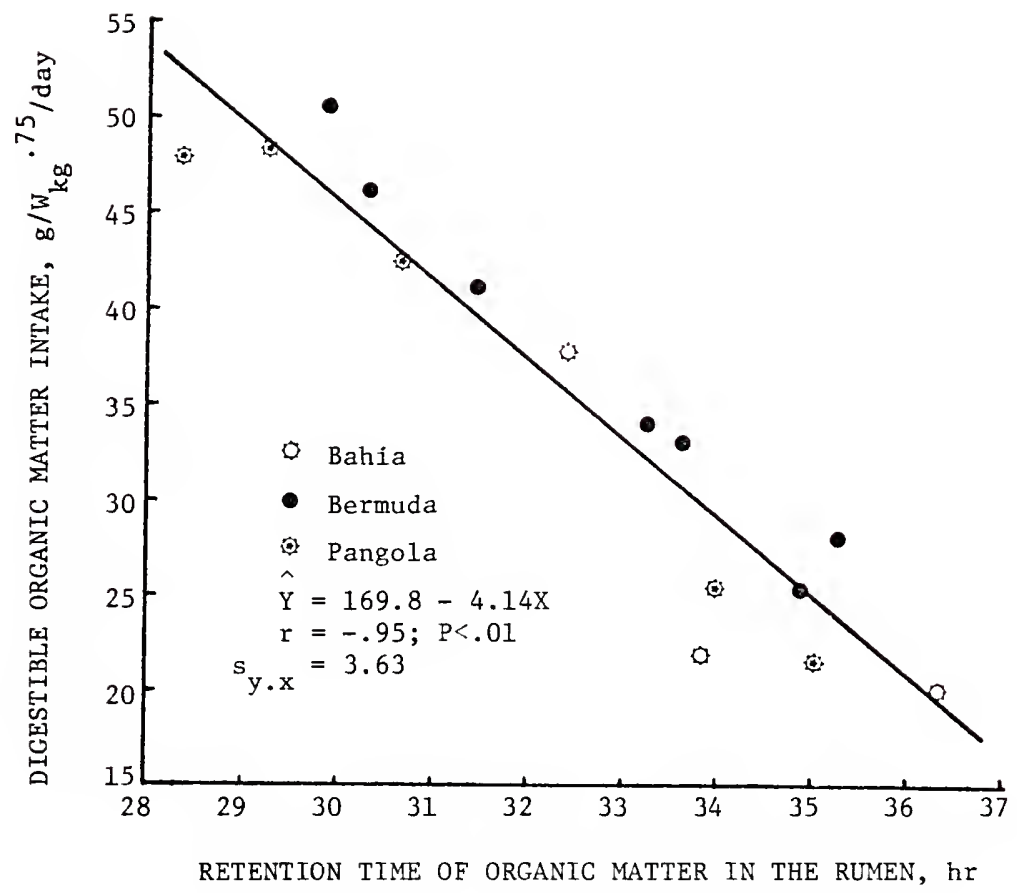

Figure 5. Relationshipbetween digestible organic matter intake and retention time of organic matter in the rumen for three species of warm-season grasses. 
actual on predicted in vivo OMI for these grasses produced an $r$ of $.95\left(r^{2}=.91\right)$ and an $s_{y . x}$ of 3.2 units. Empirical predictions of OMI from $A D F$ as a percentage of $D M$ were made as suggested by Weller (1973). Figure 6 shows the empirical equation used to predict OMI from $\mathrm{ADF}$ :

$$
\hat{Y}=169.0-2.82(\mathrm{ADF}),
$$

where $\hat{\mathrm{Y}}$ represents predicted OMI $\left(\mathrm{g} / \mathrm{W}_{\mathrm{kg}} \cdot 75 /\right.$ day $)$. This equation was generated with 15 of the 31 grasses and used to predict OMI for the other 16. Measures of central tendency and dispersion are shown in table 8. Regression of in vivo OMI on OMI predicted from ADF yielded an $r$ value of only $.77\left(r^{2}=.59\right)$ and an $s_{y \cdot x}$ of 6.6 units. Thus, empirical use of $A D F$ to predict $O M I$ appears less promising than use of $(D O M I \div O M D)$ when both of these latter parameters are predicted rationally.

Testing of DOMI and OMI Predictions

Acceptability limits for quality and intake predictions

Differences between actual and predicted values of DOMI (forage quality) or OMI were deemed acceptable in a conservative sense if the absolute values of these differences were less than or equal to the weighted average of the expression $t(s / \sqrt{n})$ at the .95 confidence level for all 31 grasses utilized in this investigation. Such differences were termed acceptable in a liberal sense when their absolute values were less than or equal to the weighted average of $2 \mathrm{~s}$ for all 31 grasses. Though in this study acceptability limits were calculated for each grass species, only limits applicable to all grasses were used to test predictions. This would negate the necessity of referring 


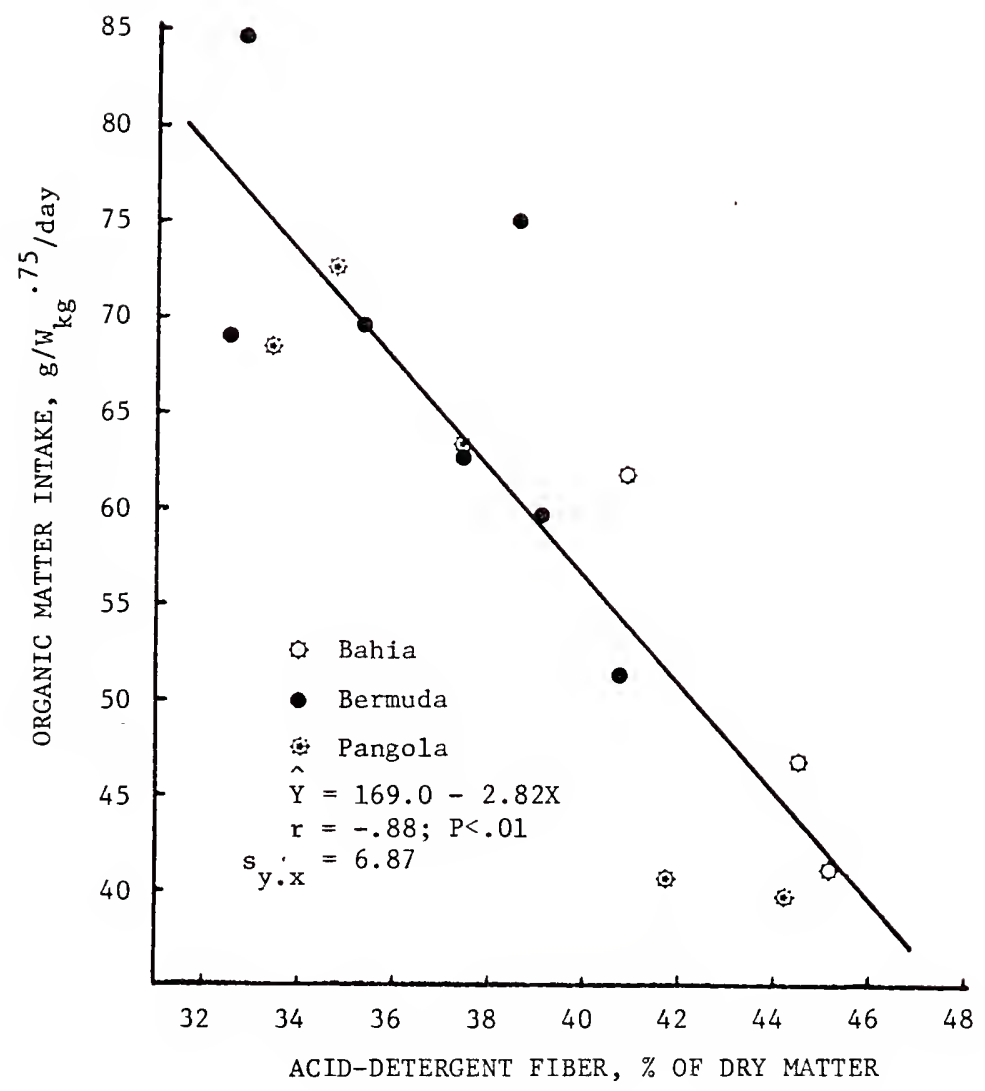

Figure 6. Relationship between organic matter intake and acid-detergent fiber percentage for three species of warm-season grasses. 
to limits for individual grass species when qualifying predictions of quality in practice. Conservative and liberal acceptability limits determined by applying their respective expressions across all forages, as well as to bahiagrass, bermudagrass or Pangola digitgrass alone, are shown in table 9.

Acceptability of quality and intake predictions

Figure 7 shows the test of acceptability for forage quality (DOMI) predictions. The points plotted in this figure are coordinates of actual DOMI and predicted DOMI values, and the continuous middle line represents the set of points where actual DOMI equals predicted DOMI. Thus, the vertical deviation of any plotted point from the continuous middle line represents error in predicting that value of DOMI. The inner set of broken lines represent conservative acceptability limits, and the outer set of broken, dotted lines mark the liberal acceptability limits. In this study, all DOMI predictions were acceptable when judged by liberal limits, and 14 of the 16 predictions were acceptable when judged by conservative limits. Thus, the theoretically rational prediction of DOMI from RTOM may provide an acceptable method for prediction of quality for warm-season grasses. Unacceptability in a conservative sense of quality predictions for two Pangola digitgrass hays may have been caused by effects of factors not related to RTOM upon quality measurements for these two hays. These hays exhibited RTOM values of 29.46 and $30.95 \mathrm{hr}$, and in vivo OMD's of 65.9 and 65.3 percent, respectively. Therefore, it is possible that some chemostatic regulator-influenced OMI, at least in part, for these two hays as suggested by Montgomery and Baumgardt (1965a) and Conrad (1966). 
TABLE 9. CONSERVATIVE AND LIBERAL ACCEPTABILITY LIMITS FOR TESTING PREDICTIONS OF DIGESTIBLE ORGANIC MATTER INTAKE (DOMI) AND ORGANIC MATTER INTAKE (OMI)

FORAGE SPECIES

\begin{tabular}{|c|c|c|c|c|}
\hline \multirow[b]{2}{*}{ Item } & \\
\hline & Bahia & Bermuda & Pangola & $\mathrm{A} 11$ \\
\hline \multicolumn{5}{|l|}{ DOMI, g/ $\mathrm{w}_{\mathrm{kg}} \cdot 75 /$ day } \\
\hline Conservative $[ \pm t(s / \sqrt{n})]$ & \pm 2.4 & \pm 3.7 & \pm 5.6 & \pm 3.9 \\
\hline Liberal $( \pm 2 s)$ & \pm 5.1 & \pm 7.8 & \pm 8.2 & \pm 7.5 \\
\hline \multicolumn{5}{|l|}{ OMI, $g / W_{k g} .75 /$ day } \\
\hline Conservative & \pm 4.9 & \pm 7.0 & \pm 9.0 & \pm 7.1 \\
\hline Liberal & \pm 10.3 & \pm 14.7 & \pm 13.2 & \pm 13.6 \\
\hline
\end{tabular}




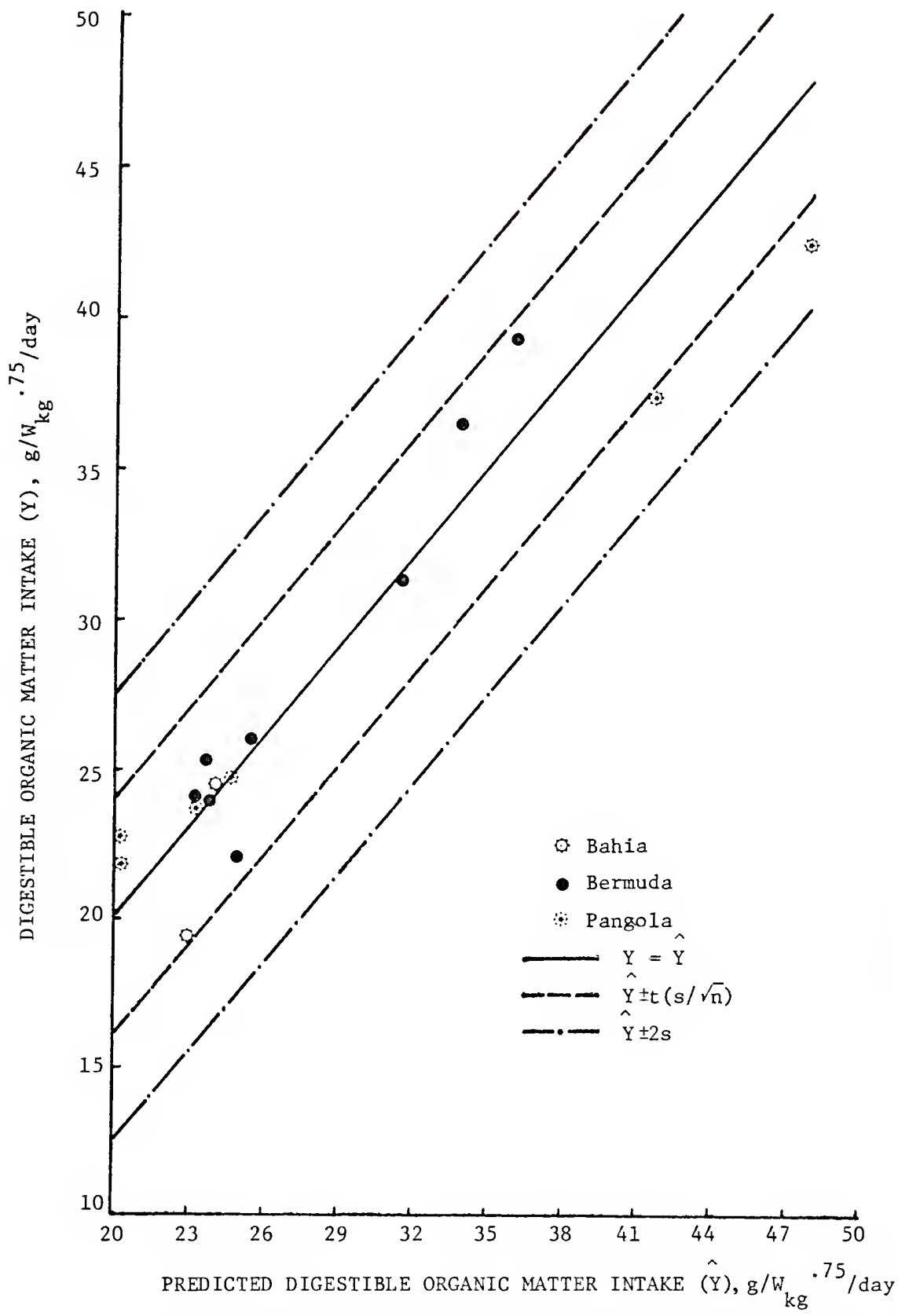

Figure 7. Test of retention time of organic matter in the rumen as a rational predictor of digestible organic matter intake. 
Perhaps quality predictions for forages which exhibit such low RTOM and high OMD values could be improved by including some rational chemostatic regulating factor along with RTOM in an equation for predicting quality.

of the 16 grasses for which quality predictions were made, 10 contained less than 7 percent CP on a DM basis. Egan (1965) and Weston (1967) indicated that OMI of such forages may be influenced more by nitrogen status of the animal than by RTOM. If this were true, it would be expected that quality predictions for such forages would be too high when determined from RTOM. Such was not the case in the present study, since quality predictions for all 10 grasses of low $C P$ percentage were acceptable when judged by conservative acceptability limits. These results, however, may not invalidate totally the assumptions of Egan (1965) and Weston (1967), but may be indicative of the different lengths of in vivo experimental periods used by these authors compared to those employed with hays used in the present investigation. Clark and Quin (1951) stated that it frequently had been found that sheep kept exclusively on a diet of poor-quality grass hay showed a gradual decline in intake from about the third week on such a treatment. Data presented by these workers showed that intake declined after the third, fourth or fifth week when low-quality forages were fed. Hays employed in the present study were fed to sheep for three weeks, while Egan (1965) used 7.5 to 11 weeks, and Weston (1967) used 7 to 13 weeks. Thus, hays studied in the present investigation may have been fed to sheep for 
periods of time too short to allow animals to achieve a nitrogen status low enough to override. RTOM as the primary determinant of DOMI. In this case, RTOM still would determine quality of forages low in CP percentages, as indicated by results reported here.

Figures 3 and 9 show tests of acceptability for OMI predictions made by rational and empirical methods, respectively. Figure 8 shows that rational prediction of OMI for 16 grasses from predicted DOMI divided by predicted OMD produced predictions which were all acceptable when judged by liberal acceptability limits, and 15 which were acceptable by conservative limits. The one bermudagrass for which predicted OMI was conservatively unacceptable exhibited a CP percentage of 5.6 on a DM basis. However, OMI predictions for the nine other grasses with less than 7 percent CP on a DM basis all fell within conservative acceptability limits. These results strengthen the conclusion that in this investigation, nitrogen status of the animal generally was less important than RTOM in determining in vivo OMI of grasses with low CP percentages. Figure 9 presents results of empirical prediction of OMI from $\mathrm{ADF}$ as a percentage of $\mathrm{DM}$, as suggested by Weller (1973). All predictions for the same 16 grasses used above were acceptable by liberal standards, but five predictions were unacceptable when judged by conservative limits. Thus, the rational method for predicting OMI was more promising among grass species than the empirical prediction method. Also, the high negative $r$ value $(-.88)$ found in this study for the relationship between OMI and $\mathrm{ADF}$ for 15 forages would not be expected in all cases. Johnson and Dehority (1968) reported an $\mathrm{r}$ value of only -.46 for the relationship between relative intake of 22 temperate grasses and ADF percentage 


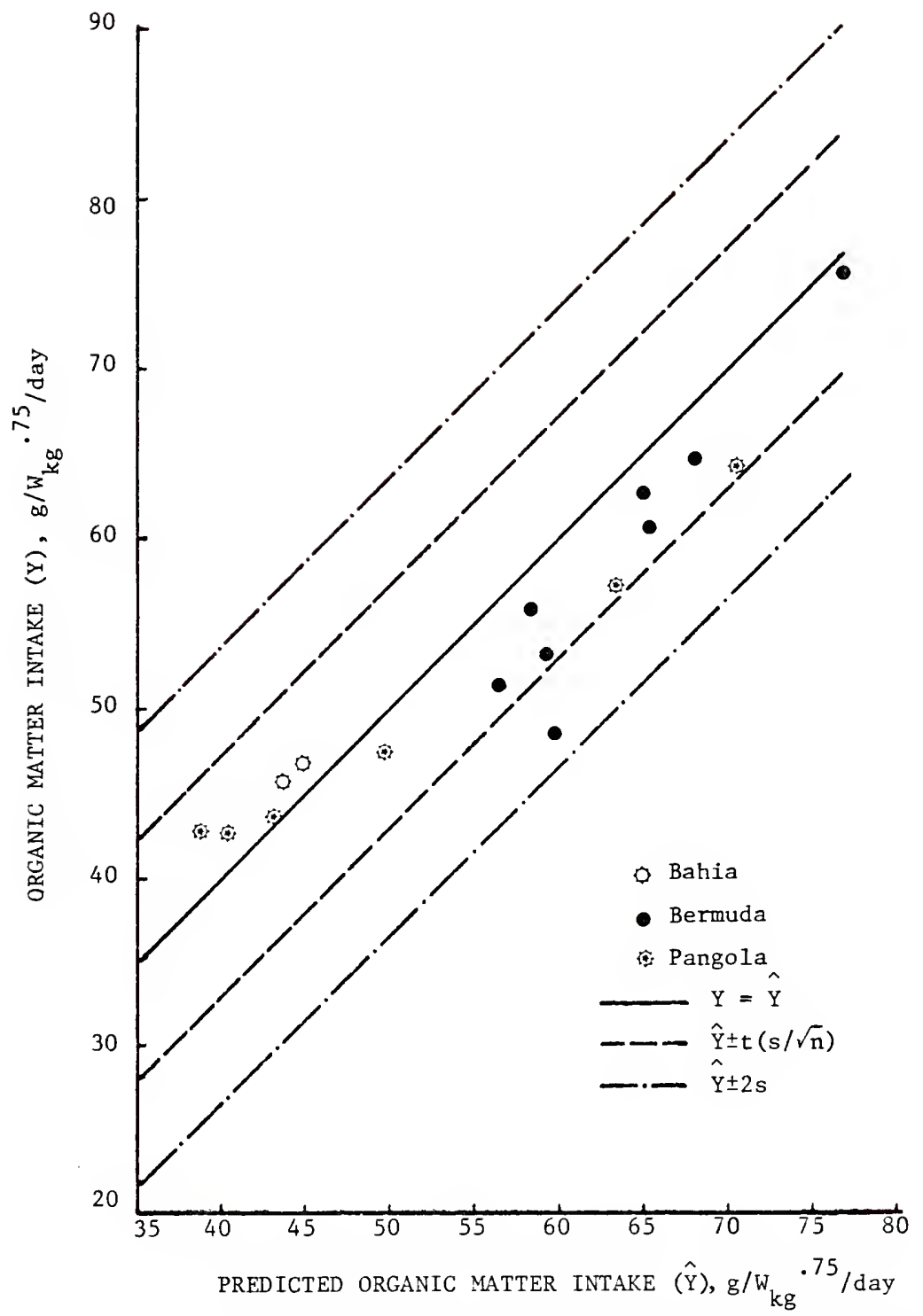

Figure 8. Test of theoretically rational method for prediction of organic matter intake. 


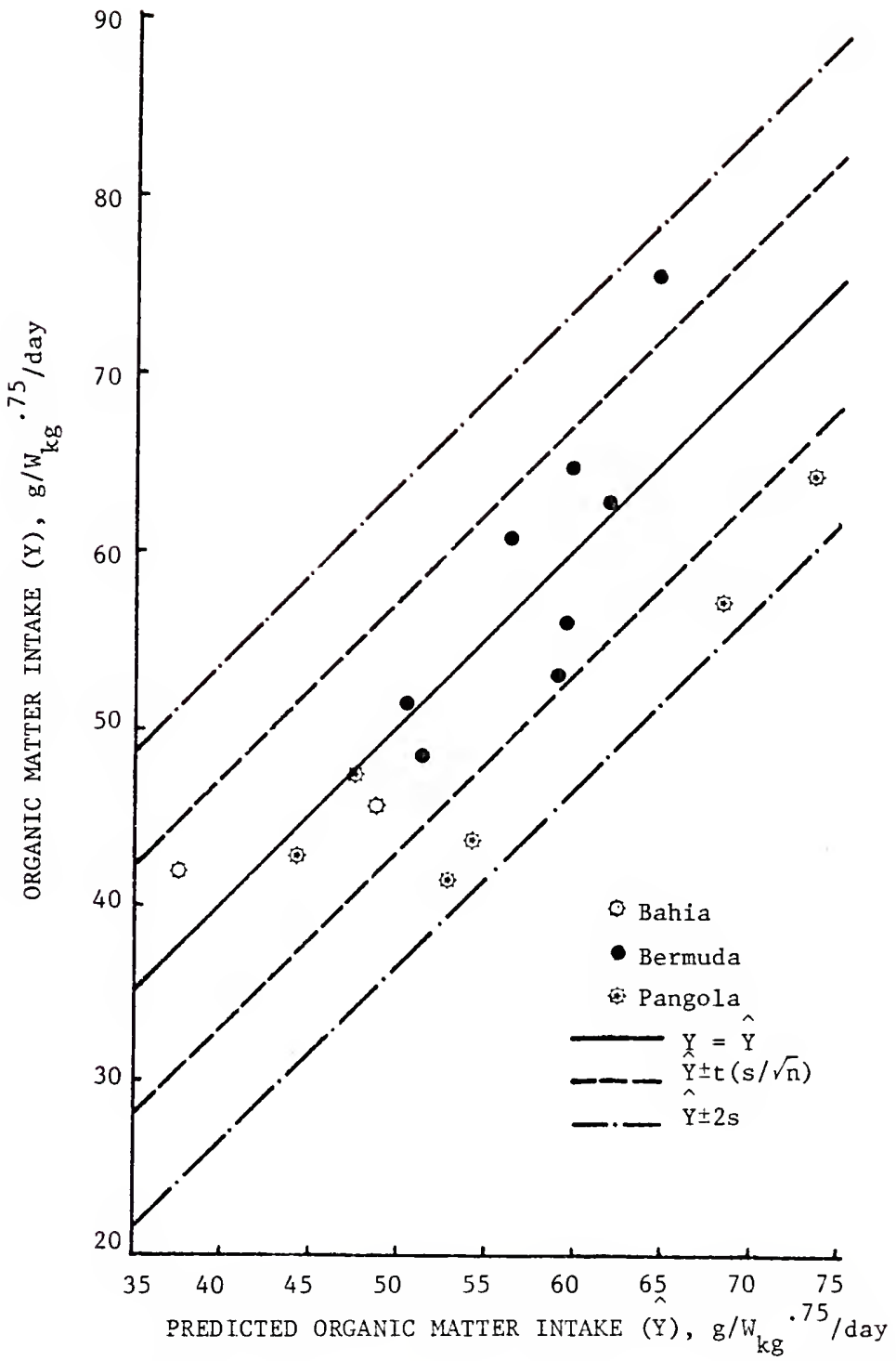

Figure 9. Test of empirical prediction of organic matter intake from acid-detergent fiber percentage of dry matter. 
of these grasses, and -.31 when legumes and mixed forages were included in the analysis. Van Soest (1965a) found $r$ values ranging from -.88 to .20 between voluntary intake and $\mathrm{ADF}$ within seven species of temperate forages. The value of this statistic was -.53 for all 83 individual forages. This author also reported that the relationship between voluntary intake and $\mathrm{ADF}$ declined as that between voluntary intake and digestibility decreased. Since this latter relationship is not always strong, especially over a wide range of forage species, it is doubtful that the $r$ value between OMI and ADF always would be as high as found in the present study. Therefore, prediction of OMI should be undertaken on a rational rather than on an empirical basis. Utility of Relationships Between Various Measurements and Analyses Prediction of organic matter digestibility

In this study, OMD was predicted with equation (11), in which NDFD was predicted from IVNDFD after $72 \mathrm{hr}$ of fermentation. Since DOM as a percentage of DM, or the numerator of equation (11), must be estimated in order to predict DE/g DM (Chapter III), prediction of OMD can be achieved simply by dividing DOM by OM as a percentage of DM. Thus, determination of IVOMD after $48 \mathrm{hr}$ of fermentation is avoided in predicting OMD. This determination apparently can be avoided in other situations where IVNDFD is measured at $72 \mathrm{hr}$. For all 31 grasses, the $r$ value for the relationship between in vivo $O M D$ and IVNDFD at $72 \mathrm{hr}$ was .96 , and $\mathrm{s}_{\mathrm{y} . \mathrm{x}}$ was 2.2 percentage units. The relationship between in vivo $\mathrm{OMD}$ and IVOMD at $48 \mathrm{hr}$ was characterized by $\mathrm{r}$ and $\mathrm{s}_{\mathrm{y} . \mathrm{x}}$ values of .96 and 2.4 percentage units, respectively. Weller (1973) reported that in vivo OMD and IVNDFD at $72 \mathrm{hr}$ were highly 
and positively correlated for 12 warm-season grasses $(r=.96$;

$s_{y \cdot x}=2.0$ percentage units). Thus, OMD probably could be predicted directly, with a high degree of accuracy, from IVNDFD after $72 \mathrm{hr}$ of fermentation. Measurement of this in vitro parameter, however, requires more time than does determination of IVOMD at $48 \mathrm{hr}$. Therefore, changing existing systems of analysis from IVOMD at $48 \mathrm{hr}$ to IVNDFD at $72 \mathrm{hr}$ of fermentation probably would be unwarranted. Prediction of intake from neutral-detergent fiber percentage Van Soest (1965a) suggested that NDF limited intake when this constituent comprised more than 55 to 60 percent of DM. In the present investigation, NDF percentage ranged from 63.6 to 81.3 percent on the DM basis. However, for all 31 grasses, the relationship between OMI and NDF was characterized by $\mathrm{r}=-.12$ and $\mathrm{s}_{\mathrm{y} \cdot \mathrm{x}}=12.4$. For bahiagrass and bermudagrass individually, these values were only slightly higher, i. e., -.23 and 9.2 , or -.47 and 9.5 , respectively. With Pangola digitgrass, $r=.91$ and $s_{y \cdot x}=5.3$. Such a strong relationship, however, may be more associative than cause and effect in nature. Johnson and Dehority (1968) reported an $r$ value of only -.21 for the relationship between relative intake and NDF percentage of temperate grasses, and -.56 for grasses, legumes and mixed forages combined. Van Soest (1965a) found this value to be -.65 for 83 temperate forages, while it ranged from -.95 to +.57 within species. Thus, results of these studies and those of the present investigation strongly indicate that NDF as a percentage of DM would not be an accurate predictor of OMI over a wide range of forage species. 
Prediction of $\mathrm{k}_{2}$

In this study, values of $\mathrm{k}_{2}$ for all 31 grasses were calculated from their actual in vivo lignin intakes. Estimates of $\mathrm{k}_{2}$ resulting from this procedure averaged $.0227 \mathrm{~g} / \mathrm{hr} / \mathrm{g}$, which agrees with the .02 $\mathrm{g} / \mathrm{hr} / \mathrm{g}$ assumed by Waldo et al. (1972). This fact and the high degrec of acceptability of forage quality predictions in the present investigation suggest that the procedure used here for estimation of $\mathrm{k}_{2}$ is acceptable. However, for prediction of forage quality in a practical situation, this procedure is inadequate because intake usually would not be known. Simple linear regression analysis involving several in vivo measurements and laboratory determinations revealed that the relationships between $k_{2}$ and lignin percentage of either DM or NDF exhibited $r$ and $s_{y . x}$ values of .82 and .001 , or .83 and .001 units, respectively. Since only a maximum of 68 percent of the variation in $\mathrm{k}_{2}$ was explained by these parameters, alternate methods for prediction of $\mathrm{k}_{2}$ were sought.

Calculated values for $\mathrm{k}_{2}$ were of low magnitude and were relatively invariant in this study (table 7 ). Thus, it was possible that assuming $k_{2}$ to be constant among grasses at its mean value, i. e., .0227 $\mathrm{g} / \mathrm{hr} / \mathrm{g}$, might not lead to errors in prediction of DOMI. Testing this assumption with the 16 grasses used throughout this study for predictive purposes, however, resulted in only six quality predictions which were acceptable when judged by Iiberal acceptability limits (table 9), and one which was acceptable by conservative standards. For two forages whose DOMI predictions were in error by only $0.1 \mathrm{~g} / \mathrm{W}_{\mathrm{kg}} .75 /$ day when predictions were generated using calculated $\mathrm{k}_{2}$ values, prediction 
errors rose to 6.4 and $7.5 \mathrm{~g} / \mathrm{W}_{\mathrm{kg}} .75 / \mathrm{day}$ when the mean value of $\mathrm{k}_{2}$ was used. The mean underestimated the calculated values by only .0010 and $.0011 \mathrm{~g} / \mathrm{hr} / \mathrm{g}$, respectively. For two other forages, DOMI predictions generated with calculated $k_{2}$ values were in error by .8 and 2.8 units, but prediction errors were 8.5 and 8.3 units, respectively, using the mean value of $k_{2}$. Calculated $k_{2}$ values were underestimated by .0011 and $0009 \mathrm{~g} / \mathrm{hr} / \mathrm{g}$, respectively, by the mean. Therefore, assuming $k_{2}$ to be constant over a wide range of forages does not provide consistently acceptable predictions of forage quality. Since estimates of $k_{2}$ obviously must be quite accurate, it is not surprising that using the value of $.02 \mathrm{~g} / \mathrm{hr} / \mathrm{g}$ (Waldo et al., 1972) produced DOMI predictions which were too low. Predictions generated under the assumption that $\mathrm{k}_{2}$ was constant at $.025 \mathrm{~g} / \mathrm{hr} / \mathrm{g}$ were too high.

A second method for prediction of $k_{2}$ was suggested when simple linear regression analysis revealed that the relationship between ' $a$ ' and (NDS + DNDF), as a percentage of DM, exhibited an $r$ value of $.88\left(r^{2}=.78\right)$ and $s_{y \cdot x}$ of .034 . This relationship, it seems, should be more than simply associative. The utility of this relationship would be that, with the value of ' $a$ ' known, equation (10) could be solved for $k_{2}$ when predicted $O M D\left(O M D_{p}\right)$ was expressed as a decimal fraction rather than in percent. The resultant formula for determining $k_{2}$ would be as follows:

$$
k_{2}=\frac{a\left(k_{1}\right)\left(1-O M D_{p}\right)}{O M D_{p}-a} .
$$

To test this method for prediction of $k_{2}$, values of ' $a$ ' were first regressed on (NDS $+\mathrm{DNDF}$ ), as a percentage of $\mathrm{DM}$, using the same 15 grasses used throughout this study for generation of prediction equations. The resultant equation was the following: 


$$
' a^{\prime}=-.1878+.0071(\mathrm{NDS}+\mathrm{DNDF}) .
$$

Values of $r$ and $s_{y \cdot x}$ for equation (18) were $.88\left(r^{2}=.77\right)$ and .033 , respectively. Actual values of ' $a$ ' for the 16 remaining grasses, when regressed upon their respective predicted values from equation (18), produced a relationship which was characterized by an $r$ value of $.87\left(x^{2}=.77\right)$ and $s_{y . x}$ of .036 . Predicted values of 'a' were inserted into equation (17), and this equation was solved to predict values for $k_{2}$. Regressing calculated values of $k_{2}$ for the 16 grasses on their respective $k_{2}$ predictions produced an $r$ value of only .58 $\left(r^{2}=.33\right)$ and $s_{y \cdot x}$ of $.001 \mathrm{~g} / \mathrm{hr} / \mathrm{g}$. Therefore, at present, this method for prediction of $k_{2}$ does not appear promising. However, if some rational method could be developed which would allow more accurate prediction of ' $a$ ', then equation (17) might be useful for accurate prediction of $\mathrm{k}_{2}$. Prediction of $k_{1}$

Simple linear regression analysis revealed no laboratory chemical determination or in vivo measurement which could be used for more rapid determination of $k_{1}$ than is allowed by the in vitro procedures followed in this study. For all 31 grasses, the relationship between $k_{1}$ and lignin as a percentage of DM exhibited an $r$ value of only $.16\left(r^{2}=.02\right)$. This finding agrees with results published by Lechtenberg et al. (1974), who reported that although rate of digestion of cell walls depended upon lignin as a percentage of DM, $k_{1}$ was not affected by the magnitude of 1ignin concentration in DM. 


\section{General Discussion}

In this study, quality of warm-season grasses was predictable with a high degree of accuracy from RTOM when this time period was longer than about $31 \mathrm{hr}$. Therefore, RTOM apparently reflects both chemical composition and structural organization of OM. When RTOM was below $31 \mathrm{hr}$, as it was for two Pangola digitgrasses, DOMI predictions were acceptable when judged by liberal acceptability limits, but were unacceptable by conservative standards. Therefore, forage quality may not be always predictable from RTOM alone, since the distention mechanism and RTOM may be partially or totally overridden by factors related to other DOMI control mechanisms. This would occur when such factors reach levels at which they become important as determinants of forage DOMI. In this study, such factors may have been related to some attribute of the two Pangola digitgrasses, and may have been chemostatic in nature. Non-Forage Factors Which Could Override or Modify RTOM

It also is possible that in a given situation where RTOM is the main determinant of.forage quality, the in vivo value of RTOM may be modified by non-forage factors (factors which are not related directly to forage chemical composition or physical structure, per se) which were not included in the RTOM prediction process. Nonforage factors also might override RTOM as the main determinant of forage quality. If RTOM is overridden, or is modified with respect to its magnitude, the factors responsible need to be identified and their effects require accurate quantification. If these effects are not related to forage quality, then the manner(s) in which they are 
mediated must be elucidated. If such discoveries could be made, forage DOMI probably could be predicted accurately by dynamic computer modeling in situations where RTOM was overridden as the main determinant of DOMI, or was modified with respect to magnitude in some way that could not be taken into account in a laboratory procedure for RTOM prediction.

The number of factors which could override RTOM, or which could influence its magnitude, is undoubtedly great. Several factors which, in one of these ways, may affect DOMI of ad libitum fed animals are

(1) nitrogen status of the anima1 (Egan, 1965, 1970; Weston, 1967);

(2) environmental conditions, i. e., ambient temperature, humidity and solar radiation (Ragsdale et a1., 1953; Brobeck, 1960; Wayman et al., 1962; Warren et a1., 1974; Bhattacharya and Uwayjan, 1975; Koes and Pfander, 1975);

(3) the physical form in which forages are fed, i. e., long, chopped, ground or ground and pelleted (Rodrigue and Allen, 1956; Blaxter and Graham, 1956; Johnson et al., 1964; Minson and Milford, 19ó8; Greenhalgh and Reid, 1973);

(4) previous plane of nutrition (Tayler et al., 1957; Tayler, 1959; Heaney, 1970; 0'Donovan et al., 1972; Asplund et al., 1975);

(5) the method by which hay is processed, i. e., artificially dried, barn-dried, rack-dried or swath-dried in the field (Shepperson, 1960; Milford and Minson, 1968; Demarquilly and Jarrige, 1970);

(6) physiological state of the animal, i. e., fatness, stage of pregnancy and stage of lactation (Reid and Hinks, 1962; Graham and Williams, 1962; Hutton, 1963; Arnold and Dudzinski, 1966; Ulyatt, 1973; Capote, 1975);

(7) animal type, i. e., cattle or sheep (Buchman and Hemken, 1964; Blaxter et al., 1966; Jones et a1., 1972);

(8) animal breed within type (Hungate et al., 1960; Phillips, 1961; Kappel et al., 1972); 
(9) animal levels of macro- and micro- mineral elements (Underwood, 1962; Blaxter, 1962; Preston and Pfander, 1964; Telle et al., 1964; Miller et al., 1966; Weston, 1966; Patil and Jones, 1970; Chicco et al., 1973; Seoane et al., 1975);

(10) CP supplementation of forages which exhibit CP levels of less than 7 percent on a DM basis (Campling et al., 1961; Coombe and Tribe, 1963; Egan, 1965, 1970; Elliott, 1967; Minson and Milford, 1967b; Lourens, 1968; Moore et al., 1970; Houser, 1970; Ammerman et a1., 1972; Siebert and Kennedy, 1972; Fick et al., 1973; Ventura et a1., 1975);

(11) energy supplementation (Blaxter and Wilson, 1963; Bisschoff et al., 1967; Clanton and Rittenhouse, 1970; Tayler and Wilkinson, 1972; Fick et al., 1973; Golding, 1973); and

(12) animal levels of certain hormones (Blaxter et al., 1949; Dewar, 1962; Hervey and Hervey, 1964; Wade and Zucker, 1970).

It is important that research to quantify effects upon DOMI of factors listed above be carried out over a wide range of forage quality, and that data generated for this purpose be analyzed by regression procedures. Research must be carried out in this fashion so that (a) results are applicable to a wide range of forage species; (b) effects can be predicted continuously over this range instead of only at a few widely scattered, intermittent points; and (c) efficient and accurate dynamic modeling can be practiced. Experimental designs of the central-composite or San Cristobal type require a smaller number of experimental animals than full-scale factoral designs, and could be utilized in attaining these goals.

Theoretical Methods for Prediction of $k_{2}$

Two theoretically possible methods for prediction of $\mathrm{k}_{2}$ remain to be tested. First, the amount of OM in the rumen per $W_{k g} .75$ has been found constant among forages when forage CP is greater than 
7 percent on a DM basis (Blaxter et al., 1961; Ulyatt et al., 1967;

Thornton and Minson, 1972). If this quantity of OM could be ascertained for a given set of non-forage factors, then multiplying this quantity by .63 theoretically should approximate the amount of ruminal oM per $\mathrm{W}_{\mathrm{kg}} .75$ which is partially digestible. The other 37 percent would estimate $O M$ which had been in the rumen for longer than a period of time equal to RTOM, and this should be mostly indigestible. Multiplying partially digestible ruminal OM per $W_{\mathrm{kg}} .75$ by predicted $\mathrm{OMD}$ would approximate ruminal $\mathrm{OM}$ which is totally digestible per $\mathrm{W}_{\mathrm{kg}}{ }^{.75}$, and dividing this quantity by the originally assumed amount of ruminal OM per $W_{k g} .75$ should produce an accurate estimate of ' $a$ '. Inserting this 'a' value into equation (17) should produce an accurate prediction of $k_{2}$. Potential problems to be encountered with this method are, first, though ruminal OM per $W_{k g} .75$ has been found statistically constant among forages this amount of $O M$ does vary numerically. Assuming this quantity to be constant, therefore, could produce inaccurate estimates of ' $a$ ' over a wide range of forages, and this could result in inaccurate $\mathrm{k}_{2}$ predictions. Also, assuming the 37 percent of total ruminal om per $\mathrm{W}_{\mathrm{kg}} .75$ which has been in the rumen for longer than RTOM to be totally indigestible may not always be correct, and this could result in underestimation of ' $a$ '. A further difficulty would arise when forage contains less than 7 percent CP on a DM basis. In such cases, ruminal OM per $\mathrm{W}_{\mathrm{kg}} .75$ apparently is not constant (Campling et al., 1961; Egan, 1970). Thus, separate estimates of ruminal oM per $W_{k g} .75$ would have to be made for such forages. This method for prediction of $k_{2}$ deserves to be tested, however, to see if it would produce acceptable predictions for this parameter. 
The second possible method for $k_{2}$ prediction is based upon the fact that rate of passage of $O M$ from the rumen is equal to $k_{2}$ multiplied by the amount of OM undergoing passage. This method would require measurement of the electrical energy required to grind a known amount of forage OM in a Wiley mill. Such determinations have been made by Chenost (1966) and Laredo and Minson (1973).

It is possible that the electrical energy required to grind a known amount of forage OM may be related to rate of OM breakdown in (Laredo and Minson, 1973), and rate of OM passage from, the rumen. If this is true among forages and if the $O M$ undergoing grinding is a constant percentage among forages of the amount of OM which passes from the rumen under steady-state conditions, then dividing the energy required to grind OM by the amount of OM being ground should produce a value not equal to, but highly correlated with, $k_{2}$. The value of $k_{2}$ then could be predicted from a regression equation generated using a wide range of forages for which $k_{2}$ and grinding energy for an amount of OM highly correlated with rate of OM passage from the rumen divided by $k_{2}$ were known.

The difficult part of this procedure would be determination of the amount of OM which should undergo grinding. This quantity should be a constant percentage among forages of the amount of OM which undergoes passage from the rumen under steady-state conditions. At present, quantification of OM undergoing passage requires knowledge of OMI. Thus, a method which does not require such knowledge must be devised for quantifying OM which passes from the rumen. It may be that a constant relationship exists between grinding energy and amount of OM being ground. If this were true, then any quantity of OM could be 
ground. If such a relationship does not exist, however, a mathematician might be able to aid in quantifying $O M$ which passes from the rumen under steady-state conditions.

\section{Summary}

Thirty-one warm-season grasses of known in vivo intake and digestibility were used to develop and test a theoretically rational method for prediction of forage quality in terms of digestible organic matter (OM) intake (DOMI). These grasses included bahiagrasses, bermudagrasses and Pangola digitgrasses which ranged in maturity from 2 to 14 weeks of regrowth. Retention time of OM in the rumen (RTOM) was hypothesized to be a theoretically rational independent variable for prediction of forage quality. Values of RTOM for all grasses were estimated from an equation presented by Waldo et al. (1972) for plotting disappearance of cellulose from the rumen through time. This equation was used in reference to OM instead of cellulose for each forage. The value of the rate constant $\left(k_{1}\right)$ for rate of digestion was estimated using in vitro procedures, while the rate constant $\left(k_{2}\right)$ for rate of passage was calculated from known lignin intake. Estimates of the potentially digestible fraction of ruminal OM ('a') were made using the formula for ' $a$ ' developed in this study, and the potentially indigestible fraction of ruminal $O M$ was equal to one minus ' $a$ '. Fifteen grasses selected as representative of the total of 31 were used to generate an equation to produce acceptably accurate predictions of forage quality. Predictions of DOMI were judged acceptable in a conservative sense if their absolute errors in relation to actual DOMI values were less than or equal to the value of one side of the 95 percent confidence interval for the mean weighted across all 31 grasses. Predictions 
were deemed liberally acceptable if the prediction errors were less than or equal to the value of two standard deviation estimates weighted across all grasses.

Fourteen of the 16 DOMI predictions were acceptable when judged by conservative acceptability limits, while all predictions were acceptable by liberal standards. Ten of the 16 grasses exhibited crude protein percentages of less than 7 percent of DM. Factors not related to RTOM may have influenced the actual quality of the two Pangola digitgrasses for which DOMI predictions were conservatively unacceptable. Inclusion in the prediction equation of some rational factor related to the chemostatic mechanism for controlling forage intake possibly may increase accuracy of DOMI predictions in such cases.

Rational prediction of OM intake (OMI) from predicted DOMI divided by predicted OM digestibility (OMD) appeared a better method than empirical prediction of OMI from acid-detergent fiber percentage. Though all predictions generated by this latter method were liberally acceptable, such success might not be expected over a wider range of forages which included more genetic diversity. Empirical predictions of OMI from neutral-detergent fiber (NDF) percentage were inaccurate.

Values of $\mathrm{OMD}$ were predicted accurately by dividing predicted digestible OM (DOM) by OM. Fast and accurate DOM predictions, however, await development of a rapid, simple laboratory determination for accurate estimation of digestible NDF or NDF digestibility. Actual OMD could be predicted as accurately from in vitro NDF digestion 
after $72 \mathrm{hr}$ of fermentation as from in vitro OM digestion after $48 \mathrm{hr}$. The former determination, however, requires more time.

Values of $k_{2}$, though relatively invariant, cannot be assumed constant among forages, nor can these values be predicted accurately at present from predicted values of 'a'. Estimation of $k_{1}$ must be achieved at present by use of in vitro methods. Lignin as a percentage of DM was not correlated highly with $k_{1}$. 
APPENDIX 


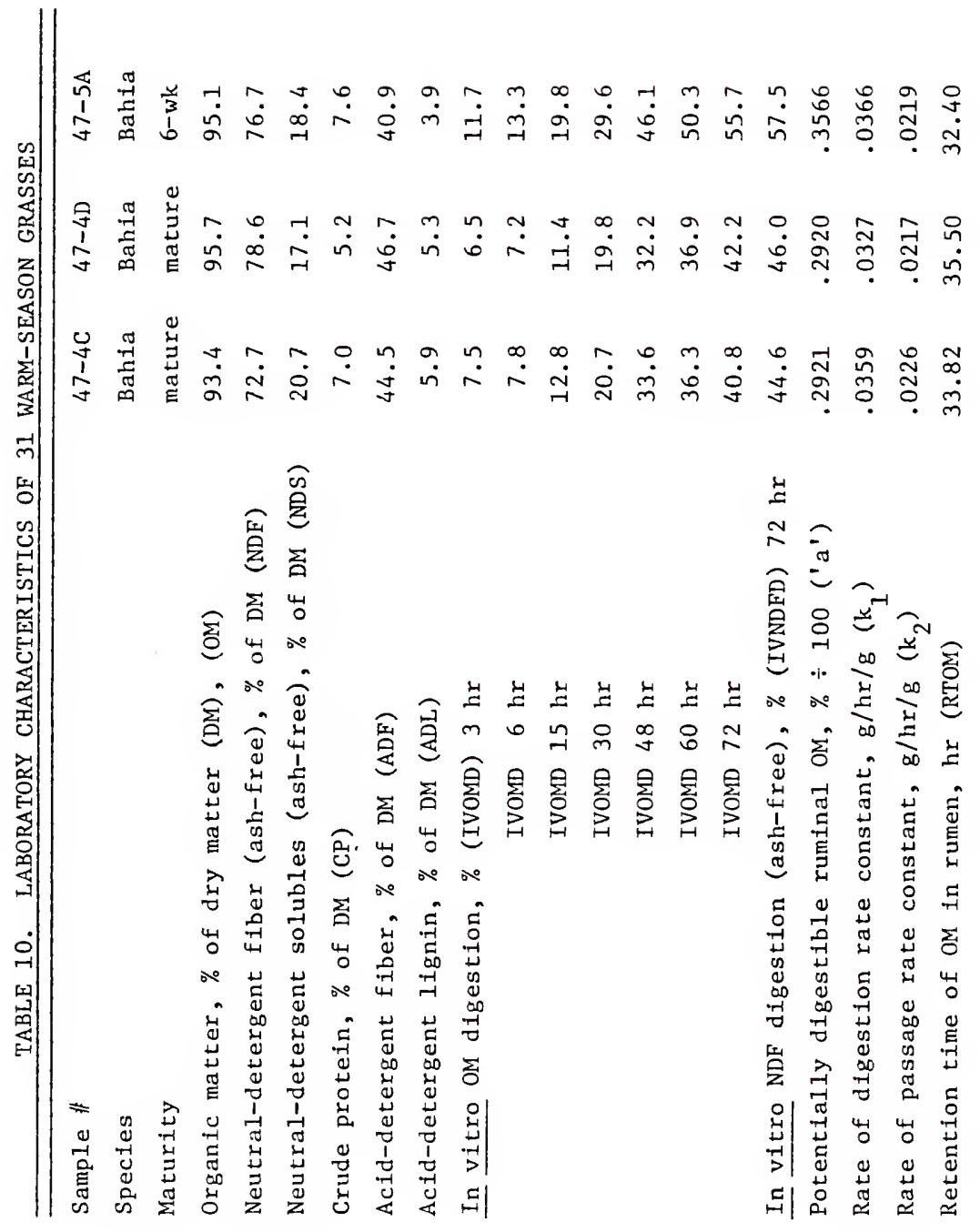




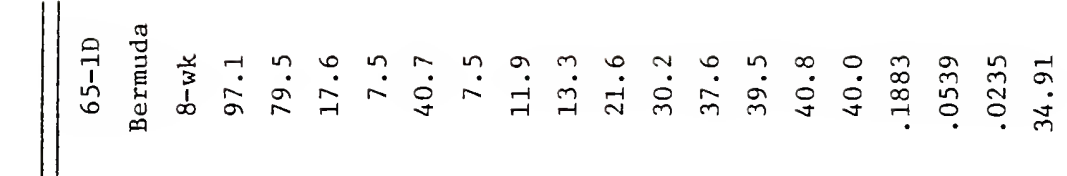

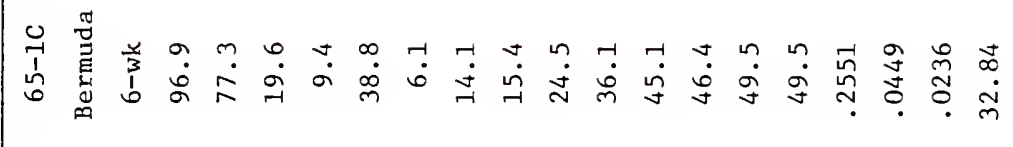

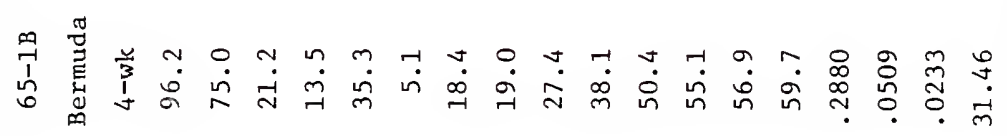

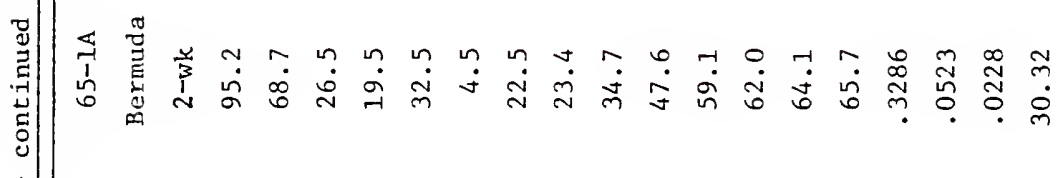

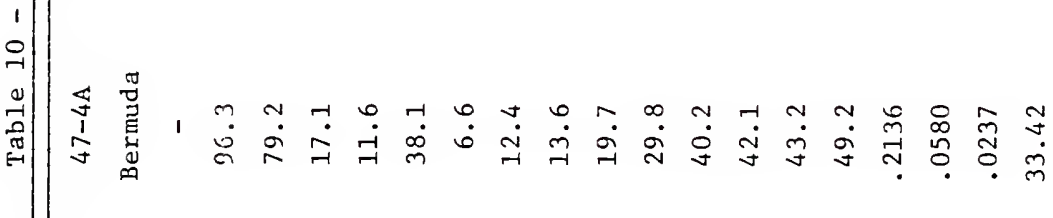

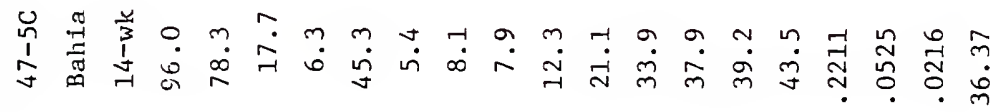

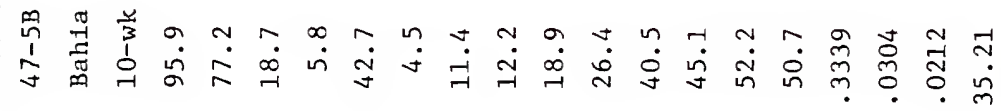

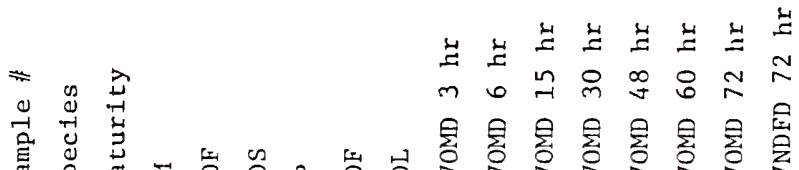

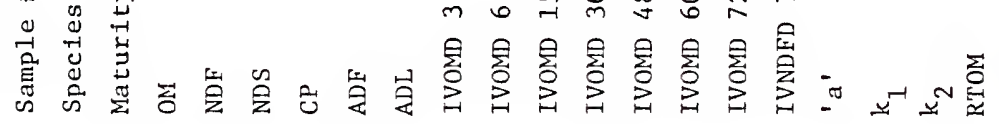




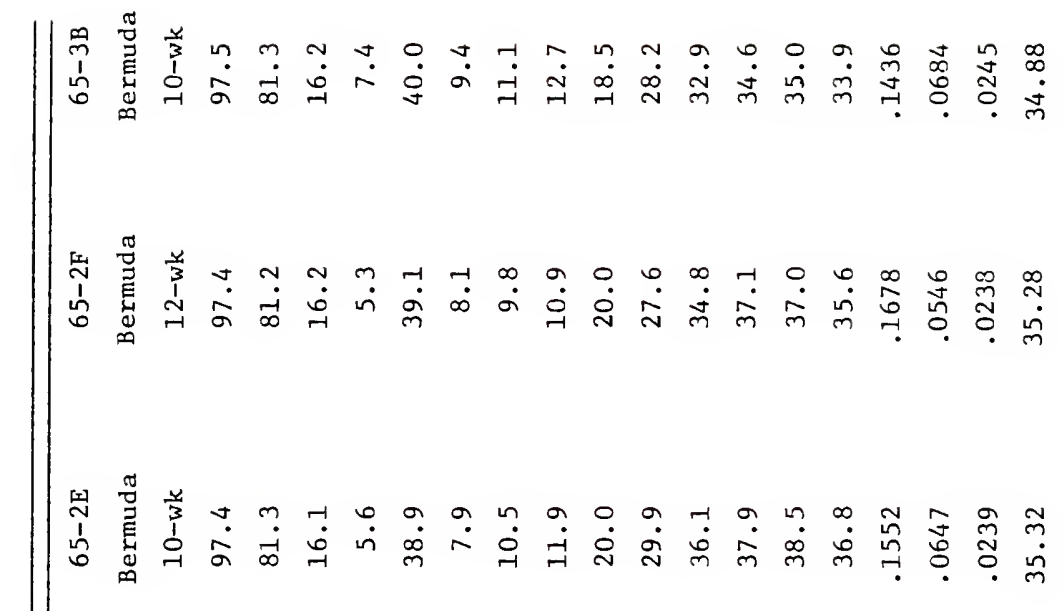

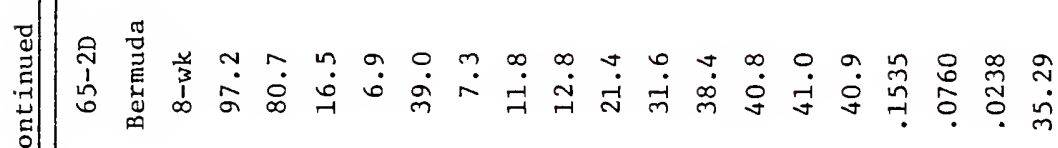

$$
\begin{aligned}
& \text { 1. }
\end{aligned}
$$

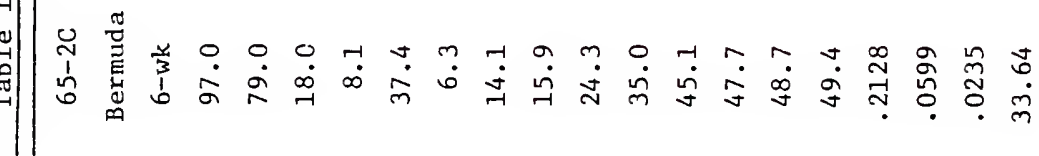

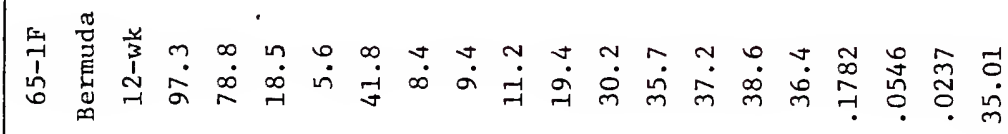

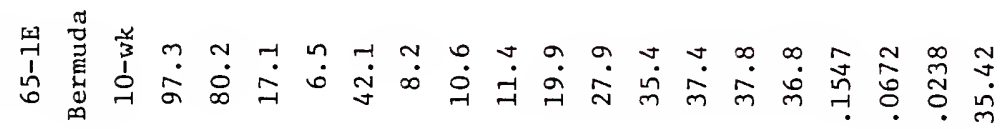

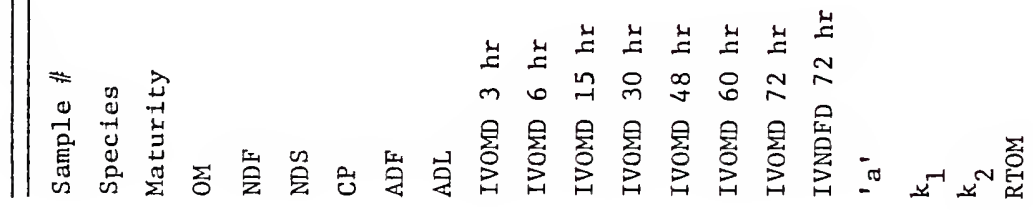




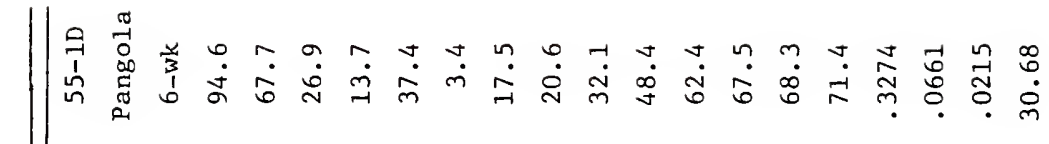

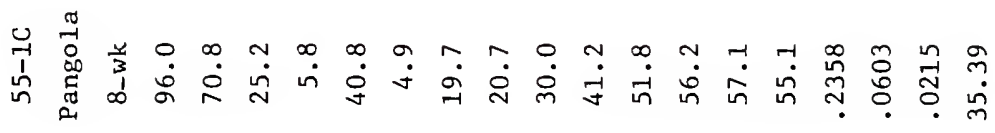

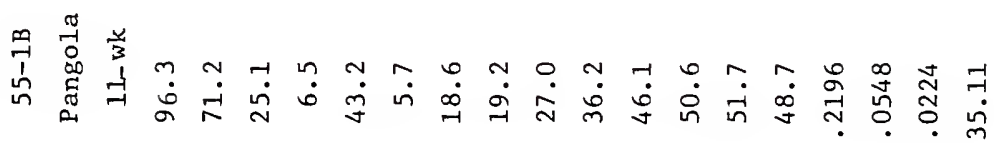

$$
\begin{aligned}
& \text { : }
\end{aligned}
$$

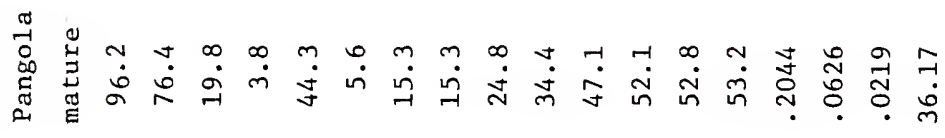

$$
\begin{aligned}
& \text { 㲾 }
\end{aligned}
$$

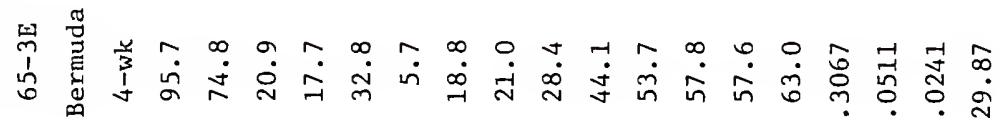

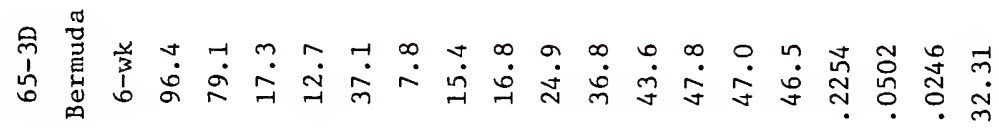

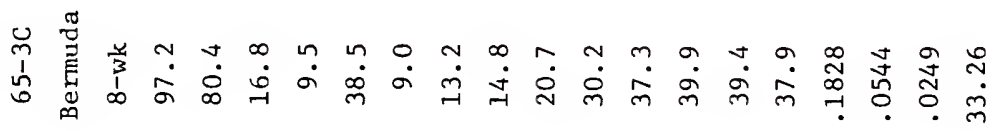

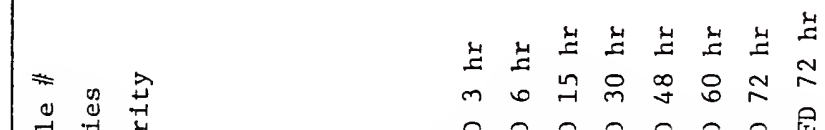

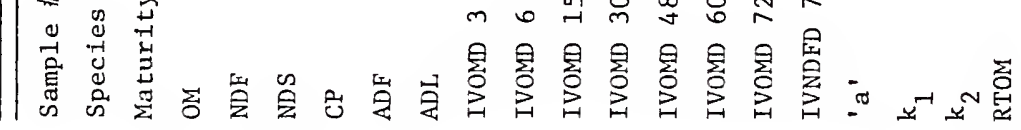




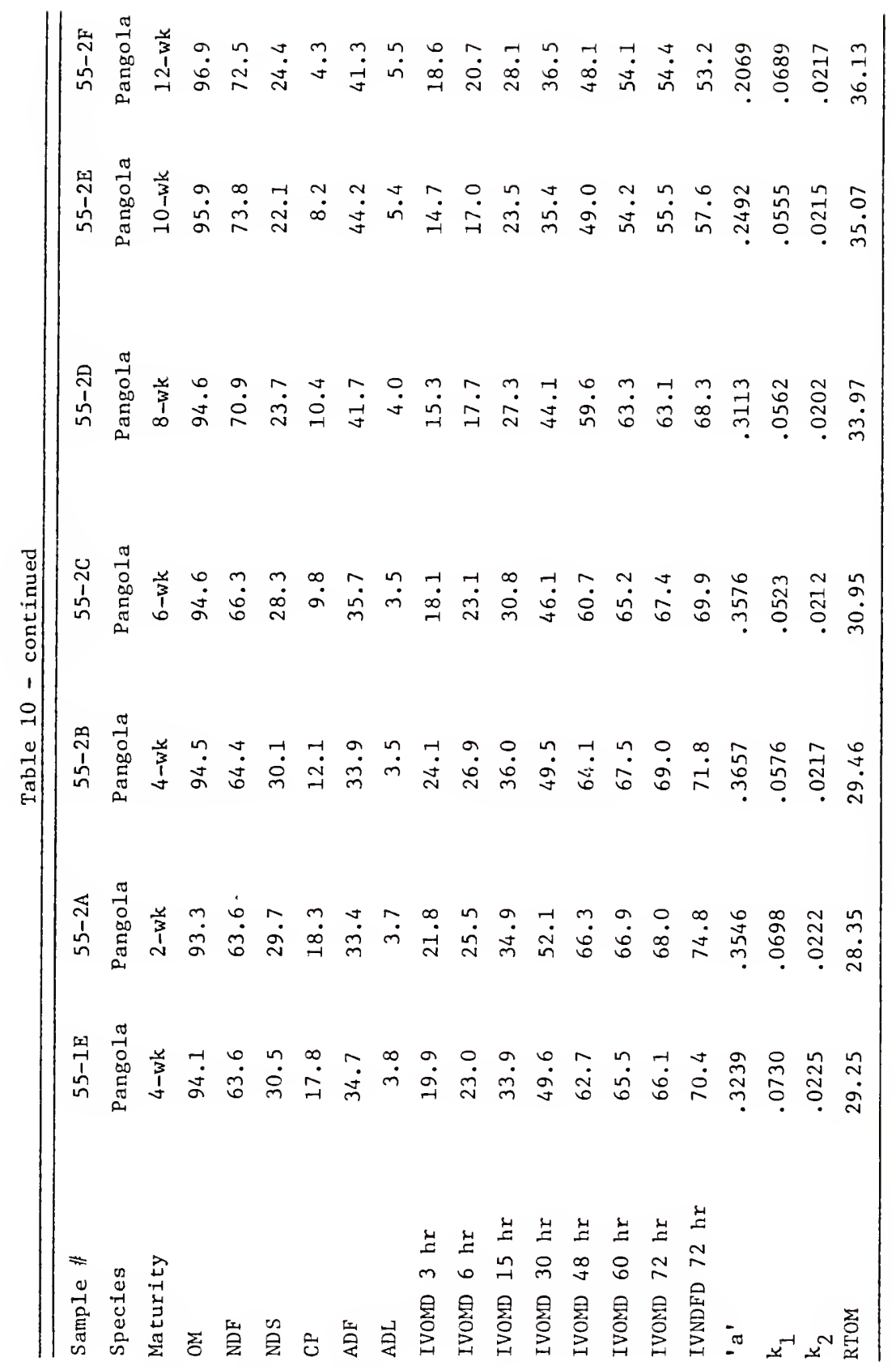




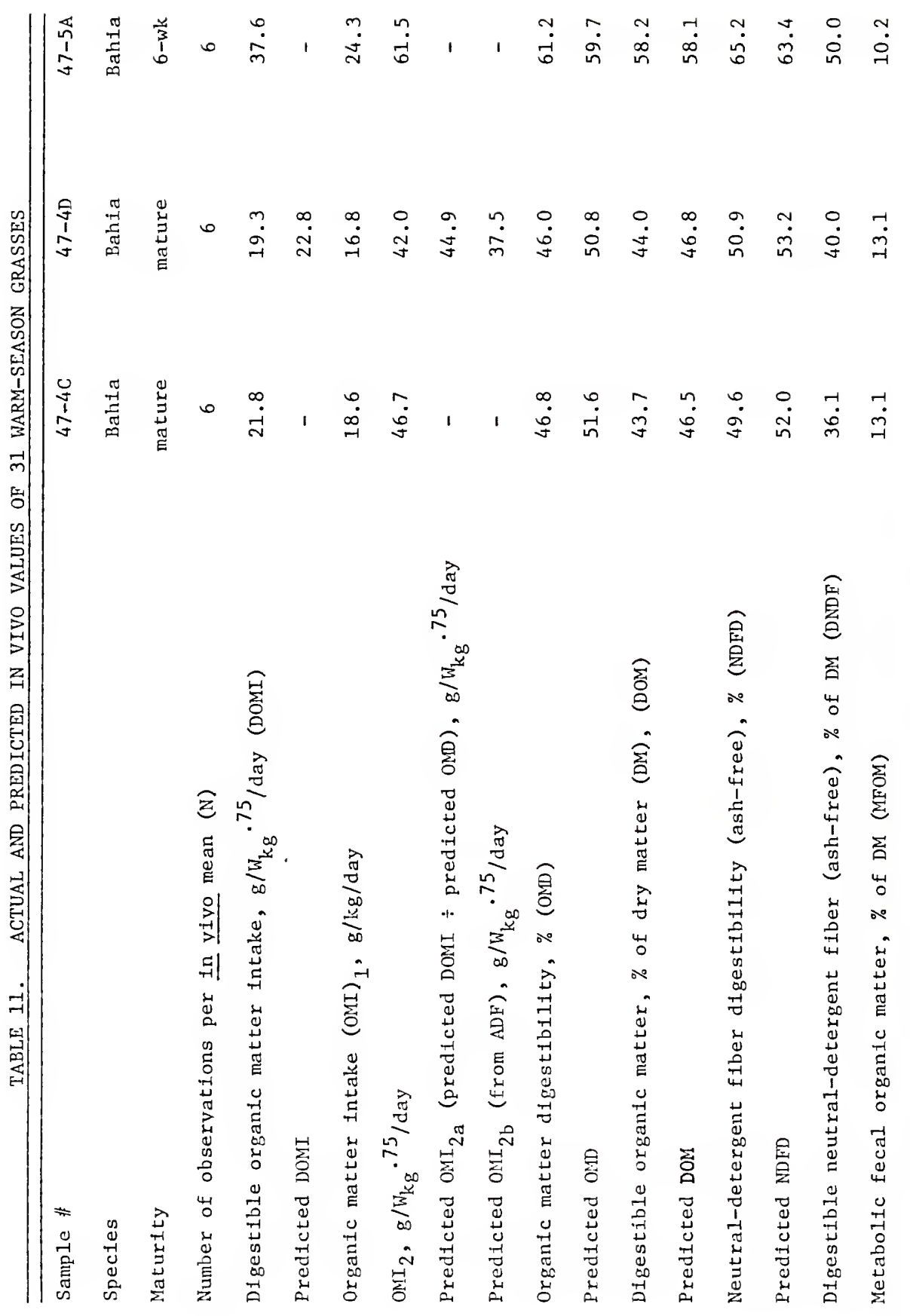




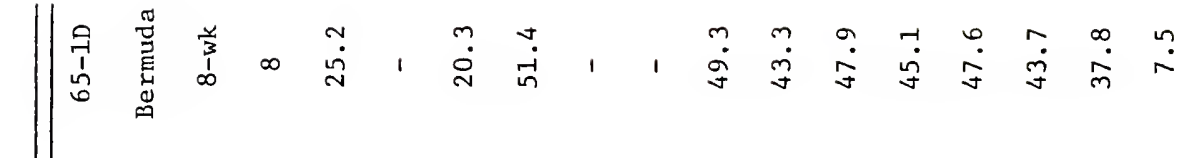

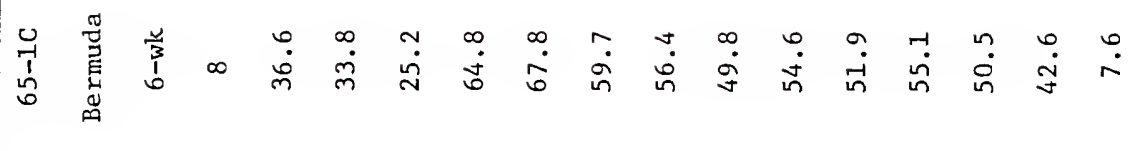

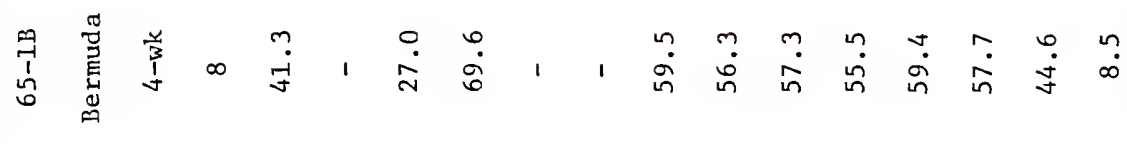

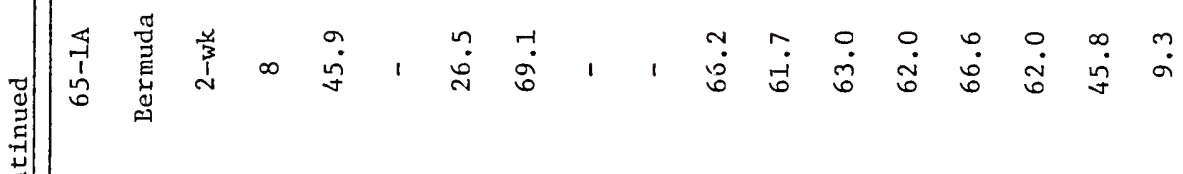

$$
\begin{aligned}
& \text { : }
\end{aligned}
$$

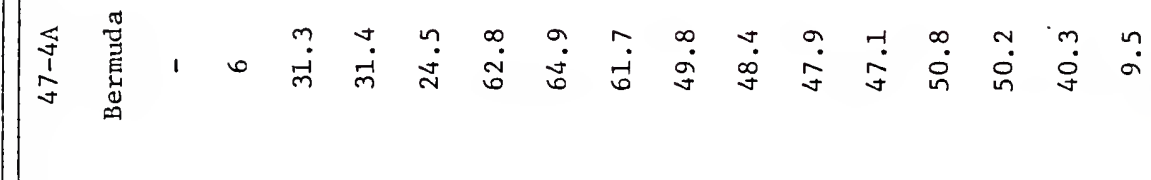

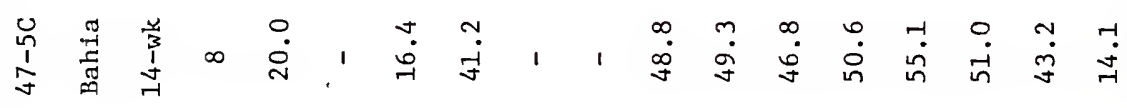

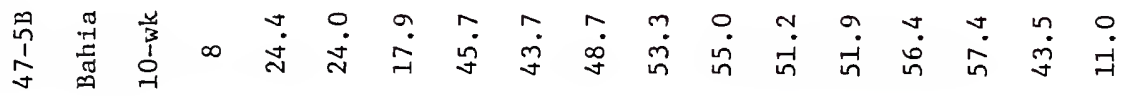

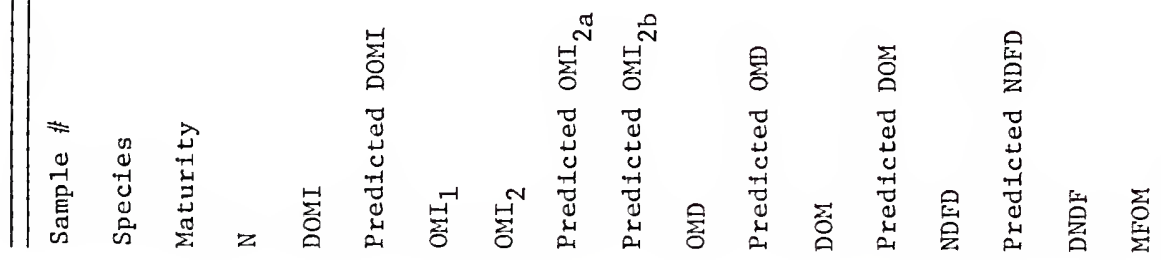




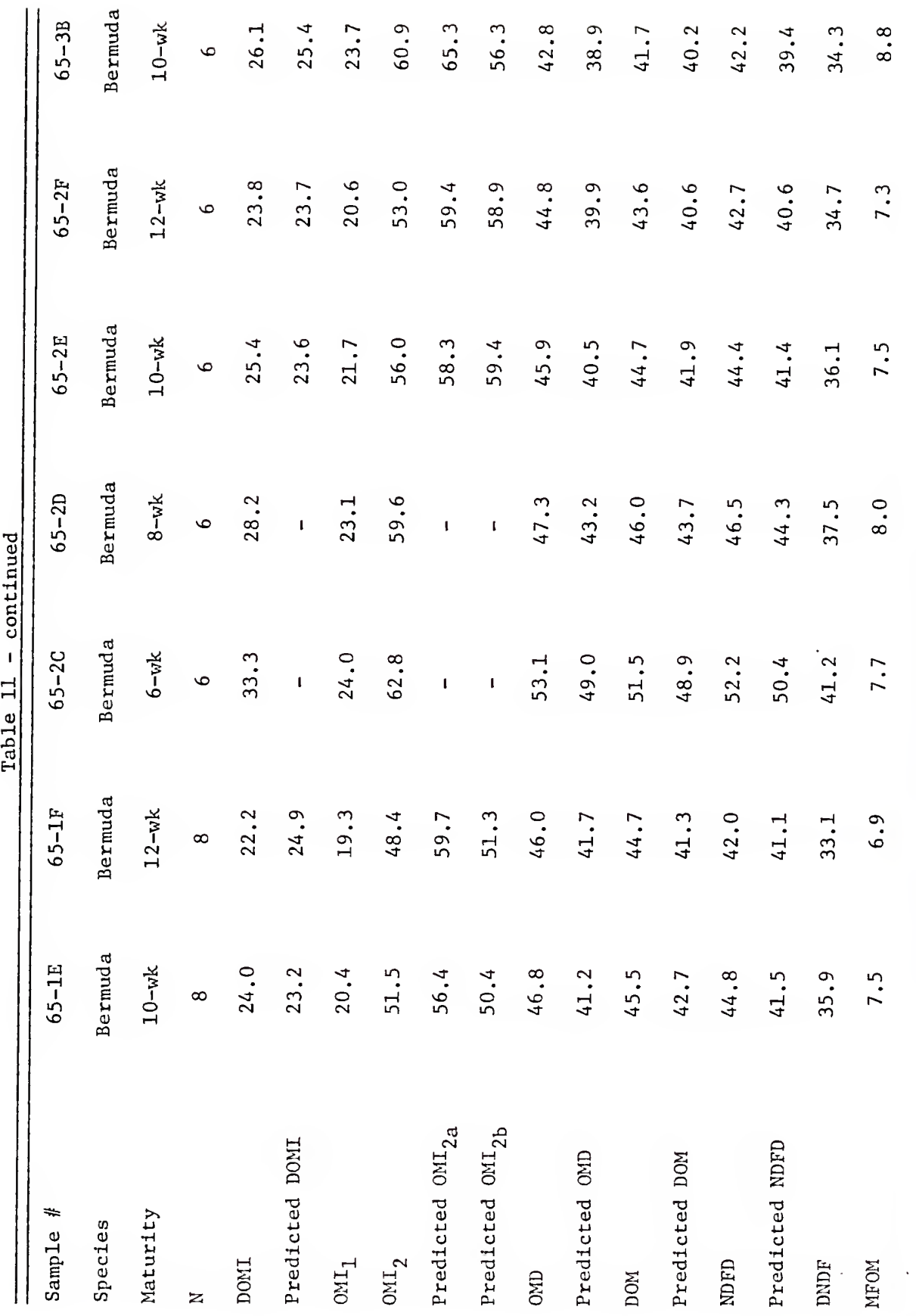




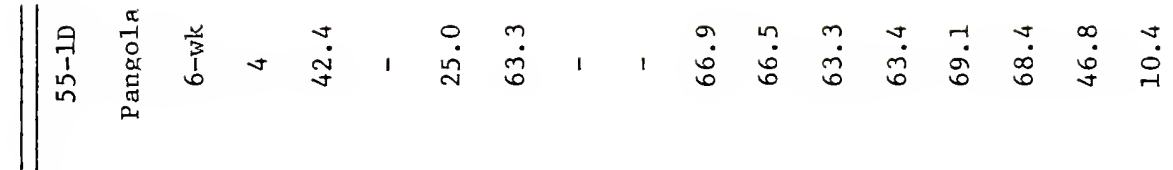

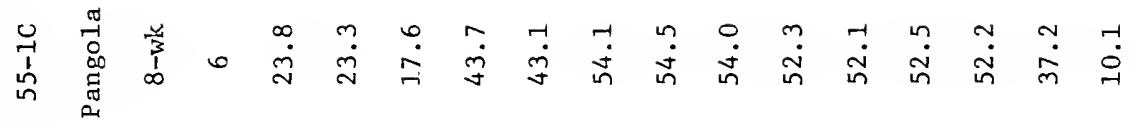

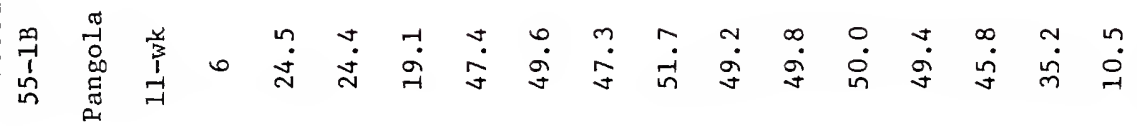

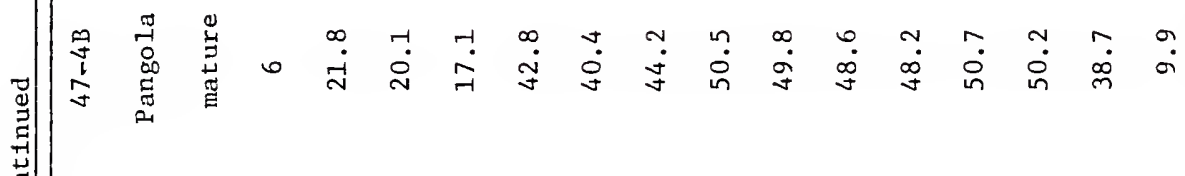

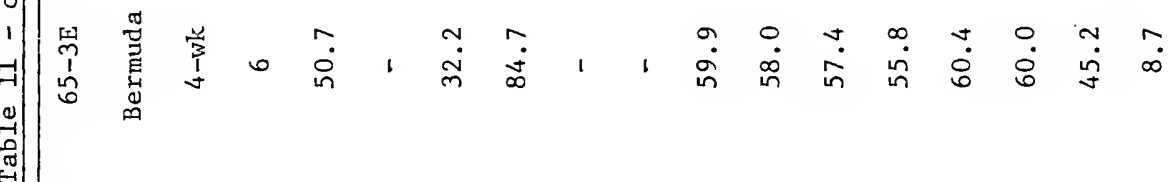

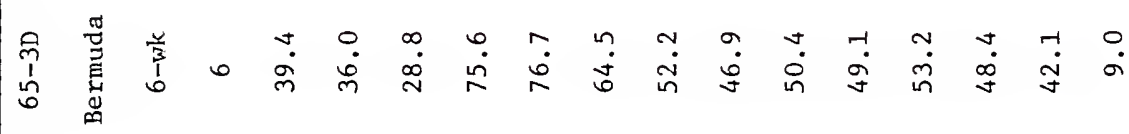

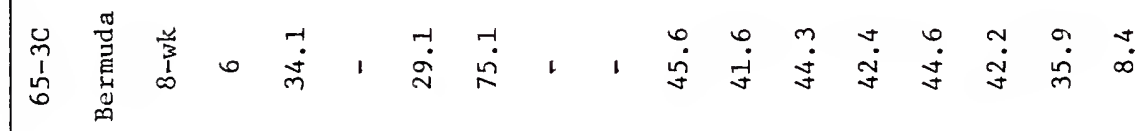

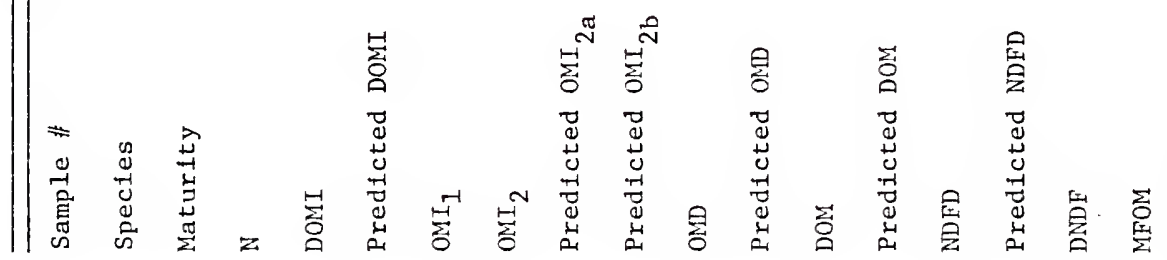




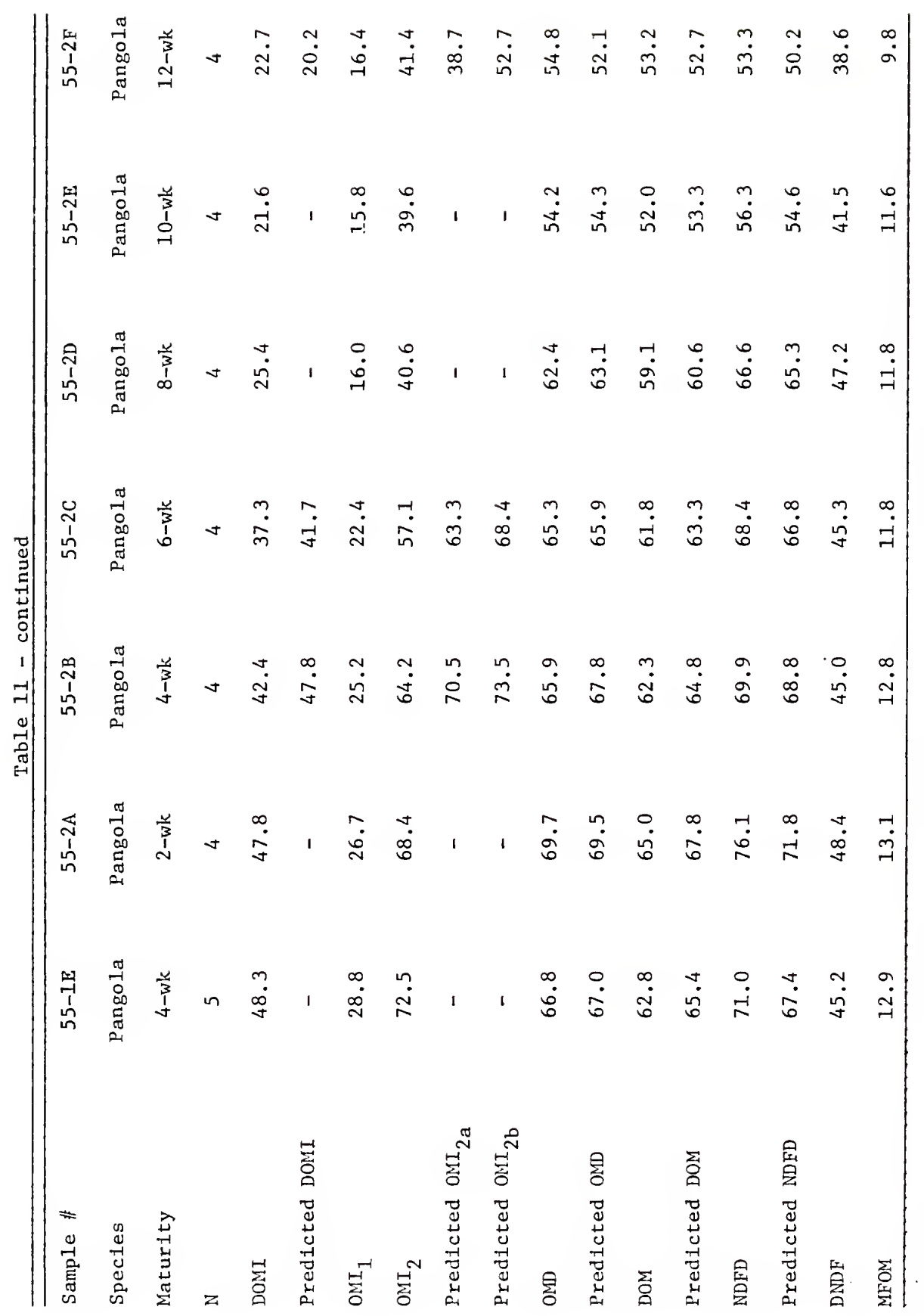




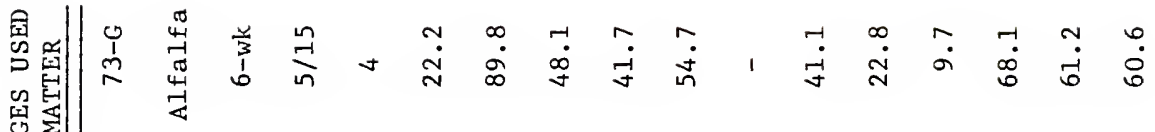
c0

咨

夏我

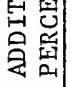

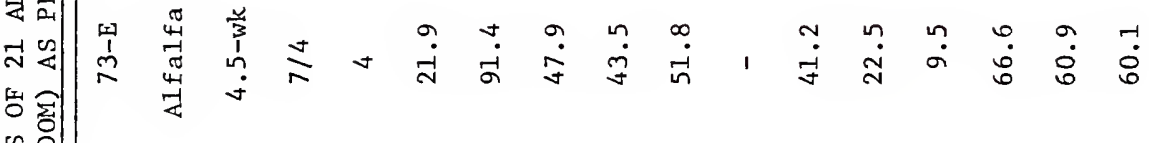
为

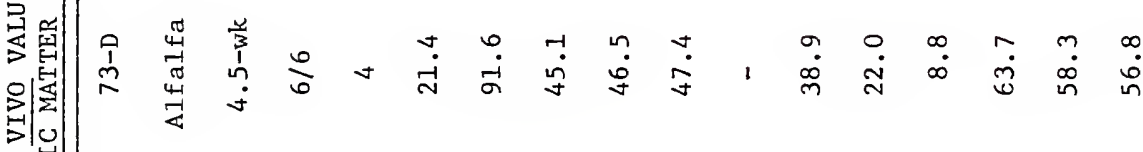
否怒

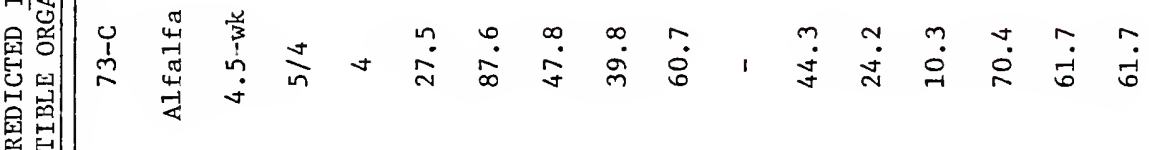
舟

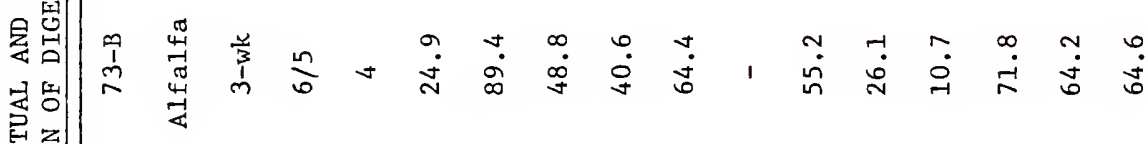
品吕

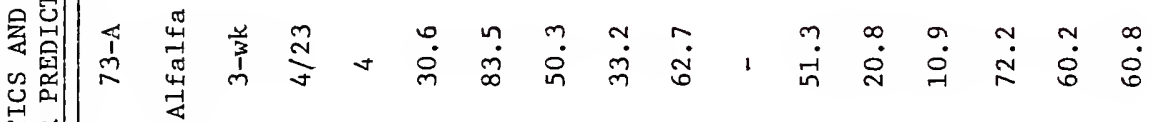
点果

is

곡

岁䃾

起㚸

년

沗

泍

号密

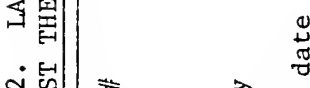

동

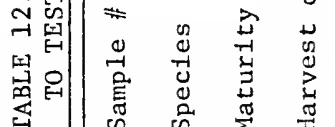

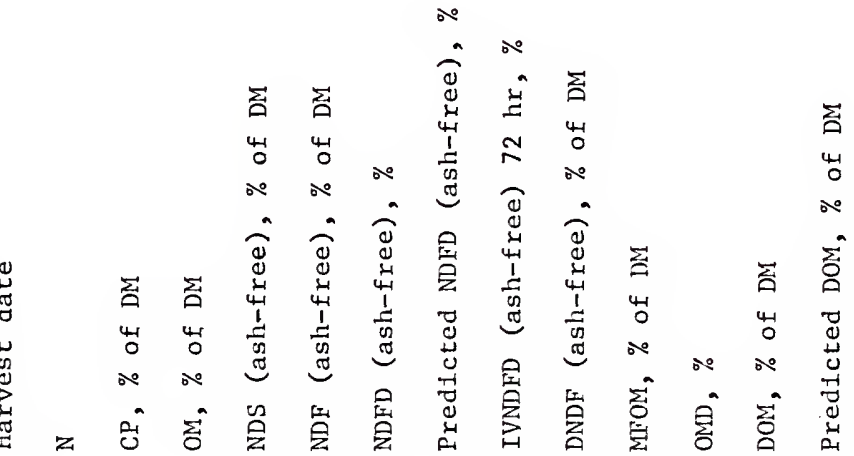




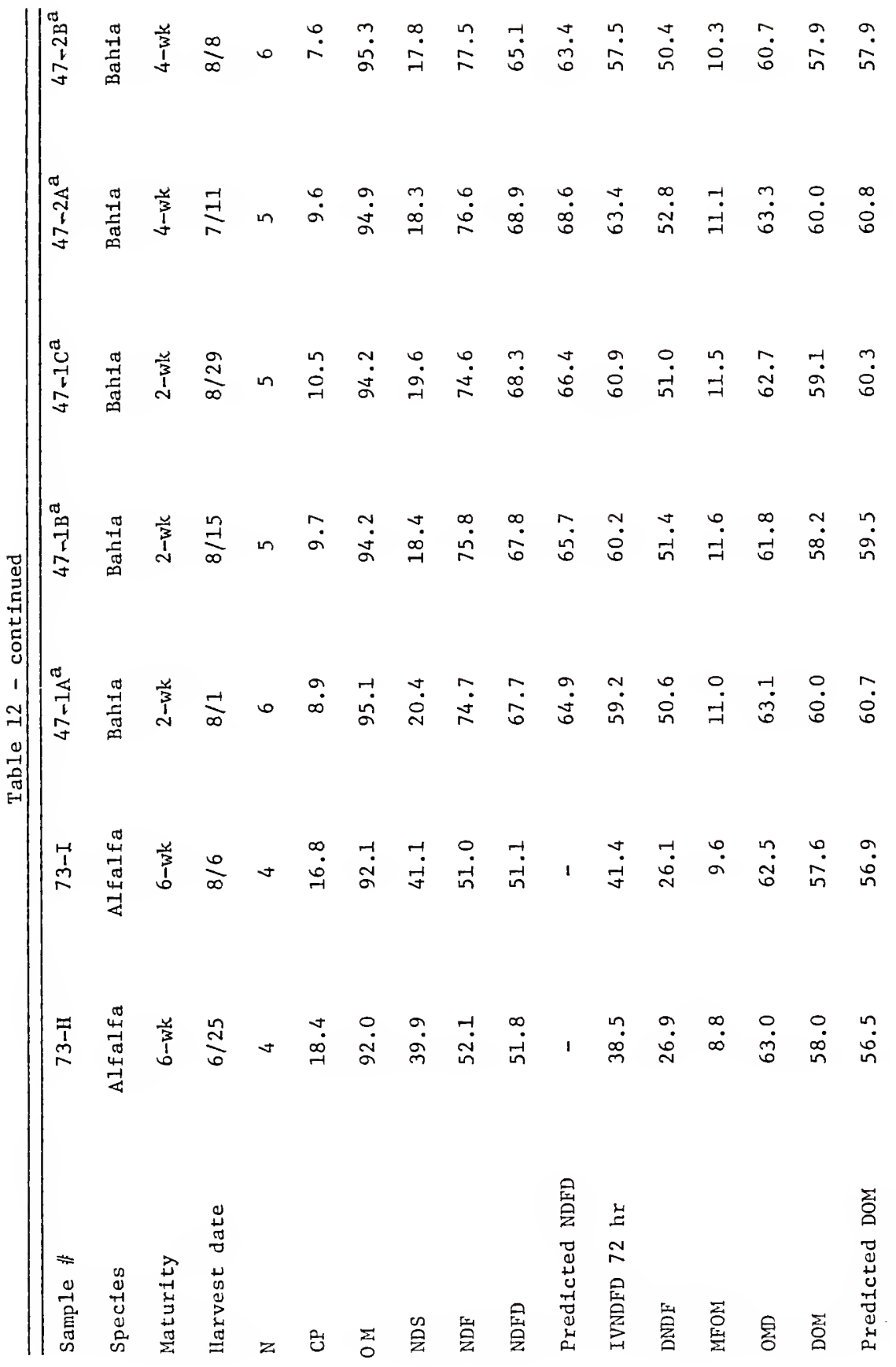




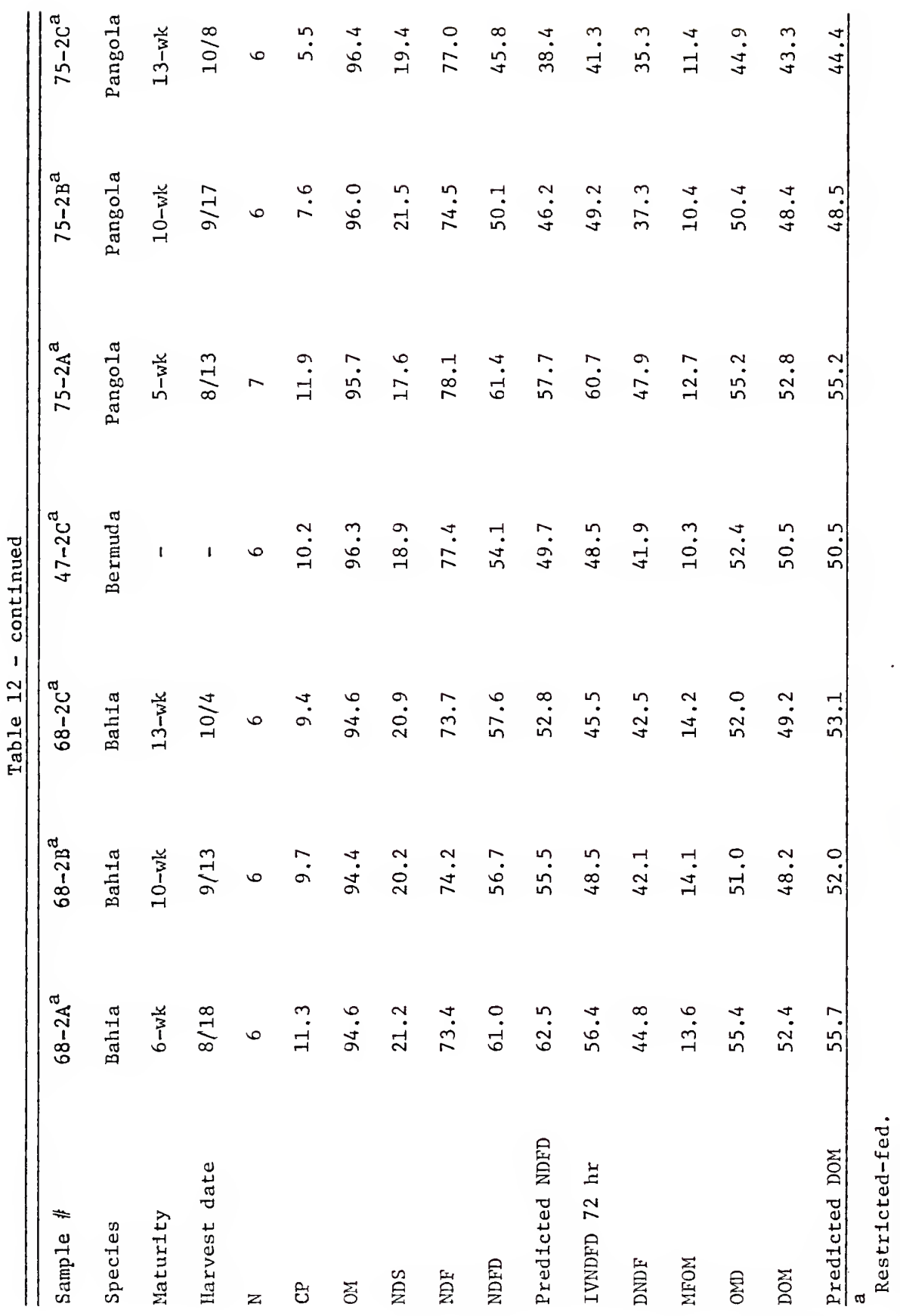


TABLE 13. ALGEBRAIC MANIPULATIONS OF EQUATION 9 REQUIRED TO PRODUCE EQUATION 10 (CHAPTER V)

$$
\begin{aligned}
& \frac{1}{24\left(k_{1}+k_{2}\right)}\left(O M D_{p}\right)(O M I) \\
& a=\frac{1}{\frac{1}{24\left(k_{1}+k_{2}\right)}\left(O M D_{p}\right)(O M I)+\frac{1}{24 k_{2}}\left(100-O D_{p}\right)(O M I)}= \\
& \frac{\frac{{ }^{O M D}}{24\left(k_{1}+k_{2}\right)}}{\frac{{ }^{O M D}{ }_{p}}{24\left(k_{1}+k_{2}\right)}+\frac{\left(100-O M D_{p}\right)}{24 k_{2}}}= \\
& \frac{O M D}{24\left(k_{1}+k_{2}\right)} \\
& \frac{24 \mathrm{k}_{2}\left(\mathrm{OMD} \mathrm{p}_{\mathrm{p}}\right)+24\left(\mathrm{k}_{1}+\mathrm{k}_{2}\right)\left(100-O \mathrm{ND}_{\mathrm{p}}\right)}{(24)(24)\left(\mathrm{k}_{1}+\mathrm{k}_{2}\right)\left(\mathrm{k}_{2}\right)}= \\
& \mathrm{OMD}_{\mathrm{p}}(24)(24)\left(\mathrm{k}_{1}+\mathrm{k}_{2}\right)\left(\mathrm{k}_{2}\right) \\
& {\left[24\left(k_{1}+k_{2}\right)\right]\left[24\left(k_{2}\right)\left(O M D_{p}\right)+24\left(k_{1}+k_{2}\right)\left(100-O M D_{p}\right)\right]} \\
& \mathrm{OMD}_{\mathrm{p}}\left(\mathrm{k}_{1}+\mathrm{k}_{2}\right)\left(\mathrm{k}_{2}\right) \\
& \left(k_{1}+k_{2}\right)\left[\left(k_{2}\right)\left(O M D_{p}\right)+\left(k_{1}+k_{2}\right)\left(100-O M D_{p}\right)\right] \\
& \frac{\left(k_{2}\right)\left(O M D_{p}\right)}{\left[\left(k_{2}\right)\left(O M D_{p}\right)\right]+\left[\left(k_{1}+k_{2}\right)\left(100-O M D_{p}\right)\right]}=a
\end{aligned}
$$




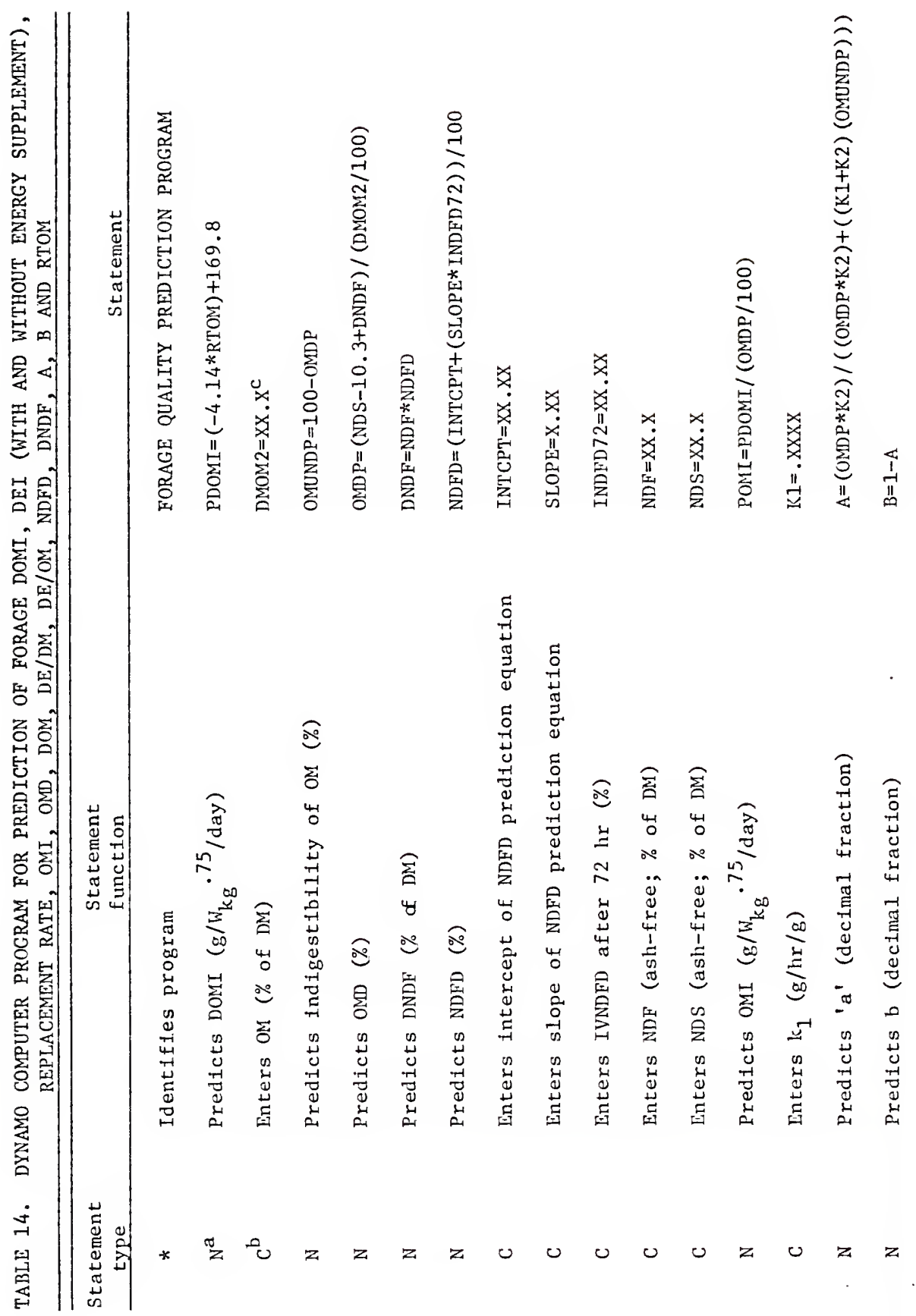




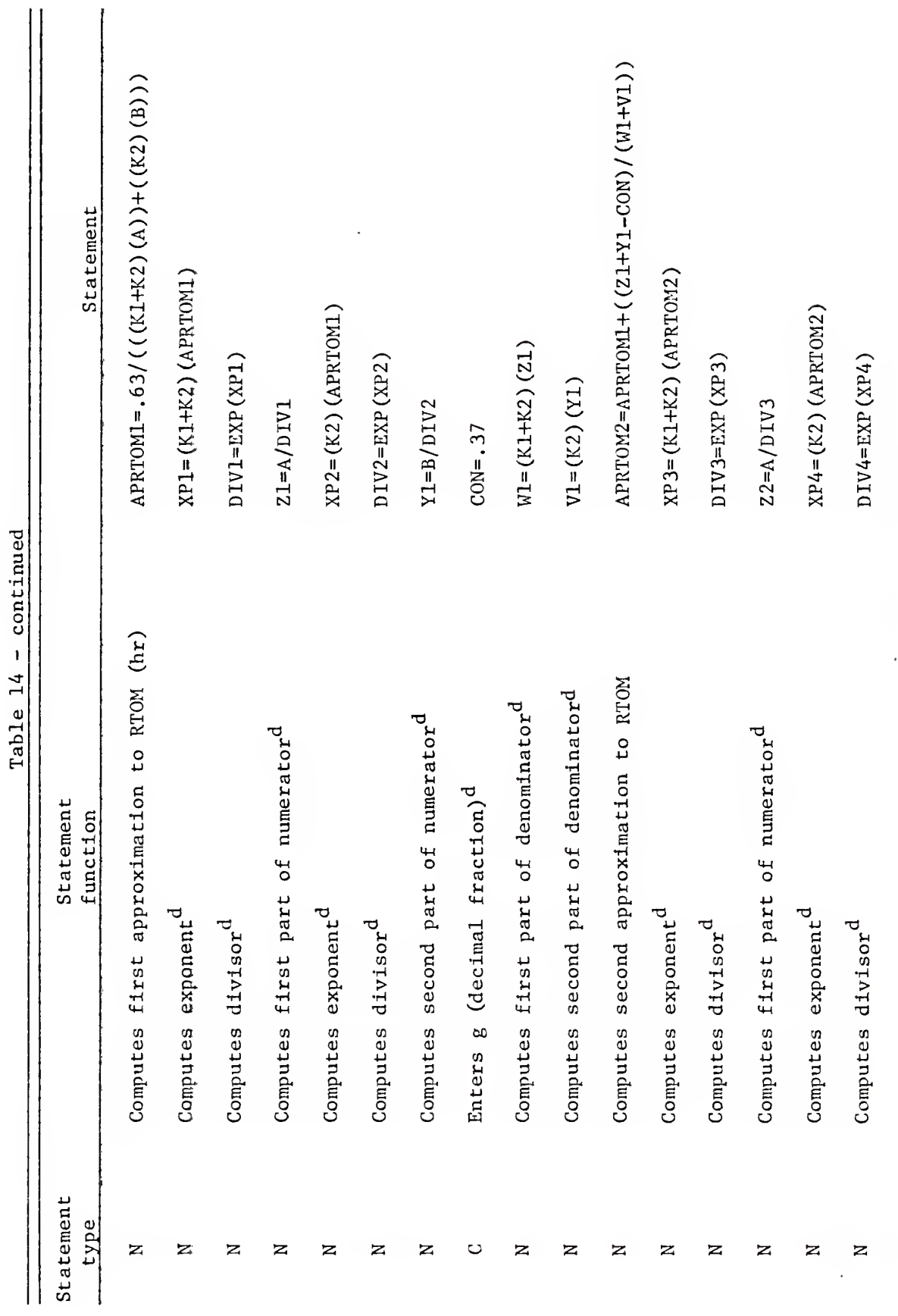




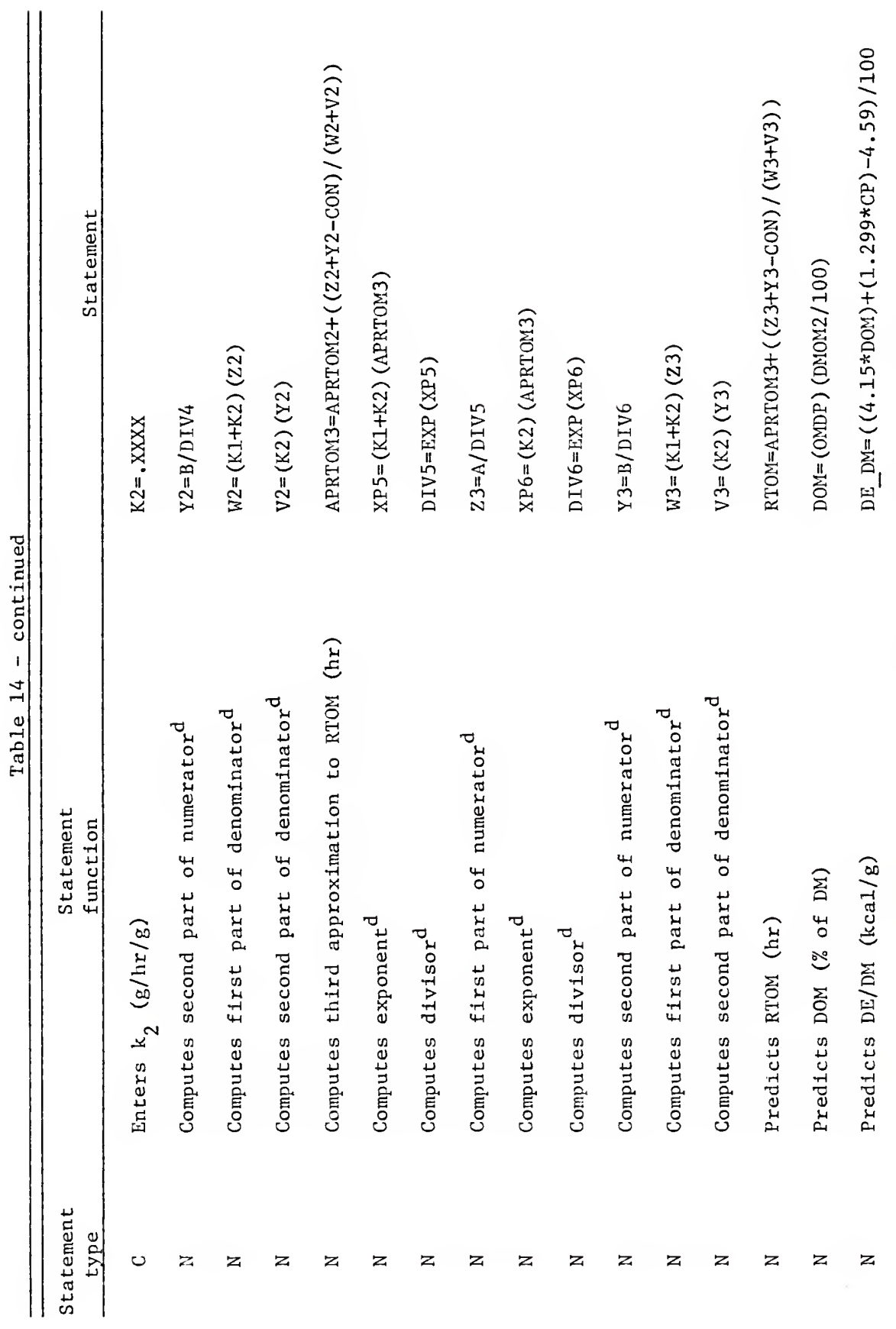




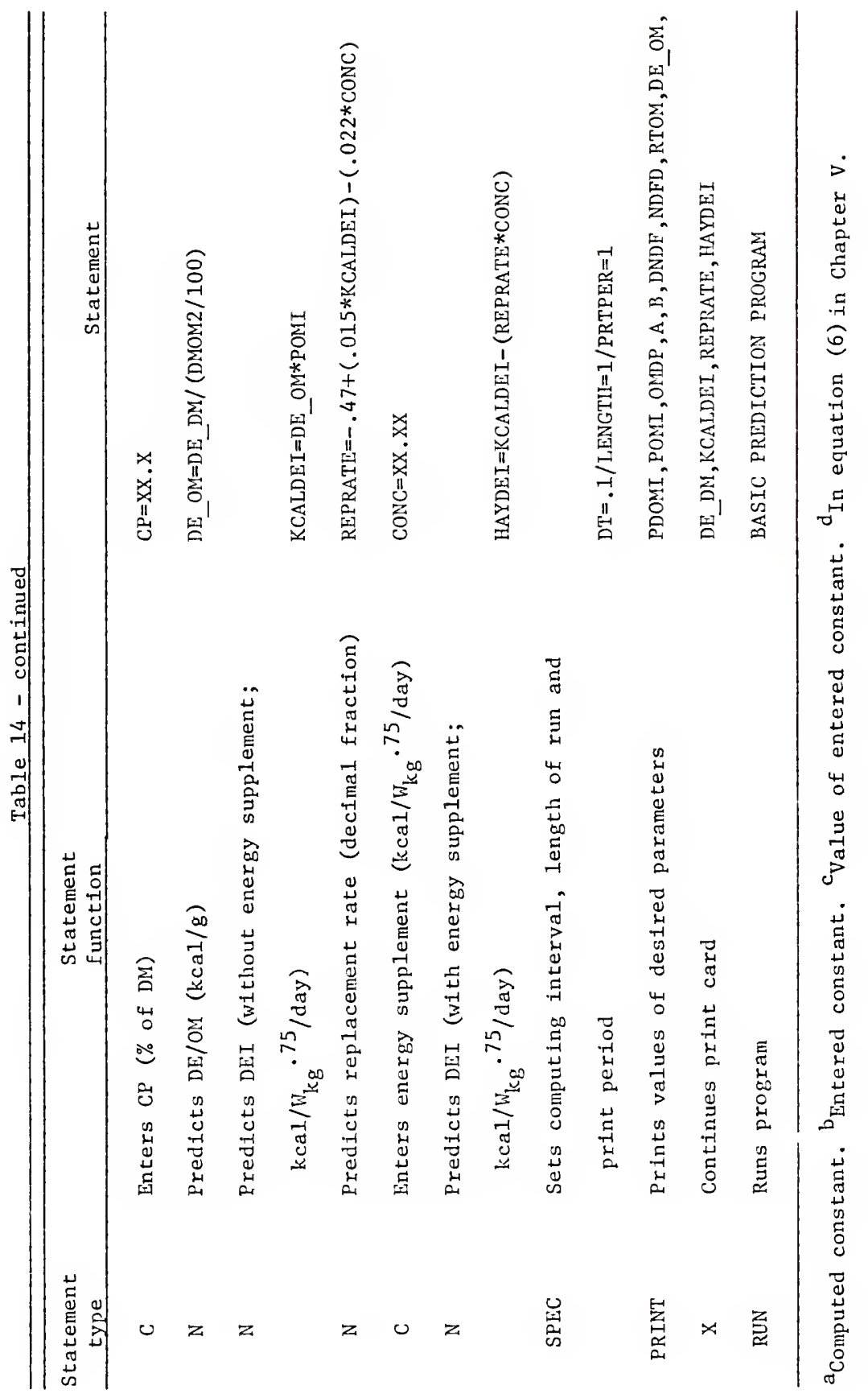




\section{LITERATURE CITED}

Akin, D. E. and D. Burdick. 1973. Nicroanatomical differences of warm-season grasses revealed by light and electron microscopy. Agron. J. 65:533.

Akin, D. E., H. E. Amos, F. E. Barton, II, and D. Burdick. 1973. Rumen microbial degradation of grass tissue revealed by scanning electron microscopy. Agron. J. 65:825.

Akin, D. E., D. Burdick and H. E. Amos. 1974a. Comparative degradation of Coastal bermudagrass, Coastcross -1 bermudagrass, and Pensacola bahiagrass by rumen microorganisms revealed by scanning electron nicroscopy. Crop. Sci. 14:537.

Akin, D. E., D. Burdick and G. E. Michaels. 1974b. Rumen bacterial interrelationships with plant tissue during degradation revealed by transmission electron microscopy. Applied Microbiology. 27:1149.

Alexander, C. L., E. E. Bartley and R. M. Meyer. 1969. Incorporation of ${ }^{14} \mathrm{C}$ from labeled alfalfa in rumen bacterial and volatile fatty acid carbon and rumen removal rate of fiber and soluble fractions. J. Anim. Sci. 29:948.

Alexander, R. A., J. F. Hentges, Jr., J. T. McCall and W. 0. Ash. 1962. Comparative digestibility of nutrients in roughages by cattle and sheep. J. Anim. Sci. 21:373.

Ammerman, C. B., G. J. Verde, J. E. Moore, W. C. Burns and C. F. Chicco. 1972. Biuret, urea and natural proteins as nitrogen supplements for low-quality roughage for sheep. J. Anim. Sci. 35:121.

Anderson, J. R. 1972. Economic models and agricultural production systems. Proc. Aust. Soc. Anim. Prod. 9:77.

A.O.A.C. 1970. Official Methods of Analysis (11th edition). Association of Official Analytical Chemists. Washington, D.C.

Armstrong, D. G. 1964. Evaluation of artificially dried grass as a source of energy for sheep. II. The energy value of cocksfoot, timothy, and two strains of rye-grass at varying stages of maturity. J. Agr. Sci. 62:399.

Armstrong, D. G., K. L. Blaxter and R. Waite. 1964. The evaluation of artificially dried grass as a source of energy for sheep. III. The prediction of nutritive value from chemical and biological measurements. J. Agr. Sci. 62:417. 
Arnold, G. W. and M. L. Dudzinski. 1966. Studies on the diet of the grazing animal. II. The effect of physiological status in ewes and pasture availability on herbage intake. Aust. J. Agr. Res. $18: 349$.

Ashton, G. C. 1962. Comparative nitrogen digestibility in Brahman, Brahman $x$ Shorthorn, Africander $x$ Hereford and Hereford steers. J. Agr. Sci. 58:333.

Asplund, J. M., H. B. Hedrick and C. D. Haugebak. 1975. Performance, digestibility and $40_{\mathrm{K}}$ levels in lambs during compensation for feed restriction. J. Anim. Sci. 40:138.

Baile, C. A. 1968. Regulation of feed intake in ruminants. Fed. Proc. $27: 1361$.

Bailey, C. B. 1964. Effect of environmental temperature on feed digestion, water metabolism, body temperature, and certain blood characteristics of sheep. Can. J. Anim. Sci. 44:68.

Baldwin, R. L. and N. E. Smith. 197la. Application of a simulation modeling technique in analyses of dynamic aspects of animal energetics. Fed. Proc. 30:1459.

Baldwin, R. L. and N. E. Smith. 1971b. Intermediary aspects and tissue interactions of ruminant fat metabolism. J. Dairy Sci. $54: 583$.

Baldwin, R. L., H. L. Lucas and R. Cabera. 1970. Energetic relationships in the formation and utilization of fermentation end-products. In: Physiology of Digestion and Metabolism in the Ruminant. A. T. Phillipson (Ed.). Oriel Press. Newcastle upon Tyne, England.

Barnes, R. F. 1973. Laboratory methods of evaluating feeding value of herbage. In: Chemistry and Biochemistry of Herbage (Vol. 3). G. W. Butler and R. W. Bailey (Eds.). Academic Press. New York.

Bell, F. R. 1961. Some observations on the physiology of rumination. In: Digestive Physiology and Nutrition of the Ruminant. D. Lewis (Ed.). Butterworths. London.

Bhattacharya, A. N. and M. Uwayjan. 1975. Effect of high ambient temperature and low humidity on nutrient utilization and on some physiological responses in Awasi sheep fed different levels of roughage. J. Anim. Sci. 40:320.

Bines, J. A., S. Suzuki and C. C. Balch. 1969. The quantitative significance of long-term regulation of feed intake in the cow. $\mathrm{Br}$. J. Nutr. 23:695.

Bisschoff, W. V. A., L. R. Quinn, G. O. Mott and G. L. da Rocha. 1967. Supplemental feeding of steers on pasture with proteinenergy supplements. Pesquisa Agropecuaria Brasileira. Vol. II. 
Blaxter, K. L. 1962. The Energy Metabolism of Ruminants.

Charles C. Thomas. Springfield, Illinois.

Blaxter, K. L. and N. McC. Graham. 1956. The effect of the grinding and cubing process on the utilization of the energy of dried grass. J. Agr. Sci. 47:207.

Blaxter, K. L. and F. W. Wainman. 1961. Environmental temperature and the energy metabolism and heat emission of steers. J. Agr. Sci. 56:81.

Blaxter, K. L. and R. S. Wilson. 1963. The assessment of a crop husbandry technique in terms of animal production. Anim. Prod. $5: 27$.

Blaxter, K. L., N. McC. Graham and F. W. Wainman. 1956. Some observations on the digestibility of food by sheep, and on related problems. Br. J. Nutr. 10:69.

Blaxter, K. L., F. W. Wainman and J. L. Davidson. 1966. The voluntary intake of food by sheep and cattle in relation to their energy requirements for maintenance. Anim. Prod. 8:75.

Blaxter, K. L., F. W. Wainman and R. S. Wilson. 1961. The regulation of food intake by sheep. Anim. Prod. 3:51.

Blaxter, K. L., N. P. Reineke, E. W. Crampton and W. E. Peterson. 1949. The role of thyroidal materials and of synthetic goitrogens in animal production and an appraisal of their practical use. J. Anim. Sci. 8:307.

Blincoe, C. 1975. Computer simulation of iodine metabolism by mammals. J. Anim. Sci. 40:342.

Brandt, C. S. and E. J. Thacker. 1958. A concept of rate of food passage through the gastro-intestinal tract. J. Anim. Sci. 17:218.

Bravo, B. F. 1973. Beef Production Systems: A Simulation Approach. Ph. D. Dissertation. University of New England. Armidale, N. S. W., Australia.

Brobeck, J. R. 1960. Food and temperature. Recent Progress in Hormone Res. $16: 439$.

Brown, L. D. 1966. Influence of intake on feed utilization. J. Dairy Sci. 49:223.

Buchman, D. T. and R. W. Hemken. 1964. Ad libitum intake and digestibility of several alfalfa hays by cattle and sheep. J. Dairy Sci. $47: 861$.

Burroughs, W., P. Gerlaugh and R. M. Bethke. 1948. Influence of alfalfa ash and water extract of alfalfa upon roughage digestion in cattle. J. Anim. Sci. 7:522. 
Burroughs, W., P. Gerlaugh, B. H. Edington and R. M. Bethke. 1949. The influence of corn starch upon roughage digestion in cattle. J. Anim. Sci. 8:271.

Butterworth, M. H. 1964. The digestible energy content of some tropical forages. J. Agr. Sci. 63:319.

Butterworth, M. H. and J. A. Diaz L. 1970. Use of equations to predict the nutritive value of tropical grasses. J. Range Mgt. 23:55.

Campling, R. C. 1964. Factors affecting the voluntary intake of grass. Proc. Nutr. Soc. 23:80.

Campling, R. C. 1965. The voluntary intake of conserved grass by cattle. Proc. 9th Int. Grass1. Congr. p. 903.

Campling, R. C. 1966. The effect of concentrates on the rate of disappearance of digesta from the alimentary tract of cows given hay. J. Dairy Res. 33:13.

Campling, R. C. 1970. Physical regulation of voluntary intake. In: Physiology of Digestion and Metabolism in the Ruminant. A. T. Phillipson (Ed.). Oriel Press. Newcastle upon Tyne, England.

Campling, R. C. and C. C. Balch. 1961. Factors affecting the voluntary intake of food by cows. 1. Preliminary observations on the effect, on the voluntary intake of hay, of changes in the amount of the reticulo-ruminal contents. Br. J. Nutr. 15:523.

Campling, R. C. and M. Freer. 1966. Factors affecting the voluntary intake of food by cows. 8. Experiments with ground, pelleted roughages. Br. J. Nutr. 20:229.

Campling, R. C., M. Freer and C. C. Balch. 1961. Factors affecting the voluntary intake of food by cows. 2. The relationship between the voluntary intake of roughages, the amount of digesta in the reticulo-rumen and the rate of disappearance of digesta from the alimentary tract. Br. J. Nutr, 15:531.

Campling, R. C., M. Freer and C. C. Balch. 1962. Factors affecting the voluntary intake of food by cows. 3. The effect of urea on the voluntary intake of oat straw. Br. J. Nutr. 16:115.

Campling, R. C., M. Freer and C. C. Balch. 1963. Factors affecting the voluntary intake of food by cows. 6 . A preliminary experiment with ground, pelleted hay. Br. J. Nutr. 17:263.

Capote, F. A. 1975. Voluntary Intake as Affected by Age and Size of Sheep and Quality of Forage. Ph. D. Dissertation. University of Florida. Gainesville, Florida. 
Chapman, H. L., Jr. and A. E. Kretschemer, Jr. 1964. Effect of nitrogen fertilization on digestibility and feeding value of Pangolagrass hay. Proc. Soil and Crop Sci. Soc. F1a. 24:176.

Chenost, M. 1966. Fibrousness of forages: Its determination and its relation to feeding value. Proc. 10th Int. Grass1. Congr. p. 406.

Chicco, C. F., C. B. Ammerman and P. E. Loggins. 1973. Effect of age and dietary magnesium on voluntary feed intake and plasma magnesium in ruminants. J. Dairy Sci. 56:822.

Christian, K. R., J. S. Armstrong, J. R. Donne11y, J. L. Davidson and M. Freer. 1972. Optimization of a grazing management system. Proc. Aust. Soc. Anim. Prod. 9:124.

Church, D. C. 1969. Digestive Physiology and Nutrition of Ruminants (Vol. 1). Oregon State University Press. Corvallis, Oregon.

Cipolloni, M. A., B. H. Schneider, H. L. Lucas and H. M. Pavlech. 1951. Significance of the differences in digestibility of feeds by cattle and sheep. J. Anim. Sci. 10:337.

Clanton, D. C. and L. R. Rittenhouse. 1970. Protein-energy relationships in range supplements. Proc. Nat'1. Confr. on Forage Qual. Eval. and Util. Paper "G".

Clark, R. and J. I. Quin. 1951. Studies on the alimentary tract of the Merino sheep in South Africa. XXIII. The effect of supplementing poor quality grass hay with molasses and nitrogenous salts. Onderstepoort J. Vet. Res. 25:93.

Colburn, M. W., J. L. Evans and C. H. Ramage. 1968. Apparent and true digestibility of forage nutrients by ruminant animals. J. Dairy Sci. $51: 1450$.

Comline, R. S. and D. A. Titchen. 1961. Nervous control of the ruminant stomach. In: Digestive Physiology and Nutrition of the Ruminant. D. Lewis (Ed.). Butterworths. London.

Conrad, H. R. 1966. Symposium on factors influencing the voluntary intake of herbage by ruminants: Physiological and physical factors limiting feed intake. J. Anim. Sci. 25:227.

Conrad, H. R., A. D. Pratt and J. W. Hibbs. 1964. Regulation of feed intake in dairy cows. I. Change in importance of physical and physiological factors with increasing digestibility. J. Dairy Sci. $47: 54$.

Coombe, J. B. and D. E. Tribe. 1963. The effects of urea supplements on utilization of straw plus molasses by sheep. Aust. J. Agr. Res. 14:70. 
Crampton, E. W. 1957. Interrelations between digestible nutrient and energy content, voluntary dry matter intake, and the overall feeding value of forages. J. Anim. Sci. 16:546.

Crampton, E. W., E. Donefer and L. E. Lloyd. 1960. A nutritive value index for forages. J. Anim. Sci. 19:538.

Deinum, B. and P. J. Van Soest. 1969. Prediction of forage digestibility from some laboratory procedures. Neth. J. Agr. Sci. 17:119.

de la Torre, R. A. 1974. Micro-histological Characteristics of Three Warm-season Grasses in Relation to Forage Quality. Ph. D. Dissertation. University of Florida. Gainesville, Florida.

de la Torre, R., J. E. Moore and M. M. Griffith. 1974. Digestion of tissues in warm-season grasses. J. Anim. Sci. 39:195. (Abstr.).

Demarquilly, C. and F. Jarrige. 1970. The effect of method of forage conservation on digestibility and voluntary intake. Proc. 11th Int. Grass1. Congr. p. 733.

Demarquilly, C., J. M. Boissaee and G. Cuylle. 1965. Factors affecting the voluntary intake of green forage by sheep. Proc. 9 th Int. Grass1. Congr. p. 877.

Dewar, A. D. 1962. The nature of the weight gain induced by progesterone in mice. Acta Endocrinol. Suppl. 67:112.

Donefer, E., E. W. Crampton and L. E. Lloyd. 1960. Prediction of the nutritive value index of a forage from in vitro rumen fermentation data. J. Anim. Sci. 19:545.

Donnelly, J. R., A. Axelsen and F. H. W. Morley. 1970. Effect of flock size and grazing management on sheep production. Aust. J. Exp. Agr. Anim. Husb. 10:271.

Duncan, D. B. 1955. Multiple range and multiple F-tests. Biometrics. $11: 1$.

Egan, A. R. 1965. Nutritional status and intake regulation in sheep. II. The influence of sustained duodenal infusions of casein or urea upon voluntary intake of low-protein roughages by sheep. Aust. J. Agr. Res. 16:451.

Egan, A. R. 1970. Nutritional status and intake regulation in sheep. IV. Evidence of variation of setting in an intake regulatory mechanism, relating to digesta content of the reticulorumen. Aust. J. Agr. Res. 21:735.

Elliott, R. C. 1967. Voluntary intake of low-protein diets by ruminants. I. Intake of food by cattle. J. Agr. Sci., Camb. 69:375. 
Elliott, R. C. and J. H. Topps. 1960. Voluntary intake of low protein diets by sheep. Proc. 8th Int. Grassl. Congr. p. 269.

Elliott, R. C., K. Fokkema and C. H. French. 1961. Herbage consumption studies by beef cattle. Rhodesia Agr. J. 58:124.

el-Shazley, K., B. A. Dehority and R. R. Johnson. 1961. Effect of starch on the digestion of cellulose in vitro and in vivo by rumen microorganisms. J. Anim. Sci. 20:268.

Eng, K. S., Jr., M. E. Riewe, J. H. Craig, Jr. and J. C. Smith. 1964. Rate of passage of concentrate and roughage through the digestive tract of sheep. J. Anim. Sci. 23:1129.

Essig, H. W., R. L. Moore and L. J. Smithson. 1974. Influence of breeds of beef cattle on ration utilization. J. Anim. Sci. 40:192. (Abstr.).

Fick, K. R., C. B. Ammerman, C. H. McGowan, P. E. Loggins and J. A. Cornell. 1973. Influence of supplemental energy and biuret nitrogen on the utilization of low quality roughage by sheep. J. Anim. Sci. 36:137.

Foot, J. 2. 1972. A note on the effect of body condition on the voluntary intake of dried grass wafers by Scottish blackface ewes. Anim. Prod. 14:131.

Forrester, J. W. 1968. Principles of Systems. Wright-Allen Press, Inc. Cambridge, Massachusetts.

French, M. H. 1956. The importance of water in the management of cattle. E. African Agr. J. 21:171.

Fruton, J. S. and S. Simmonds. 1958. General Biochemistry (2nd edition). John Wiley and Sons, Inc. New York.

Gill, S. S., H. R. Conrad and J. W. Hibbs. 1969. Relative rate of in vitro cellulose disappearance as a possible estimator of digestible dry matter intake. J. Dairy Sci. 52:1687.

Glover, J. and H. W. Dougall. 1960. The apparent digestibility of the non-nitrogenous components of ruminant feeds. J. Agr. Sci. $55: 391$.

Glover, J., D. W. Duthie and H. W. Dougall. 1960. The total digestible nutrients and gross digestible energy of ruminant feeds. J. Agr. Sci. 55:403.

Goering, H. K. and P. J. Van Soest. 1970. Forage fiber analyses (apparatus, reagents, procedures, and some applications). A. R. S. - U. S. D. A. Ag. Handbook No. 379. p. 14. 
Golding, E. J. 1973. Formulation of Hay: Grain Diets Based on Predicted Qualities of Four Bermudagrass Hays for Ruminants. M. S. Thesis. University of Florida. Gainesville, Florida.

Graham, N. McC. 1967. The net energy value of three subtropical forages. Aust. J. Agr. Res. 18:137.

Graham, N. McC. and A. J. Williams. 1962. The effects of pregnancy on the passage of food through the digestive tract of sheep. Aust. J. Agr. Res. 13:894.

Greenhalgh, J. F. D. and G. W. Reid, 1973. The effect of pelleting various diets on intake and digestibility in sheep and cattle. Anim. Prod. 16:223.

Harris, L. E., L. C. Kearl and P. V. Fonnesbeck. 1972. Use of regression equations in predicting availability of energy and protein. J. Anim. Sci. 35:658.

Harvey, W. R. 1960. Least-squares analysis of data with unequal subclass numbers. U.S.D.A. Pub. A. R. S. 20-8.

Heaney, D. P. 1970. Voluntary intake as a component of an index to forage quality. Proc. Nat'1. Confr. on Forage Qual. Eval. and Util. Paper "C".

Heaney, D. P., G. I. Pritchard and W. J. Pigden. 1968. Variability in ad libitum forage intakes by sheep. J. Anim. Sci. 27:159.

Hershberger, T. V., T. A. Long, E. W. Hartsook and R. W. Swift. 1959. Use of the artificial rumen technique to estimate the nutritive value of forages. J. Anim. Sci. 18:770.

Hervey, G. R. and E. H. Hervey. 1964. Effects of progesterone on food intake and body composition. J. Endocrinol. 30:vii.

Holmes, J. H. G., M. C. Franklin and L. J. Lambourne. 1966. The effects of season, supplementation, and pelleting on intake and utilization of some sub-tropical pastures. Proc. Aust. Soc. Anim. Prod. 6:354.

Holter, J. A. and J. T. Reid. 1959. Relationship between the concentration of crude protein and apparently digestible protein in forages. J. Anim. Sci. 18:1339.

Houser, R. H. 1970. Physiological Effects of Supplemental Nitrogen and Energy in Sheep Fed Low-quality Roughage. Ph. D. Dissertation. University of Florida. Gainesville, Florida.

Hungate, R. E. 1966. The Rumen and Its Microbes. Academic Press. New York. 
Hungate, R. E., G. D. Phillips, D. P. Hungate and A. MacGregor. 1960. A comparison of the rumen fermentation in European and Zebu cattle. J. Agr. Sci. 54:196.

Hutton, J. B. 1963. The effect of lactation on intake in the dairy cow. Proc. N. Z. Soc. Anim. Prod. 23:39.

Ingalls, J. R., J. W. Thomas, M. B. Tesar and D. L. Carpenter. 1966. Relations between ad libitum intake of several forage species and gut fill. J. Anim. Sci. 25:283.

Joandet, G. E. 1967. Growth Patterns and Efficiency of TDN Utilization in Beef Cattle. Ph. D. Dissertation. Texas A\& M University. College Station, Texas.

Joandet, G. E. and T. C. Cartwright. 1975. Modeling beef production systems. J. Anim. Sci. 41:1238.

Johnson, R. R. and B. A. Dehority. 1968. A comparison of several laboratory techniques to predict digestibility and intake of forages. J. Anim. Sci. 27:1738.

Johnson, R. R., B. A. Dehority, H. R. Conrad and R. R. Davis. 1962a. Relationship of in vitro cellulose digestibility of undried and dried mixed forages to their in vivo dry matter digestibility. J. Dairy Sci. 45:250.

Johnson, R. R., B. A. Dehority, J. L. Parsons and H. W. Scott. 1962 b. Discrepancies between grasses and alfalfa when estimating nutritive value from in vitro cellulose digestibility by rumen microorganisms. J. Anim. Sci. 21:892.

Johnson, R. R., G. E. Ricketts,E. W. Klosterman and A. L. Moxon. 1964. Studies on the utilization and digestion of long, ground and pelleted alfalfa and mixed hay. J. Anim. Sci. 23:94.

Jones, D. I. H. 1972. The chemistry of grass for animal production. Outlook on Agriculture. $7: 32$.

Jones, D. I. H. and R. W. Bailey. 1974. Hydrolysis of the cell-wall carbohydrates of grasses by carbohydrases in relation to voluntary intake by sheep. J. Agr. Sci. 83:105.

Jones, G. M., R. E. Larsen, A. H. Javed, E. Donefer and J. M. Caudreau. 1972. Voluntary intake and nutrient digestibility of forages by goats and sheep. J. Anim. Sci. 34:830.

Jones, J. G. W. 1969. Lamb production. In: Use of Models in Agricultural and Biological Research. J. G. W. Jones (Ed.). G. R. I. Hurley, Berks, England. 
Kappel, L. C., F. G. Hambry, P. E. Humes, P. E. Schilling and R. H. Klett. 1972. Climatic, breed and ration effects on feedlot performance and carcass characteristics of steers. J. Anim. Sci. $35: 591$.

Karn, J. F., R. R. Johnson and B. A. Dehority. 1967. Rates of in vitro cellulose and dry matter digestion at 5, 8 and 11 hours as predictors of forage nutritive value. J. Anim. Sci. 26:381.

Kay, R. N. B. 1963. Reviews of the progress of dairy science. Section A. Physiology. Part 1 . The physiology of the rumen. J. Dairy Res. 30:261.

Koes, R. M. and W. H. Pfander. 1975. Heat load and supplement effects on performance and nutrient utilization by lambs fed orchard-grass hay. J. Anim. Sci. 40:313.

Laredo, M. A. and D. J. Minson. 1973. The voluntary intake, digestibility, and retention time by sheep of leaf and stem fractions of five grasses. Aust. J. Agr. Res. 24:875.

Laredo, M. A. and D. J. Minson. 1975. The effect of pelleting on the voluntary intake and digestibility of leaf and stem fractions of three grasses. Br. J. Nutr. 33:159.

Lechtenberg, V. L., V. F. Colenbrander, L. F. Bauman and C. L. Rhykerd. 1974. Effect of lignin on rate of in vitro cell wall and cellulose disappearance in corn. J. Anim. Sci. 39:1165.

Ledger, H. P., A. Rogerson and G. H. Freeman. 1970. Further studies on the voluntary food intake of Bos indicus, Bos taurus and crossbred cattle. Anim. Prod. 12:425.

Leek, B. F. 1969. Reticulo-ruminal mechanoreceptors in sheep. J. Physiol. 202:585.

Lourens, M. J. 1968. Supplementation of natural veld. Farming in South Africa. 44:45.

Lucas, H. L., Jr. and W. W. G. Smart. 1959. Chemical composition and the digestibility of forages. Rep. 16th S. Pasture Forage Crop. Improve. Conf. (State College, Mississippi). p. 23.

Marsh, R. 1974. The performance of early-weaned calves offered concentrates or artificially dried grasses. Anim. Prod. 18:201.

Maynard, L. A. and J. K. Loosli. 1969. Animal Nutrition (6th edition). McGraw-Hill, Inc. New York.

McLeod, M. N. and D. J. Minson. 1974a. Differences in carbohydrate fractions between Lolium perenne and two tropical grasses of similar dry-matter digestibility. J. Agr. Sci. 82:449. 
McLeod, M. N. and D. J. Minson. 1974b. Predicting organic-matter digestibility from in vivo and in vitro determinations of dry-matter digestibility. J. Br. Grassl. Soc. 29:17.

Meites, S., R. C. Bunell and T. S. Sutton. 1951. Factors influencing the in vitro digestion of cellulose by rumen liquor in the presence of an antiseptic. J. Anim. Sci. 10:203.

Mendenhal1, W. 1971. Introduction to Probability and Statistics (3rd edition). Duxbury Press. Belmont, California.

Meyer, $\mathrm{R}_{14}$ M., C. L. Alexander and E. E. Bartley. 1967. Incorporation of ${ }^{14} \mathrm{C}$ from labeled alfalfa into rumen bacterial and volatile fatty acid carbon and its rate of rumen removal and appearance in feces. Report on Conference on Rumen Function. Chicago, Illinois.

Milford, R. 1967. Nutritive values and chemical composition of seven tropical legumes and lucerne grown in subtropical southeastern Queensland. Aust. J. Exp. Agr. and Anim. Husb. 7:540.

Milford, R, and D. J. Minson. 1965a. Intake of tropical pasture species. Proc. 9th Int. Grass1. Congr. p. 815.

Milford, R. and D. J. Minson. 1965b. The relation between the crude protein content and the digestible crude protein content of tropical pasture plants. J. Br. Grass1. Soc. 20:177.

Milford, R. and D. J. Minson. 1968. The effect of age and method of haymaking on the digestibility and voluntary intake of the forage legumes Dolichos $1 \mathrm{ablab}$ and Vigna sinensis. Aust. J. Exp. Agr. and Anin. Husb. 8:409.

Miller, W. J., D. M. Blackmon, G. W. Powell, R. P. Gentry and J. M. Hiers. 1966. Effects of zinc deficiencyper se and of dietary zinc level on urinary and endogenous fecal excretion of $65 \mathrm{Zn}$ from a single intravenous dose by ruminants. J. Nutr. 90:335.

Minson, D. J. 1966. The apparent retention of food in the reticulorumen at two levels of feeding by means of an hourly feeding technique. Br. J. Nutr. 20:765.

Minson, D. J. 1967. The voluntary intake and digestibility, in sheep, of chopped and pelleted Digitaria decumbens (pangola grass) following a late application of fertilizer nitrogen. Br. J. Nutr. 21:587.

Minson, D. J. 1968. Quality. Proc. Aust. Grassl. Confr. p. 25.

Minson, D. J. 1971a. The nutritive value of tropical pastures. J. Aust. Inst. Agr. Sci. 37:225. 
Minson, D. J.. 1971b. Influence of lignin and silicon on a summative system for assessing the organic matter digestibility of Panicum. Aust. J. Agr. Res. 22:589.

Minson, D. J. and K. P. Haydock. 1971. The value of pepsin dry matter solubility for estimating the voluntary intake and digestibility of six Panicum varieties. Aust. J. Exp. Agr. and Anim. Husb. $11: 181$.

Minson, D. J. and R. Milford. 1966. The energy values and nutritive value indices of Digitaria decumbens, Sorghum almum, and Phaseolus atropurpureus. Aust. J. Agr. Res. 17: 411 .

Minson, D. J. and R. Milford. 1967a. In vitro and faecal nitrogen techniques for predicting the voluntary intake of Chloris gayana. J. Br. Grass1. Soc. 22:170.

Minson, D. J. and R. Milford. 1967b. The voluntary intake and digestibility of diets containing different proportions of legume and mature Pangola grass (Digitaria decumbens). Aust. J. Exp. Agr. and Anim. Husb.

Minson, D. J. and R. Milford. 1968. The nutritional value of four tropical grasses when fed as chaff and pellets to sheep. Aust. J. Exp. Agr. and Anim. Husb. 8:270.

Minson, D. J., C. E. Harris, W. F. Raymond and R. Milford. 1964. The digestibility and voluntary intake of S 22 and $\mathrm{H} .1$ ryegrass, S 170 tall fescue, S 48 timothy, S 215 meadow fescue and germinal cocksfoot. J. Br. Grass1. Soc. 19:298.

Moe, P. W., J. T. Reid and H. F. Tyrrell. 1965. Effect of level of intake on digestibility of dietary energy by high-producing cows. J. Dairy Sci. 48:1053.

Moir, K. W. 1972. An assessment of the quality of forage from its cell-wall content and amount of cell wall digested. J. Agr. Sci., Camb. $78: 355$.

Moir, R. J. 1961. A note on the relationship between the digestible dry matter and the digestible energy content of ruminant diets. Aust. J. Exp. Agr, and Anim. Husb. 1:24.

Monson, W. G., J. B. Powell and G. W. Burton. 1972. Digestion of fresh forage in rumen fluid. Agron. J. 64:231.

Montgomery, M. J. and B. R. Baumgardt. 1965a. Regulation of food intake in ruminants. 1. Pelleted rations varying in energy concentration. J. Dairy Sci. 48:569. 
Montgomery, M. J. and B. R. Baumgardt. 1965b. Regulation of food intake in ruminants. 2. Rations varying in energy concentration and physical form. J. Dairy Sci. 48:1623.

Moore, J. E. 1968. Factors influencing the nutritive value of forages for beef cattle. Paper presented at Seventeenth Annual Florida Beef Cattle Short Course. University of Florida. Gainesville, Florida.

Moore, J. E. and G. O. Mott. 1973. Structural inhibitors of quality in tropical grasses. In: Anti-quality Components of Forages. Crop Sci. Soc. America. Madison, Wisconsin. Special Publication No. 4. p. 53.

Moore, J. E. and G. O. Mott. 1974. Recovery of residual organic matter from in vitro digestion of forages. J. Dairy Sci. 57:1258.

Moore, J. E., O. C. Ruelke, C. E. Rios and D. E. Franke. 1970. Nutritive evaluation of Pensacola bahiagrass hays. Proc. Soil and Crop Sci. Soc. F1a. 30:211.

Morley, F. H. W. and C. R. W. Spedding. 1968. Agricultural systems and grazing experiments. Herbage Abstr. 38:279.

N. R. C. 1971. Atlas of Nutritional Data on United States and Canadian Feeds. N. R. C. - N. A. S. p. xvi.

O'Donovan, P. B., A. Conway and J. O'Shea. 1972. A study of the herbage intake and efficiency of feed utilization of grazing cattle previously fed two winter planes of nutrition. J. Agr. Sci. 78:87.

01tjen, R. R., T. S. Rumsey and P. A. Putnam. 1971. A11-forage diets for finishing beef cattle. J. Anim. Sci. 32:327.

Osbourn, D. F., D. J. Thomson and R. A. Terry. 1966. The relationship between voluntary intake and digestibility of forage crops, using sheep. Proc. 10th Int. Grassl. Congr. p. 363.

Osbourn, D. F., S. B. Camme11, R. A. Terry and G. E. Outen. 1970. The effect of chemical composition and physical characteristics of forage on their voluntary intake by sheep. Grassl. Res. Inst. AnnualReport. p. 67.

Paine, M. D., J. A. Witz, A. F. Butchbaker, C. M. Bacon and J. E. McCroskey. 1972. Mathematical simulation of energy metabolism in beef animals. Am. Soc. Agr. Engin. Paper 72-510.

Paltridge, G. W. 1972. Experiments on a mathematical model of a pasture. Agr. Meteorol. 10:39. 
Patil, B. D. and D. I. H. Jones. 1970. The mineral status of some temperate herbage varieties in relation to animal performance. Proc. 11th Int. Grass1. Congr. p. 726.

Patten, B. C. 1972. A simulation of the shortgrass prairie ecosystem. Simulation. 19:177.

Pfander, W. H. 1970. Forage intake and digestibility research... Now and When? Proc. Nat'1 Confr. on Forage Qual. Eval. and Util. Paper "H".

Phillips, G. D. 1961. Physiological comparisons of European and Zebu steers. I. Digestibility and retention times of food and rate of fermentation of rumen contents. Res. Vet. Sci. 2:202.

Phillips, G. D., R. E. Hungate, A. MacGregor and D. P. Hungate. 1960. Experiments on rumen retention time, fermentation rate and dry matter digestibility in Zebu and European-type cattle on a grass hay ration. J. Agr. Sci. 54:417.

Preston, R. I. and W. H. Pfander. 1964. Phosphorus metabolism in lambs fed varying phosphorus intakes. J. Nutr. 83:369.

Pugh, A. L., III. 1973. Dynamo II User's Manual ( 4 th edition). The MIT Press. Cambridge, Massachusetts.

Purser, D. B. and R. J. Moir. 1966. Rumen volume as a factor involved in individual sheep differences. J. Anim. Sci. 25:509.

Ragsdale, A. C., H. T. Thompson, D. M. Worstell and S. Brody. 1953. Environmental physiology and shelter engineering. XXI. The effect of humidity on milk production and composition, feed and water consumption, and body weight in cattle. Mo. Agr. Exp. Sta. Res. Bull. No. 521 .

Raymond, W. F. 1968. Components in the nutritive value of forages. In: Forage, Economics - Quality. Specia1 Pub. 13. Amer. Soc. Agron. Madison, Wisconsin. p. 47.

Rajmond, W. F. 1969. The nutritive value of forage crops. Adv. in Agron. $21: 1$.

Reid, R. L. and N. T. Hinks. 1962. Studies on the carbohydrate metabolism of sheep. XVII. Feed requirements and voluntary feed intake in late pregnancy, with particular reference to prevention of hypoglycaemia and hyperketonaemia. Aust. J. Agr. Res. 13:1092.

Riewe, M. E. and H. Lippke. 1970. Considerations in determining the digestibility of harvested forages. Proc. Nat'I. Confr. on Forage Qual. Eval. and Util. Paper "F". 
Rodrigue, C. B. and N. N. Allen. 1956. The effect of fine grinding of hay on the digestibility of its nutrients and rate of passage through the digestive tract. J. Dairy Sci. 39:937. (Abstr.).

Seoane, J. R., C. L. McLaughlin and C. A. Baile. 1975. Feeding following intrahypothalamic injections of calcium and magnesium ions in sheep. J. Dairy Sci. 58:349.

Shepperson, G. 1960. Effect of time of cutting and method of making on the feed value of hay. Proc. 8th Int. Grassl. Congr. p. 704.

Shumway, C. R., E. Bentley and E. R. Barrick. 1974. Economic analysis of beef production innovation: dairy-beef crossbreeding. North Carolina State University Economic Res. Rep. No. 26.

Siebert, B. D. and P. M. Kennedy. 1972. The utilization of spear grass (Heteropogon contortus). I. Factors limiting intake and utilization by cattle and sheep. Aust. J. Agr. Res. 23:35.

Smith, C. A. 1962. The utilization of Hyparrhenia veld for the nutrition of cattle in the dry season. III. Studies on the digestibility of the produce of mature veld and veld hay, and the effect of feeding supplementary protein and urea. J. Agr. Sci. $58: 173$.

Smith, L. W., H. K. Goering and C. H. Gordon. 1972. Relationships of forage compositions with rates of cell wall digestion and indigestibility of cell walls. J. Dairy Sci. 55:1140.

Smith, L. W., H. K, Goering, D. R. Waldo and C. H. Gordon. 1971. In vitro digestion rate of forage cell wall components. J. Dairy Sci. 54:71.

Smith, R. C. G. and W. A. Williams. 1973. Model development for a deferred grazing. J. Range Mgt. 26:454.

Snedecor, G. W. and G. W. Cochran. 1967. Statistical Methods (6th edition). Iowa State University Press. Ames, Iowa.

Tayler, J. C. 1959. A relationship between weight of internal fat, 'fill', and the herbage intake of grazing cattle. Nature. 184:2021.

Tayler, J. C. and J. M. Wilkinson. 1972. The influence of level of concentrate feeding on the voluntary intake of grass and on liveweight gain by cattle. Anim. Prod. 14:85.

Tayler, J. C., F. E. Alder and J. E. Rudman. 1957. Fill and carcass changes of yard-fed and outwintered beef cattle turned on to spring pasture. Nature. 179:197.

Telle, P. O., R. L. Preston, L. D. Kintner and W. H. Pfander. 1964. Definition of the ovine potassium requirement. J. Anim. Sci. 23:59. 
Terry, R. A., S. B. Cammell and D. F. Osbourn. 1972. Factors influencing the digestion of sugars, starches and the cell wall constituents in feeds. Grass1. Res. Inst. Annual Report. p. 88 .

Thomas, G. B., Jr. 1972. Calculus and Analytic Geometry (alternate edition). Addison-Wesley Publishing Company, Inc. Reading, Massachusetts.

Thomas, J. W., J. R. Ingal1s, M. Yang and B. S. Reddy. 1961. Effect of ad libitum or equalized feeding of alfalfa hay or silage on rumen contents and its characteristics. J. Dairy Sci. 44:1203. (Abstr.).

Thornton, R. F. and D. J. Minson. 1972. The relationship between voluntary intake and mean apparent retention time in the rumen. Aust. J. Agr. Res. 23:871.

Thornton, R. F. and D. J. Minson. 1973. The relationship between apparent retention time in the rumen, voluntary intake, and apparent digestibility of legume and grass diets in sheep. Aust. J. Agr. Res. 24:889.

Tilley, J. M. A., R. A. Terry, R. E. Deriaz and G. E. Outen. 1969. The digestibility of structural carbohydrates of grasses by rumen microorganisms in vitro. J. Br. Grass1. Soc. 24:238.

Trebeck, D. B. 1972. Simulation as an aid to research into extensive beef production. Proc. Aust. Soc. Anim. Prod. 9:94.

Ulyatt, M. J. 1970. Factors contributing to differences in the quality of short-rotation ryegrass, perennial ryegrass and white clover. Proc. 11th Int. Grassl. Congr. p. 709.

Ulyatt, M. J. 1973. The feeding value of herbage. In: Chemistry and Biochemistry of Herbage (Vol. 3). G. W. Butler and R. W. Bailey (Eds.). Academic Press. New York.

Ulyatt, M. J., K. L. Blaxter and I. McDonald. 1967. The relations between the apparent digestibility of rcughages in the rumen and lower gut of sheep, the volume of fluid in the rumen and voluntary feed intake. Anim. Prod. 9:463.

Underwood, E. J. 1962. Trace Elements in Human and Animal Nutrition. Academic Press. New York.

Van Soest, P. J. 1963. Use of detergents in the analysis of fibrous feeds. II. A rapid method for the determination of fiber and lignin. J. A. O. A. C. 45:829. 
Van Soest, P. J. 1964. Symposium on nutrition and forage and pastures: New chemical procedures for evaluating forages. J. Anim. Sci. $23: 838$.

Van Soest, P. J. 1965a. Symposium on factors influencing the voluntary intake of herbage by ruminants: Voluntary intake in relation to chemical composition and digestibility. J. Anim. Sci. 24:834.

Van Soest, P. J. 1965b. Comparison of two different equations for prediction of digestibility from cell contents, cell wall constituents, and lignin content of acid detergent fiber. J. Dairy Sci. $48: 815$.

Van Soest, P. J. 1967. Development of a comprehensive system of feed analysis and its application to forages. J. Anim. Sci. $26: 119$.

Van Soest, P. J. and R. H. Wine. 1967. Use of detergents in the analysis of fibrous feeds. IV. Determination of plant cellwall constituents. J. A. O. A. C. 50:50.

Van Soest, P. J., R. H. Wine and L. A. Moore. 1966. Estimation of the true digestibility of forages by the in vitro digestion of cell walls. Proc. 10th Int. Grass1. Congr. p. 438.

Velasquez, J.A. 1974. Prediction of In Vivo Digestibility in Warm Season Grasses by Summative Equations and In Vitro Digestions. M. S. Thesis. University of Florida. Gainesville, Florida.

Ventura, M. 1973. Forage Intake and Its Relation to the Chemical Composition of the Diet and Some Physiological Factors in Sheep. Ph. D. Dissertation. University of Florida. Gainesville, Florida.

Ventura, M., J. E. Moore, O. C. Ruelke and D. E. Franke. 1975. Effect of maturity and protein supplementation on voluntary intake and nutrient digestibility of Pangola digitgrass hays. J. Anim. Sci. $40: 769$.

Vickery, P. J. 1972. Grazing and net primary production of a temperate grassland. J. Appl. Ecology. 9:307.

Vickery, P. J. and D. A. Hedges. 1974. Simulation in animal-pasture ecosystem research. Simulation 22(3) Center Section.

Wade, G. N. and I. Zucker. 1970. Development of hormonal control over food intake and body weight in female rats. J. Comp. Physiol. Psycho1. 70:213.

Waldo, D. R. 1970. Factors influencing the voluntary intake of forages. Proc. Nat'1. Confr. on Forage Qual. Eval. and Util. Paper "E". 
Waldo, D. R., L. W. Smith and E. L. Cox. 1972. Model of cellulose disappearance from the rumen. J. Dairy Sci. 55:125.

Waldo, D. R., R. W. Miller, M. Okamoto and L. A. Moore. 1965. Ruminant utilization of silage in relation to hay, pellets, and hay plus grain. II. Rumen content, dry matter passage, and water intake. J. Dairy Sci. 48:1473.

Warren, W. P., F. A. Martz, K. H. Asay, E. S. Hilderbrand, C. G. Payne and J. R. Vogt. 1974. Digestibility and rate of passage by steers fed tall fescue, alfalfa and orchardgrass hay in 18 and 32 C ambient temperatures. J. Anim. Sci. 39:93.

Wayman, O., H. D. Johnson, C. P. Merilan and I. R. Berry. 1962. Effect of ad libitum or force-feeding of two rations on lactating dairy cows subject to temperature stress. J. Dairy Sci. 45:1472.

Wedin, W. F., H. J. Hodgson and N. L. Jacobson. 1975. Utilizing plant and animal resources in producing human food. J. Anim. Sci. 41:667.

Welch, J. G. 1967. Appetite control in sheep by indigestible fibers. J. Anim. Sci. 26:849.

Weller, F. E. 1973. Prediction of Voluntary Intake and Nutrient Digestibility of Warm-season Grasses by Laboratory Methods.

M. S. Thesis. University of Florida. Gainesville, Florida.

Weston, R. H. 1966. Factors limiting the intake of feed by sheep. I. The significance of palatability, the capacity of the alimentary tract to handle digesta, and the supply of glucogenic substrate. Aust. J. Agr. Res. 17:939.

Weston, R. H. 1967. Factors limiting the intake of feed by sheep. II. Studies with wheaten hay. Aust. J. Agr. Res. 18:983.

Weston, R. H. and J. P. Hogan. 1967. The digestion of chopped and ground roughages by sheep. I. The movement of digesta through the stomach. Aust. J. Agr. Res. 18:789.

Wright, A. 1970. Systems research and grazing systems. Management oriented simulation. Farm Mgt. Bull. IV. University of New England. Armidale, N. S. W., Australia. 


\section{BIOGRAPHICAL SKETCH}

Edward John Golding, III, was born April 11, 1944, in Toledo, Ohio. In June, 1962, he graduated from DeVilbiss High School in Toledo. From September, 1962, to June, 1963, he attended Northwestern University at Evanston, I1linois. In September, 1963, he transferred to the University of Idaho, Moscow, Idaho, and received a Bachelor of Science degree in Forestry (Range Management) in June, 1967. From September, 1967, to June, 1970, he served as a Peace Corps Volunteer in Cauquenes, Chile. After his return to Toledo in June, 1970, he worked for one year at Girkins Welders. In September, 1971, he enrolled in the Department of Animal Science at the University of Florida, and received the Master of Science in Agriculture degree in August, 1973. At present he is a candidate for the degree of Doctor of Philosophy in the Department of Animal Science, University of Florida.

He is married to the former Astrid Semler Chipoco, and they have a daughter, Nicole, and a son, Christopher. The author is a member of Gamma Sigma Delta, Phi Kappa Phi and Xi Sigma Pi. 
I certify that I have read this study and that in my opinion it conforms to acceptable standards of scholarly presentation and is fully adequate, in scope and quality, as a dissertation for the degree of Doctor of Philosophy.

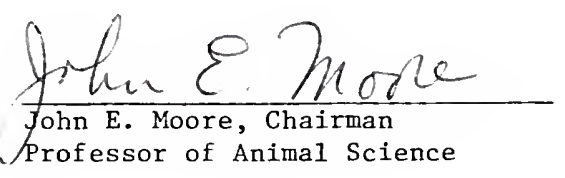

I certify that I have read this study and that in my opinion it conforms to acceptable standards of scholarly presentation and is fully adequate, in scope and quality, as a dissertation for the degree of Doctor of Philosophy.

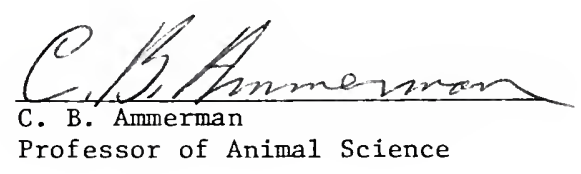

I certify that I have read this study and that in my opinion it conforms to acceptable standards of scholarly presentation and is fully adequate, in scope and quality, as a dissertation for the degree of Doctor of Philosophy.

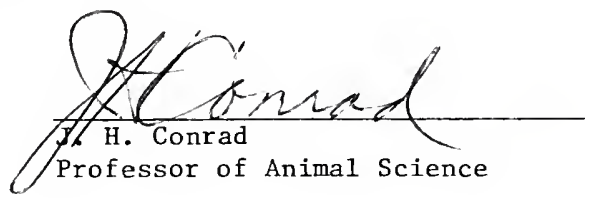

I certify that I have read this study and that in my opinion it conforms to acceptable standards of scholarly presentation and is fully adequate, in scope and quality, as a dissertation for the degree of Doctor of Philosophy.

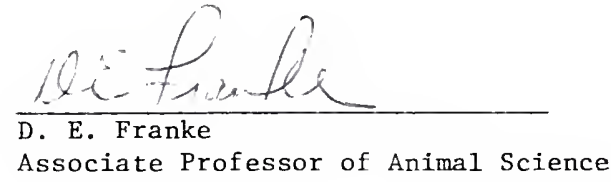


I certify that I have read this study and that in my opinion it conforms to acceptable standards of scholarly presentation and is fully adequate, in scope and quality, as a dissertation for the degree of Doctor of Philosophy.

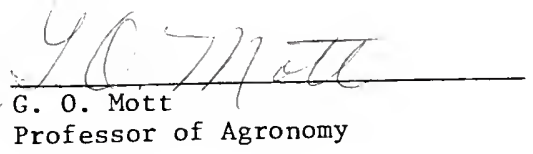

This dissertation was submitted to the Graduate Faculty of the College of Agriculture and to the Graduate Council, and was accepted as partial fulfillment of the requirements for the degree of Doctor of Philosophy.

March, 1976

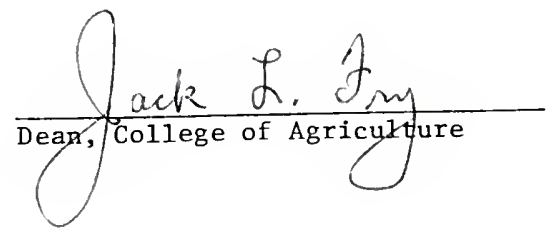

Dean, Graduate School 
UNIVERSITY OF FLORIDA

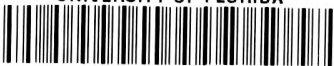

31262086669297 